US Army Corps

of Engineers ${ }_{\circledast}$

Engineer Research and

Development Center

\title{
ERD
}

ERDC 6.2 Advanced Low-Logistics Water $\left(\mathrm{ALL}-\mathrm{H}_{2} \mathrm{O}\right)$

\section{Cross-Comparison of Advanced Oxidation Processes for Remediation of Organic Pollutants in Water Treatment Systems}

Emma K. Ambrogi, Emily Asenath-Smith, Will A. Ballard,

Lee C. Moores, and Jonathon A. Brame

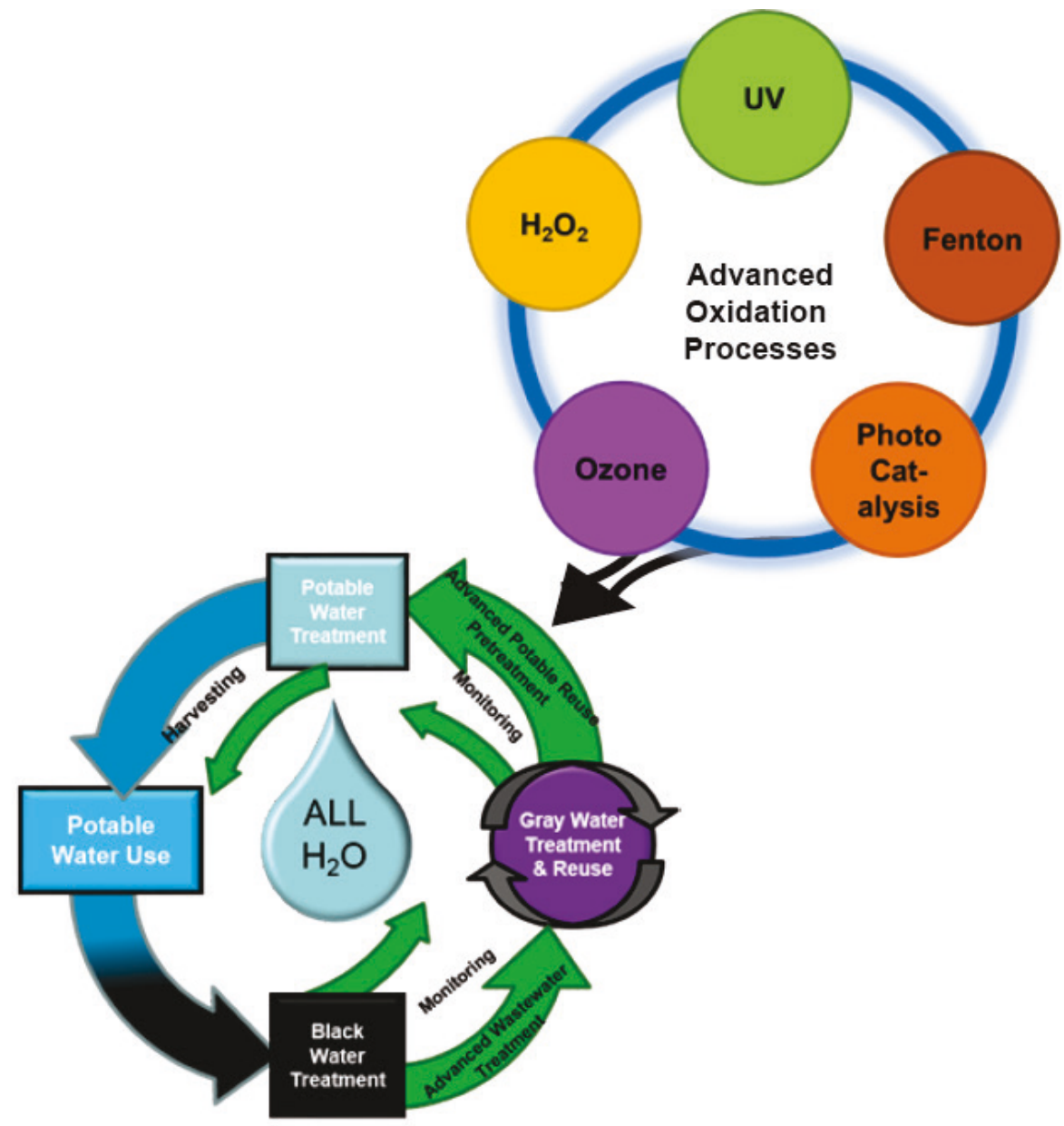


The U.S. Army Engineer Research and Development Center (ERDC) solves the nation's toughest engineering and environmental challenges. ERDC develops innovative solutions in civil and military engineering, geospatial sciences, water resources, and environmental sciences for the Army, the Department of Defense, civilian agencies, and our nation's public good. Find out more at www.erdc.usace.army.mil.

To search for other technical reports published by ERDC, visit the ERDC online library at http://acwc.sdp.sirsi.net/client/default. 


\section{Cross-Comparison of Advanced Oxidation Processes for Remediation of Organic Pollutants in Water Treatment Systems}

Emma K. Ambrogi and Emily Asenath-Smith

Cold Regions Research and Engineering Laboratory (CRREL)

U.S. Army Engineer Research and Development Center (ERDC)

72 Lyme Rd.

Hanover, NH 03755

William A. Ballard, Lee C. Moores, and Jonathon A. Brame

Environmental Laboratory (EL)

U.S. Army Engineer Research and Development Center (ERDC) 3909 Halls Ferry Rd

Vicksburg, MS 39180

Final report

Approved for public release; distribution is unlimited.

Prepared for U.S. Army Corps of Engineers

Washington, DC 20314-1000

Under ERDC 6.2 Advanced Low Logistics Water $\left(\mathrm{ALL}-\mathrm{H}_{2} \mathrm{O}\right)$ "Task 6: Catalytic Coatings for Oxidative/Reductive Destruction of Micropolutants," Program Element 622720048, "Industrial Operations Pollution Control Guidance." 


\section{Abstract}

A vital issue in military and civilian water treatment is the persistence of pollutants that are difficult to remove via traditional physical, chemical, and biological treatment technologies. Advanced oxidation processes (AOP) are a viable treatment alternative that allow targeting of specific organic pollutants for removal prior to release or reuse of treated water. Many methods have shown positive potential at the bench scale, however, their relative effectiveness in real treatment trains is difficult to assess. To achieve viable technology transfer, bench-scale research needs to feed into pilot-scale and full-scale studies; and that cannot happen without wellestablished metrics and means of comparison.

The goal of this research is to validate and compare the effectiveness of AOP technologies to degrade and eliminate contaminants so that their use in wastewater treatment trains for military and civil applications can be realized. To this end, several AOP that can effectively remove emerging pollutants from a treated wastewater effluent stream have been tested, enabling the water to be reused as potable fresh water. Reaction kinetics for the degradation of pollutants with eight AOP were monitored. With these results, the energy inputs required by calculating electrical energy per order (EEO) for each AOP as a potentially important metric for comparison was analyzed.

DISCLAIMER: The contents of this report are not to be used for advertising, publication, or promotional purposes. Citation of trade names does not constitute an official endorsement or approval of the use of such commercial products. All product names and trademarks cited are the property of their respective owners. The findings of this report are not to be construed as an official Department of the Army position unless so designated by other authorized documents. 


\section{Contents}

Abstract................................................................................................................................. if

Figures and Tables..............................................................................................................

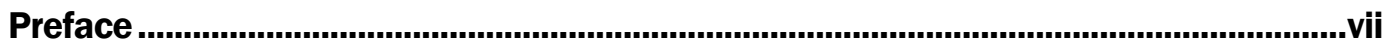

Unit Conversion Factors.....................................................................................vifi

Acronyms and Abbreviations ........................................................................................ ix

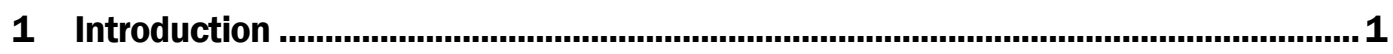

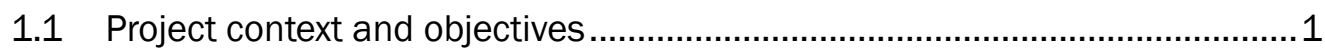

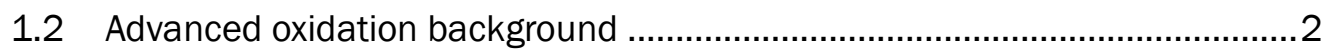

1.3 Experimental approach ..........................................................................

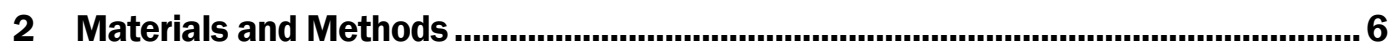

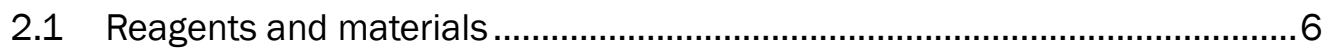

2.2 Experimental reactor specifications ......................................................... 6

2.3 Light characterization ........................................................................... 7

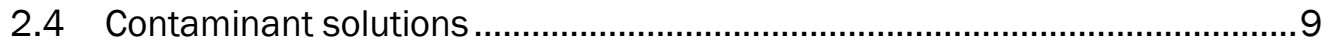

2.5 HPLC-MS and UV-Vis characterization...................................................... 9

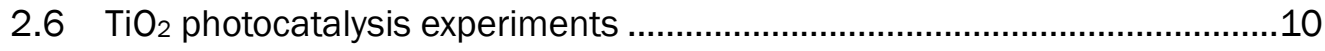

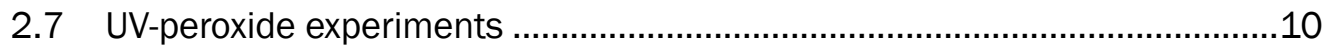

2.8 UV-hypochlorite experiments ..............................................................

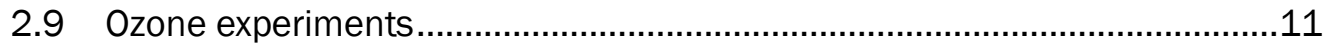

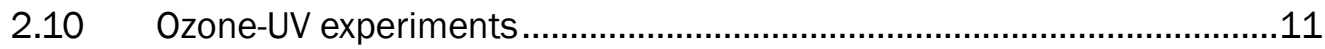

2.11 Ozone hypochlorite experiments .......................................................... 12

2.12 Fenton and photo-Fenton experiments............................................ 12

3 Results.............................................................................................................13

3.1 Light characterization and cross-lab standardization ................................ 13

3.2 Typically observed degradation products of contaminants .........................14

$3.3 \quad \mathrm{TiO}_{2}$ photocatalysis experiments ...........................................................16

3.3.1 Reaction parameters and optimization ............................................................... 16

3.3.2 Individual and combined kinetics ..................................................................... 16

3.4 UV-peroxide experiments ................................................................... 18

3.4.1 Reaction optimization and UV photolysis controls ............................................... 18

3.4.2 Individual and combined kinetics and byproducts.................................................. 19

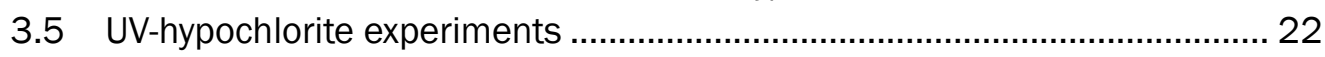

3.5.1 Reaction optimization and dark (control) reactions............................................... 22

3.5.2 Individual and combined kinetics and degradation products ................................23

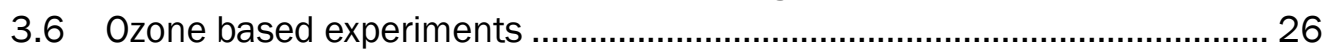

3.6.1 Ozone generator and reaction optimization ................................................. 26

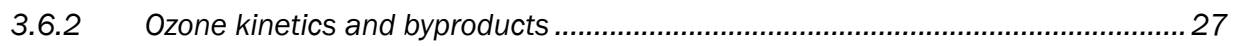


3.6.3 UV ozone kinetics and byproducts ................................................................... 29

3.6.4 Ozone- perchlorate $(\mathrm{OCl})$ kinetics and byproducts ................................................ 30

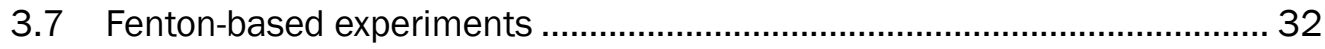

3.7.1 Overview of the Fenton and photo-Fenton reactions.............................................. 32

3.7.2 Fenton reaction kinetics ................................................................................ 33

3.7.3 Photo-Fenton reaction kinetics ....................................................................... 35

4 Discussion...................................................................................................................38

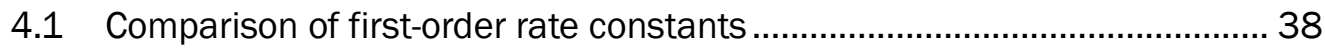

4.2 Comparison of efficiency and feasibility .................................................. 39

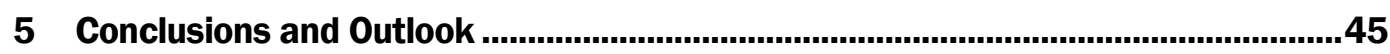

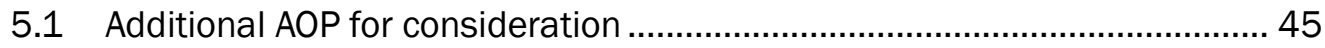

5.2 Considerations for AOP use in real applications....................................... 45

References..............................................................................................................46

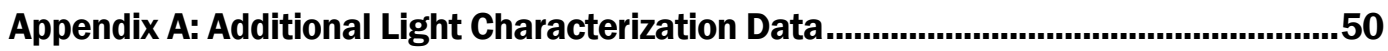

Appendix B: Chemical Analysis Data on Contaminants and Degradation

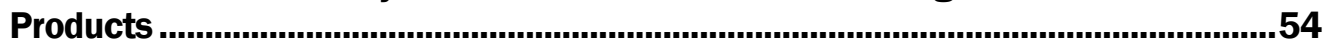

Appendix C: Additional UV-Peroxide Experimental Data ..........................................57

Appendix D: Additional UV-Hypochlorite Experimental Data ....................................60

Appendix E: Ozone Concentration Measurements with Indigo Trisulfonate.................61

Appendix F: HPLC-MS Analysis of Carbamazepine Ozonolysis Product .....................63

Appendix G: Additional Data on Contaminant Degradation Reactions by

Fenton and Photo-Fenton Processes.............................................................65

Appendix H: EEO Determinations for Fenton Reactions..........................................67

Report Documentation Page 


\section{Figures and Tables}

\section{Figures}

Figure 1. Chemical structures of chosen model contaminants. .......................................... 4

Figure 2. Dimensions of experimental photoreactors....................................................... 7

Figure 3. Configuration for optical characterization of experimental photoreactor.............. 8

Figure 4. Frequently observed degradation products of (a) MO, (b) $\mathrm{CM}$, and (c)

NB.

Figure 5. Pseudo-first order degradation kinetics of (a) individual, and (b) mixed contaminants with commercial $\mathrm{TiO}_{2}$.

Figure 6. HPLC-MS chromatograms of individual contaminants degraded with $\mathrm{TiO}_{2}$ photocatalysis.

Figure 7. Pseudo-first order rate constants of contaminant degradation under UVC illumination with varying concentrations of $\mathrm{H}_{2} \mathrm{O}_{2}$

Figure 8. Pseudo-first order degradation kinetics of (a) individual and (b) mixed contaminants with $6 \mathrm{mg} / \mathrm{L} \mathrm{H}_{2} \mathrm{O}_{2}$ and UVC illumination.

Figure 9. Pseudo-first order degradation kinetics of (a) individual and (b) mixed contaminants with $70 \mathrm{mg} / \mathrm{L} \mathrm{NaOCl}$ and UVC illumination.

Figure 10. HPLC chromatogram of $\mathrm{MO}$ degraded with $70 \mathrm{mg} / \mathrm{L} \mathrm{NaOCl}$ and UVC illumination showing a chlorinated byproduct.

Figure 11: Overview of the generation of ozone from oxygen gas.

Figure 12. Pseudo-first order degradation kinetics of (a) individual and (b) mixed contaminants with ozone.

Figure 13. Structure of BQM, proposed CM ozonolysis product.

Figure 14. Pseudo-first order degradation kinetics of (a) individual and (b) mixed contaminants with ozone and UVC illumination.

Figure 15. Pseudo-first order degradation kinetics of (a) individual and (b) mixed contaminants with ozone-hypochlorite.

Figure 16. Diagram of the Fenton cycle for both Fenton and photo-Fenton reactions.

Figure 17. Degradation of (a) individual and (b) mixed contaminants with Fenton reaction, fit to pseudo-first order model.

Figure 18. Comparison of rate enhancement to Fenton reaction with UVA and UVC illumination.

Figure 19. Degradation of (a) individual and (b) mixed contaminants with photoFenton, fit to pseudo-first order model.

Figure 20. EEO for each AOP with (a) individual and (b) mixed contaminants.

Figure 21. EEO for the degradation of (a) MO, (b) CM and (c) NB with each AOP.

\section{Tables}

Table 1. AOP test matrix 
Table 2. Photon flux of each bulb type measured in experimental photo-reactors with ferrioxalate actinometry..............................................................................................13

Table 3. Rate constants for UV-peroxide experiments and UVC photolysis experiments.

Table 4. Pseudo-first order rate constants of MO with sodium hypochlorite at

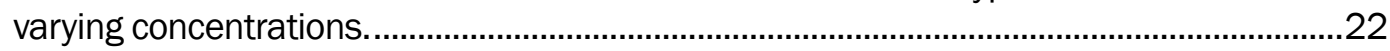

Table 5. Pseudo-first order rate constants of individual contaminants with 70

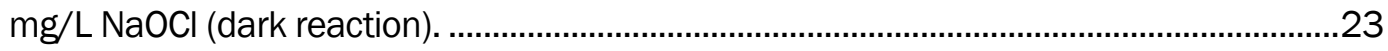

Table 6. Pseudo first-order rate constants for all AOP and contaminants...........................39 


\section{Preface}

This study was conducted for the Assistant Secretary of the Army for Acquisition, Logistics and Technology under U.S. Army Engineer Research and Development Center (ERDC) 6.2 Advanced Low Logistics Water (ALL- $\mathrm{H}_{2} \mathrm{O}$ ) "Task 6: catalytic coatings for oxidative/reductive destruction of micropolutants." The technical monitor was Mr. Kurt Kinnevan, Office of the Technical Directors, Environmental Quality and Installations.

The work was performed by the Force Projection and Sustainment Branch (CEERD-RRH) of the Research and Engineering Division (CEERD-RR), U.S. Army Engineer Research and Development Center (ERDC), Cold Regions Research and Engineering Laboratory (CRREL), and the Environmental Laboratory (EL). At the time of publication for CRREL, Dr. Harley H. Cudney was Acting Chief, CEERD-RRH, Mr. J. D. Horne was Chief, CEERD-RR. The Deputy Director of ERDC-CRREL was Dr. David B. Ringelberg, and the Director was Dr. Joseph L. Corriveau.

At the time of publication for EL, The Deputy Director of ERDC-EL was Dr. Jack E. Davis and the Director was Dr. Ilker R. Adiguzel.

COL Ivan P. Beckman was the Commander of ERDC, and Dr. David W. Pittman was the Director. 


\section{Unit Conversion Factors}

\begin{tabular}{|c|c|c|}
\hline Multiply & By & To Obtain \\
\hline cubic feet & 0.02831685 & cubic meters \\
\hline cubic inches & $1.6387064 \mathrm{E}-05$ & cubic meters \\
\hline cubic yards & 0.7645549 & cubic meters \\
\hline degrees (angle) & 0.01745329 & radians \\
\hline degrees Fahrenheit & $(F-32) / 1.8$ & degrees Celsius \\
\hline feet & 0.3048 & meters \\
\hline foot-pounds force & 1.355818 & joules \\
\hline gallons (US liquid) & 3.785412 E-03 & cubic meters \\
\hline horsepower (550 foot-pounds force per second) & 745.6999 & watts \\
\hline inches & 0.0254 & meters \\
\hline microinches & 0.0254 & micrometers \\
\hline microns & $1.0 \mathrm{E}-06$ & meters \\
\hline pints (US liquid) & 0.473176 & liters \\
\hline pounds (mass) & 0.45359237 & kilograms \\
\hline
\end{tabular}




\section{Acronyms and Abbreviations}

\begin{tabular}{|l|l|}
\hline Acronym & \multicolumn{1}{|c|}{ Meaning } \\
\hline AOP & Advanced Oxidation Processes \\
\hline CM & Carbamazepine \\
\hline CRREL & Cold Regions Research Laboratory \\
\hline EEO & Electrical Energy Per Order \\
\hline EL & Environmental Laboratory \\
\hline EPA & Environmental Protection Agency \\
\hline ERDC & Engineer Research and Development Center \\
\hline FOB & Forward Operating Bases \\
\hline HO• & Hydroxyl Radicals \\
\hline HPES & hydroxyethyl-piperazineethane-sulfonic acid \\
\hline HPLC & High Performance Liquid Chromatography \\
\hline in. & Inch \\
\hline Min & Minutes \\
\hline MO & Methyl orange \\
\hline NaOCl & Hypochlorite \\
\hline NB & Nitrobenzene \\
\hline $\mathrm{O}_{2}-$ & Superoxide \\
\hline ROS & Reactive Oxygen Species \\
\hline SERDP & Strategic Environmental Research and Development Program \\
\hline TiO 2 & Titanium Dioxide \\
\hline TOC & Total lon Chromatogram \\
\hline TR & Technical Report \\
\hline UV & Ultra Violet \\
\hline UV-Vis & Ultraviolet-visible spectroscopy \\
\hline VIPh & Valerophenone \\
\hline W & Watt \\
\hline $3 \mathrm{O}_{2}$ & Singlet Oxygen \\
\hline
\end{tabular}




\section{Introduction}

\subsection{Project context and objectives}

When operating in expeditionary settings, the U.S. Army deploys a force structure and sustainment capabilities to execute its mission in concert from the rear support areas to the front lines. Force structures can range from divisions at semi-permanent or permanent facilities to semipermanent support areas (deployable force infrastructure) to mobile units with little to no infrastructure. Depending on the nature of the operation, the deployable force infrastructure camps can function as a temporary home for several hundred to several thousand soldiers serving tours of duty, supply points for forward operations, and sizeable populations of civilians and contractors. As such, they require significant, semipermanent infrastructure, including available running water. The water requirements of these bases are significant; an Engineer Research and Development Center (ERDC) research team reported that forward operating bases (FOB) in Afghanistan used as much as 34 gallons, per capita, per day (Anderson et al. 2013). Especially in areas where water is scarce, fresh potable water is often delivered by truck convoy. This strategy eliminates the need for onsite water treatment equipment, but presents other challenges. The first is monetary cost, the cost of water delivered to these bases is up to $\$ 55$ per gallon (SERDP 2010). The second challenge is the human cost, on average, one casualty occurs per every 26 convoys on the front lines of combat operations (Eady et al. 2009).

Because of these significant challenges with existing water delivery in expeditionary settings, the U.S. Army is interested in developing an easilydeployable system to enable total water reuse in certain mission scenarios. The Army 6.2 Work Package "Advanced Low Logistics Water" or "ALL$\mathrm{H}_{2} \mathrm{O}$ " set out to address the current technology gaps that must be bridged in order to make such a system a reality. One critical requirement for the system is that it must be portable (e.g., air deployable), and relatively selfcontained. Municipal water recycling facilities exist, (City of Oxnard 2018; Los Angles Sanitation 2018) but these facilities take up multiple acres of land and require large amounts of energy, including a steady supply of chemical reagents. The ALL-H2O Project was divided into 12 tasks, each addressing a knowledge or technology gap related to water treatment. The present work focused on evaluating the use of Advanced Oxidation 
Processes (AOP) for the removal of recalcitrant molecular contaminants in an Army context. In this technical report (TR), eight AOP technologies are compared by evaluating their efficiency, potential operating costs, and overall feasibility for use in an Army water treatment system.

\subsection{Advanced oxidation background}

As water stress continues to grow worldwide, there is increased need to make treated wastewater suitable for direct potable reuse (Environmental Protection Agency (EPA) 2012). Often called water recycling, this process presents unique challenges due to the high purity standards required (City of Oxnard California 2017). One important requirement is the removal of "recalcitrant contaminants," (i.e., small organic molecules (personal care products, pesticides, pharmaceuticals, etc.)), which are not removed by traditional water treatment methods (City of Oxnard California 2017). These contaminants, while often present in natural water sources in very low levels (Furlong et al. 2017), pose a problem in a closed-loop system, as they have the potential to accumulate to harmful levels. Thus, any viable water recycling system must include a method for the degradation and/or removal of recalcitrant contaminants.

The most effective methods for removal of small molecule contaminants from water are contained within the broad umbrella of AOP. These processes are often called "advanced" because they go beyond the traditional methods of using bleach or Ultra Violet (UV) light and rely on the generation of reactive oxygen species (ROS). Some common ROS include hydroxyl radicals $\left.(\mathrm{HO})^{\bullet}\right)$, superoxide $\left(\mathrm{O}_{2}{ }^{-}\right)$and singlet oxygen $\left(3 \mathrm{O}_{2}\right)$. These highly reactive species readily participate in redox reactions with contaminants in solution, resulting in the oxidation and eventual degradation of recalcitrant organic contaminants (Miklos et al. 2018).Researchers have attempted to quantify and compare the efficiency of various AOP for several decades. In particular, Bolton et al. (2001) proposed the figure of merit "Electrical Energy Per Order" or "EEO" (defined as the electrical energy required for an AOP reactor system to decrease the concentration of a contaminant by one order of magnitude). Many studies have used this metric, which accounts for reactor design and function in addition to the fundamental chemical processes, to evaluate AOP. Examples can be found in literature comparing several AOP with a single contaminant (Liang et al. 2011; Deng et al. 2013) and of a single AOP with multiple contaminants (Shu et al. 2013). Reviews have also attempted to summarize the vast body of work on advanced oxidation 
technologies (Jimenez et al. 2018; Miklos et al. 2018). However, very few examples exist of side by side comparison of AOP used to degrade multiple compounds and mixtures of compounds. This research sought to fill that gap, by conducting laboratory experiments in such a way that experiments could be directly compared, and the efficiency and suitability of AOP for Army-relevant challenges could be evaluated.

\subsection{Experimental approach}

Eight AOP were chosen for the present work. The AOP can be divided up into three broad categories, based on the fundamental processes involved in the reaction. In the category of technologies driven primarily by UV light, $\mathrm{TiO}_{2}$ photocatalysis, UV-Peroxide, and UV-Hypochlorite were evaluated. In the category of ozone-based technologies, ozone, ozone-UV light, and ozone-hypochlorite were evaluated. In the category of Fentonbased technologies, Fenton, and Photo-Fenton reactions were evaluated. Three model contaminants were also selected. Methyl orange (MO), a common dye, was chosen for its broad use as probe molecule in AOP experiments. Carbamazepine (CM), a pharmaceutical, was chosen based on its demonstrated recalcitrance under UV illumination and chlorine treatment (Malchi et al. 2014), including its presence on lists of contaminants of emerging concern (Benotti et al. 2009). Similarly, nitrobenzene (NB), an industrial chemical, was chosen for its classification as an emerging contaminant (Richardson and Ternes 2011; EPA 2017). As a result, $\mathrm{CM}$ and $\mathrm{NB}$ could be expected to be present in wastewater scenarios of relevance to expeditionary settings. The chemical structures of the three contaminants are shown in Figure 1. 
Figure 1. Chemical structures of chosen model contaminants.

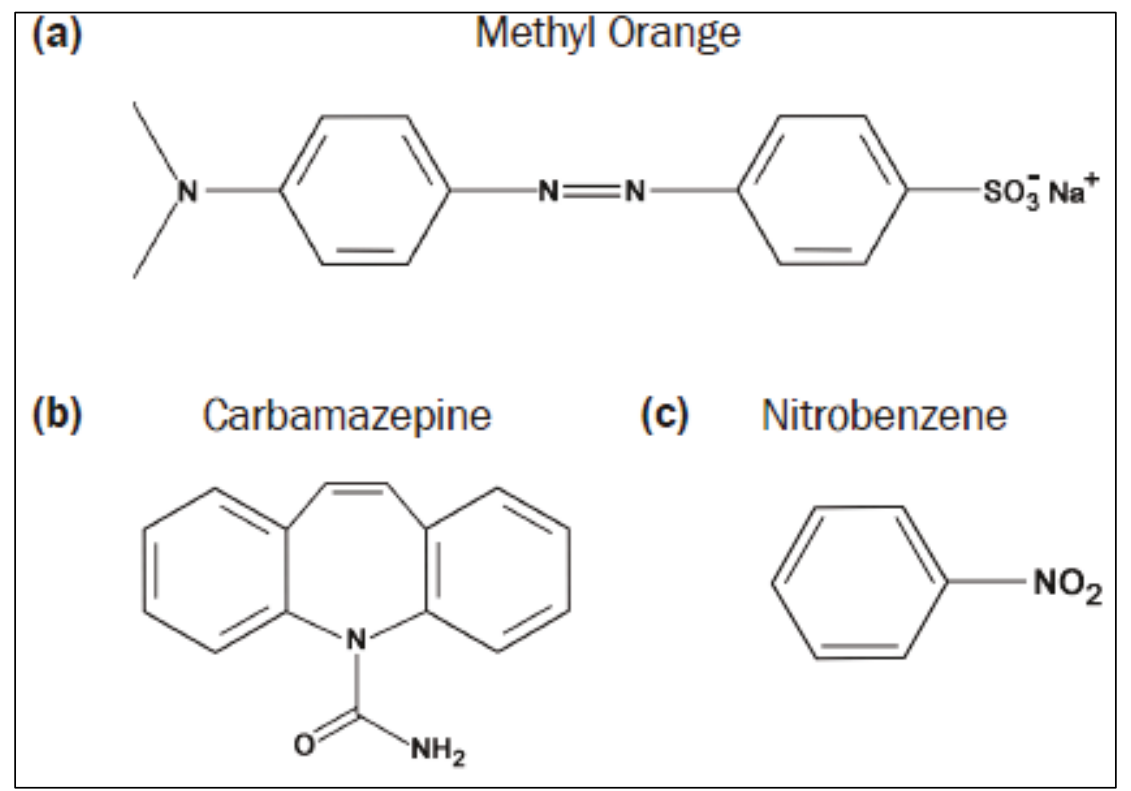

The planned experiments were divided among two ERDC labs, the Environmental Laboratory (EL) and the Cold Regions Research and Engineering Laboratory (CRREL) to correspond with available personnel, expertise, and equipment. To ensure that experiments conducted across labs were comparable, identical photochemical reactors were built. These experimental photoreactors were constructed of black polycarbonate sheeting and contained a stir plate, fan, and housing for six, 5 inch (in.). fluorescent bulbs. Identical sets of UVA and UVC bulbs were purchased for each reactor. For additional photoreactor specifications, see Section 2.2. The experimental test matrix and the division of labor among ERDC labs is shown in Table 1. The efforts to standardize experiments across AOP types and across laboratories allowed for side-by-side comparison of both the efficiency and reproducibility of advanced oxidation methods in water treatment applications, and consideration of their relevance to Army needs. 
Table 1. AOP test matrix.

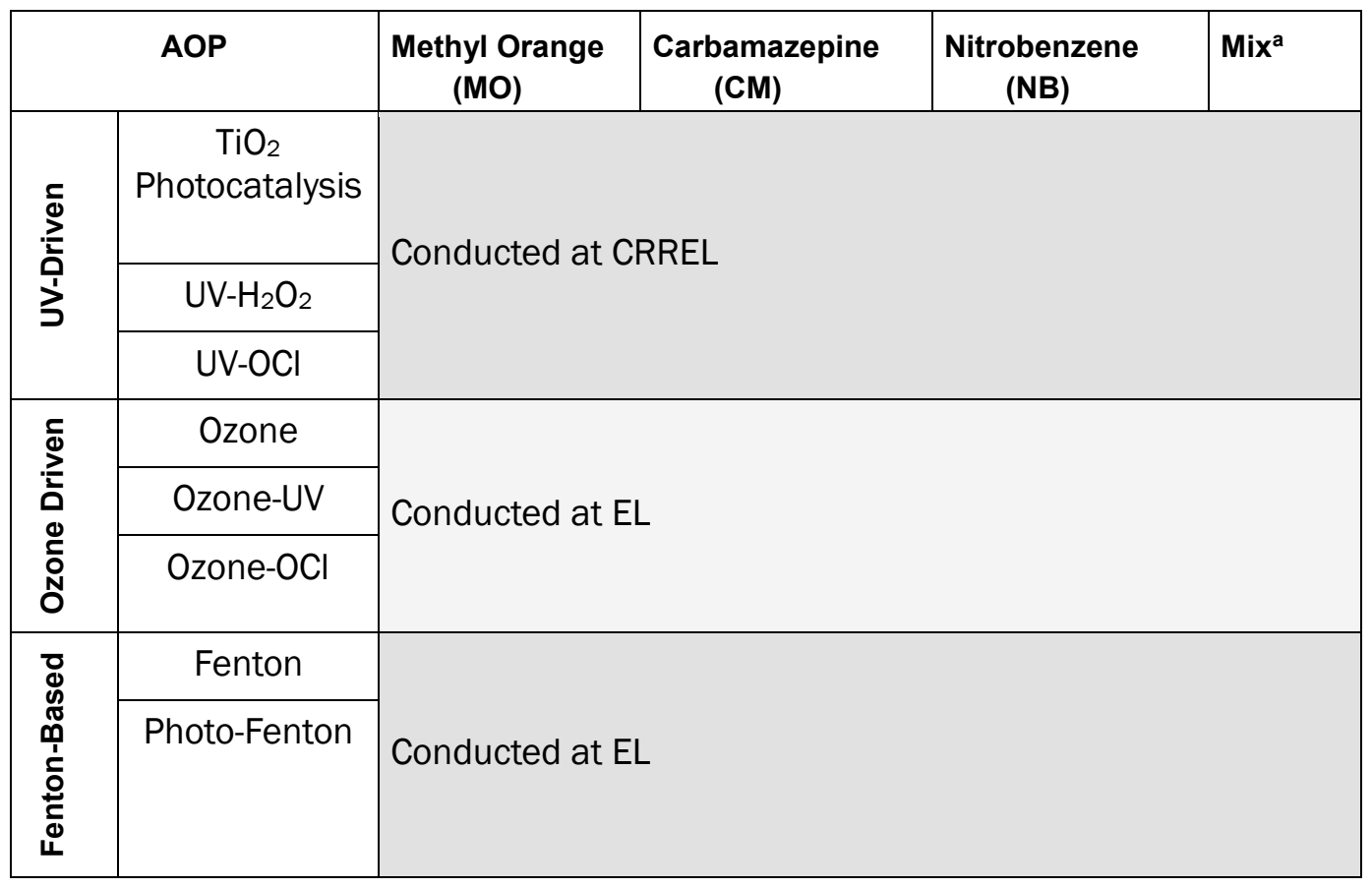




\section{Materials and Methods}

\subsection{Reagents and materials}

All reagents were used as received without further purification: methyl orange (MO) (Reag, Ph. Eur.; Sigma Aldrich), carbamazepine (CM) 98\%, Alfa Aesar), nitrobenzene (NB) (ACS Reagent Grade, $\geq 99 \%$, Sigma Aldrich), valerophenone (VlPh) (Sigma Aldrich, 99\%), titanium dioxide $\left(\mathrm{TiO}_{2}\right)(\mathrm{P} 25$, Degussa/Evonik), ammonium acetate (eluent additive for LCMS, Sigma Aldrich), acetonitrile (High Performance Liquid Chromatography (HPLC) grade, Fisher Chemical), methanol (HPLC grade, Fisher Chemical), FerroZineTM iron reagent (98\%, Sigma Aldrich), ammonium iron(III) sulfate dodecahydrate (ACS Reagent grade, Sigma Aldrich), potassium oxalate monohydrate (ACS Reagent grade, Sigma Aldrich), HEPES buffer ( $\geq 99.5 \%$, Sigma Aldrich), sulfuric acid (99.99\%, Sigma Aldrich), sodium hypochlorite (4-4.99\%, Sigma Aldrich), potassium indigo trisulfonate (Sigma Aldrich), Calcium Hypochlorite (technical grade, Sigma Aldirch), ferrous sulfate (USP Reference Grade, Sigma Aldrich), and hydrogen peroxide (30\%, Fisher Chemicals). Before analysis in photocatalysis experiments, $\mathrm{TiO}_{2}$ was filtered from the $\mathrm{MO}$, $\mathrm{CM}$, and NB solutions with a $0.22 \mu \mathrm{m}$ filter (Millex, PTFE).

For EL experiments, high purity water, $>18.2 \mathrm{M} \Omega \mathrm{cm}^{-1}$ was obtained from an Aries Filter Works Gemini purification system and used for all solutions. For CRREL experiments, high purity water $>10 \mathrm{M} \Omega \mathrm{cm}^{-1}$ was obtained from a MilliQ purification system and used for all solutions.

\subsection{Experimental reactor specifications}

Custom experimental reactors were manufactured for this research effort. They were constructed from black polycarbonate and equipped with a fan, stir plate, and fixtures for six T5, 5 in., four watt (W) fluorescent bulbs. The boxes measured $19 \times 19 \times 19 \mathrm{~cm}$, and were hinged on the front on the top for easy sampling. The lamps were positioned seven $\mathrm{cm}$ from the center of the solution flask on each side. Figure 2 shows a diagram of these photoreactors. Multiple reactors were constructed so that each lab could have at least two identical systems for experiments. 
Figure 2. Dimensions of experimental photoreactors.

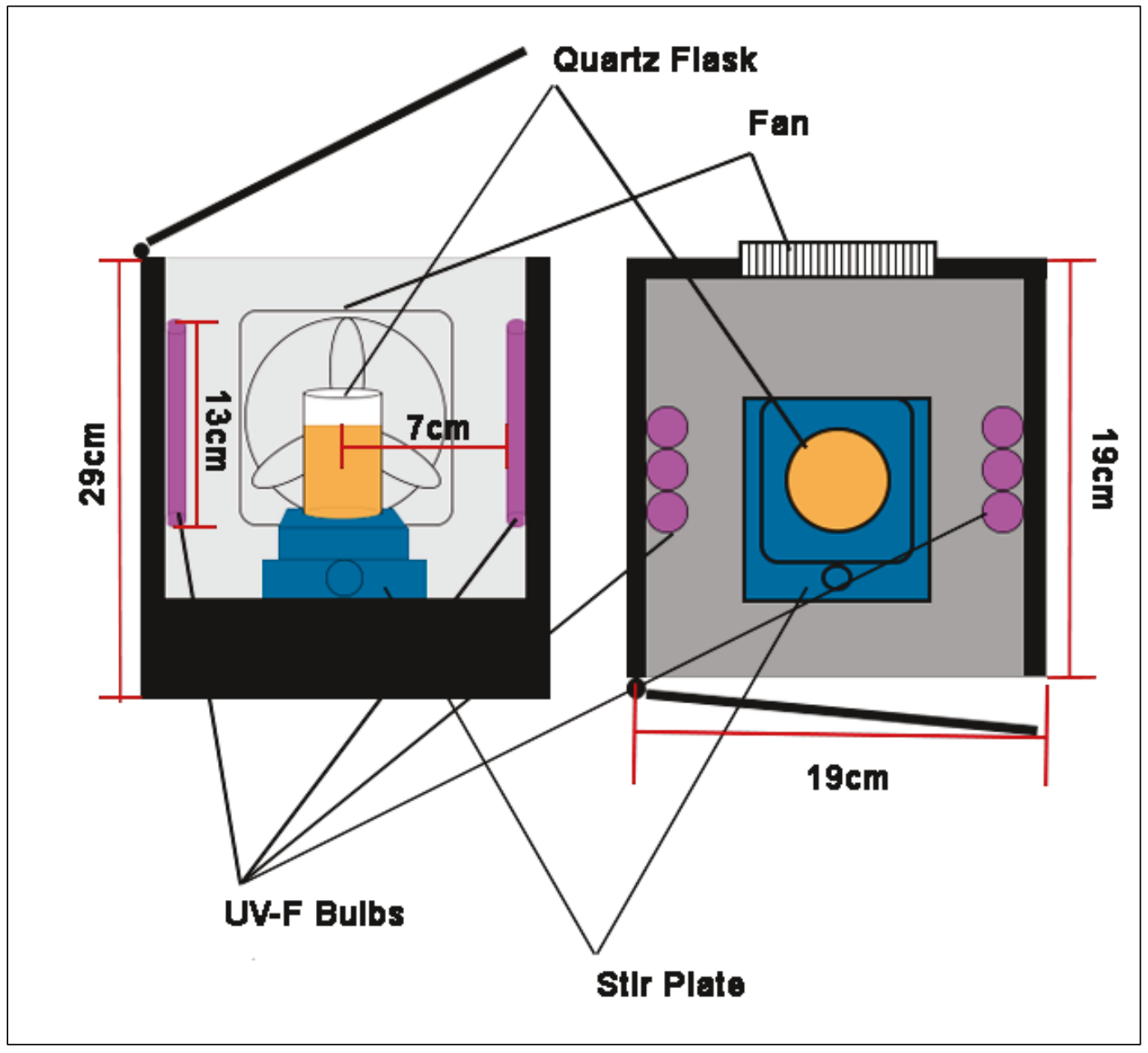

\subsection{Light characterization}

Optical characterization of the incident radiation emitted by the reactors was conducted using a diffuse reflectance panel (Spectralon ${ }^{\circledR}$, LabSphere, $\mathrm{NH}$ ). The experimental reactor was placed face down on a metal frame, with the front door of the reactor open, such that the light shone downwards. The Spectralon ${ }^{\circledR}$ panel was placed below the experimental reactor, and the optical sensors were aimed at the panel to collect measurements (Figure 3). Both sets of bulbs (UVA and UVC) were characterized with both broad spectrum and single wavelength optical instruments. 
Figure 3. Configuration for optical characterization of experimental photoreactor.

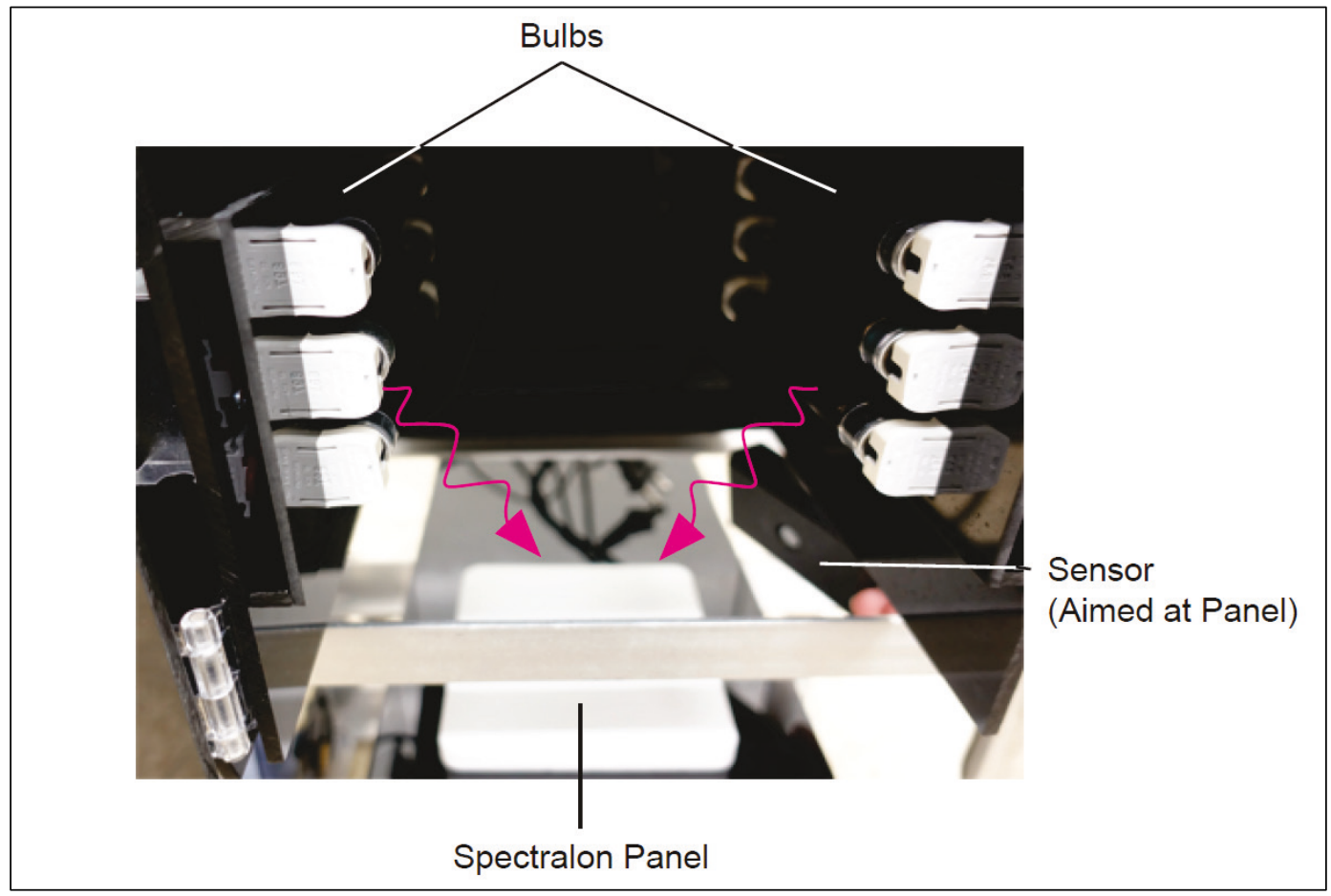

Broad spectrum optical characterization was conducted using a compact spectrometer (Model CCS200, range 200-1000 nm, with CCSA1 filter, ThorLabs, Newton, NJ). The integration time for each measurement was three seconds. Single wavelength radiance measurements were taken with a UVX point radiometer equipped with UVX -25, -31, and -36 sensors (Analytic Jena). The last date of calibration was June 2018.

Chemical characterization of UVA and UVC bulbs was done in the absence of model wastewater solutions via ferrioxalate actinometry, which was conducted following a modified procedure reported by Rao et al. (2013). The following solutions were prepared under normal laboratory light: $0.06 \mathrm{M}$ potassium oxalate in $0.05 \mathrm{M}$ sulfuric acid, $0.2 \mathrm{M}$ ammonium ferric sulfate in $0.05 \mathrm{M}$ sulfuric acid, $0.25 \mathrm{~g}$ FerroZine $^{\mathrm{TM}}$ iron reagent (3-(2Pyridyl)-5,6-diphenyl-1,2,4-triazine- $p, p^{\prime}$-disulfonic acid monosodium salt hydrate) dissolved in $5 \mathrm{~mL}$ of $0.05 \mathrm{M}$ HEPES buffer. A Genesys-10S Ultraviolet-visible spectroscopy (UV-Vis) spectrophotometer was blanked using a quartz cuvette filled with $1 \mathrm{~mL} 0.05 \mathrm{M}$ sulfuric acid and $0.65 \mathrm{~mL}$ FerroZine $^{\mathrm{TM}}$ solution. Under red illumination, $20 \mathrm{~mL}$ potassium oxalate solution was mixed with $20 \mathrm{~mL}$ ammonium ferric sulfate solution in a quartz flask. The solution was stirred in the dark for five minutes (min). A $1 \mathrm{~mL}$ aliquot was removed from solution and placed in a foil-covered vial. 
Subsequently, $1 \mathrm{~mL}$ aliquots were removed following 1, 2, 3, 4, and $5 \mathrm{~min}$ of illumination. Samples were analyzed by diluting $100 \mu \mathrm{L}$ of each sample to $10 \mathrm{~mL}$ with $0.05 \mathrm{M}$ sulfuric acid. An aliquot $(1 \mathrm{~mL})$ of the diluted sample was mixed in a quartz cuvette with $65 \mu \mathrm{L}$ FerroZine ${ }^{\mathrm{TM}}$ solution and gently shaken. The absorbance of the solution at $563 \mathrm{~nm}$ was monitored until it reached equilibrium, about two min. The final absorbance was recorded and the rate of Fe(II) production was calculated (See Appendix A for calculations).

\subsection{Contaminant solutions}

In CRREL experiments, $\mathrm{MO}$ solutions ( $25 \mu \mathrm{M})$ were made by dilution of $1 \mathrm{mM}$ MO stock solution (aqueous). Carbamazepine solutions ( $25 \mu \mathrm{M})$ were made by dilution of $10 \mathrm{mM}$ stock solution, $30 / 70 \% \mathrm{v} / \mathrm{v}$ acetonitrile/water. NB solutions $(50 \mu \mathrm{M})$ were made by dilution of $1 \mathrm{mM}$ stock solution (aqueous).

In EL experiments, reaction mixtures of $23 \mu \mathrm{M}$ solutions of MO, 5.4 or 16.5 $\mathrm{CM}, 46 \mu \mathrm{M} \mathrm{NB}$, or a combination of all three model contaminants, were prepared by dilution with high purity water. Stock solutions of NB were first made in acetonitrile as a carrier solvent, and then diluted down with high purity water to the correct concentration. The same process was carried out with $\mathrm{CM}$, with methanol as a carrier solvent for the concentrated stock.

\subsection{HPLC-MS and UV-Vis characterization}

In samples containing multiple compounds or contaminants, the absorbance of the different species overlaps. Thus, concentrations profiles of these multi-component solutions were gathered using HPLC (EL samples) or HPLC-MS (CRREL samples). The CRREL samples were run on HPLC-ESI-MS (Accela, ThermoFisher, USA) equipped with a C18 column (Zorbax Eclipse Plus $4.5 \times 150 \mathrm{~mm}, 5 \mu \mathrm{m}$ ). The EL samples were run on HPLC (Agilent HPLC 1100) equipped with C18 column (Phenomenex, Synergi, 4 um, Hydro-RP $80 \AA 250$ x $4.6 \mathrm{~mm}$ ). The HPLC method was a gradient beginning with $70 / 30$ aqueous $10 \mathrm{mM}$ ammonium acetate/ acetonitrile for $3 \mathrm{~min}$, ramping from $70 / 30$ to $50 / 50$ ammonium acetate/acetonitrile from 3-7 $\mathrm{min}$, and held at that concentration from 712 min (CRREL samples) or 7-14 min (EL samples). For the CRREL analysis, the flow rate was $600 \mu \mathrm{L} / \mathrm{min}$. for the EL analysis, the flow rate was $1.1 \mathrm{~mL} / \mathrm{min}$. The peaks were fit to Gaussian distributions and 
integrated to find peak areas; relative concentrations were calculated by the ratio of initial to final peak areas. With CRREL HPLC-MS analysis, the probe voltage was $3 \mathrm{kV}$ and the cone voltage was $75 \mathrm{~V}$ and the N2 flow rate was $12 \mathrm{~L} / \mathrm{min}$ and the nebulizing gas pressure was $75 \mathrm{psi}$. The ESI probe oscillated between negative and positive ion mode every one second.

To expedite sample analysis with single contaminants UV-Vis spectroscopy (CRREL-Model Genesys-10s, Thermofisher, USA, EL- Cary 8454, Agilent, USA) was used. For each contaminant, the maximum absorbance for each contaminant was tracked ( $464 \mathrm{~nm}$ for MO, $285 \mathrm{~nm}$ for $\mathrm{CM}$, and $267 \mathrm{~nm}$ for $\mathrm{NB}$ ), and relative concentrations were calculated by the ratio of final to initial absorbances.

\section{6 $\mathrm{TiO}_{2}$ photocatalysis experiments}

$\mathrm{TiO}_{2}$ photocatalysis experiments were conducted in the photoreactor box (see section 2.2) equipped with $365 \mathrm{~nm}$ (UVA) fluorescent bulbs. Contaminant solutions ( $40 \mathrm{~mL}$ ) were stirred with $4 \mathrm{mg} \mathrm{TiO}_{2}$ (Degussa P25) for fifteen min prior to illumination. Aliquots (1 mL) were removed from the mixture after $0,10,20$, and $40 \mathrm{~min}$ of illumination. Aliquots were filtered $(0.22 \mu \mathrm{m})$ and analyzed with UV-Vis spectroscopy (individual contaminants) or HPLC-MS (contaminant mixture).

\subsection{UV-peroxide experiments}

UV-peroxide experiments were conducted in the experimental photoreactor (see section 2.2) equipped with $254 \mathrm{~nm}$ (UVC) bulbs. Contaminant solutions $(40 \mathrm{~mL}$ ) were stirred with the desired amount of peroxide. Peroxide solution ( $0.3 \%$ ) was added to the mixture in varying amounts to achieved target concentrations ranging from 1-18 mg/L. Aliquots (six, $1 \mathrm{~mL}$ ) were removed from the solution of the course of the illumination (either 5 or $10 \mathrm{~min}$, depending on degradation rate). Aliquots were added to $100 \mu \mathrm{L}$ methanol to quench reaction and analyzed with HPLC-MS.

\subsection{UV-hypochlorite experiments}

Hypochlorite experiments performed in the dark for MO were conducted in a $3 \mathrm{~mL}$ quartz cuvette inside a UV-Vis spectrophotometer measuring absorbance at $465 \mathrm{~nm}$. Sodium hypochlorite $(\mathrm{NaOCl}, 30,15$ and $60 \mu \mathrm{L}$ of $0.5 \%$ ) was added to $2 \mathrm{~mL} 25 \mu \mathrm{M}$ MO solution in the quartz cuvette, to achieve concentrations of $7 \mathrm{O}, 35$, and $140 \mathrm{mg} / \mathrm{L} \mathrm{NaOCl}$. The cuvette was 
briefly shaken to mix solution. Solution absorbance was recorded every 15 seconds for $2 \mathrm{~min}$.

All other experiments (including dark experiments with $\mathrm{CM}$ and $\mathrm{NB}$ ) were conducted in the experimental photoreactor inside a $50 \mathrm{~mL}$ quartz flask. $\mathrm{NaOCl}$ solution $(60 \mu \mathrm{L}, 5 \%)$ were added to $40 \mathrm{~mL}$ contaminant solution and stirred. Five, $1 \mathrm{~mL}$ aliquots were removed from the solution over the course of illumination and added to $100 \mu \mathrm{L} 0.5 \mathrm{M}$ sodium thiosulfate solution in an LC-MS analysis vial. Samples were analyzed with HPLC-MS (see Section 2.5 above). For experiments conducted without illumination, sampling time zero (' $\mathrm{O}_{\mathrm{o}}$ ') corresponds to the addition of $\mathrm{NaOCl}$ to the solution. For illuminated experiments, every effort was made to turn on the lights and add $\mathrm{NaOCl}$ simultaneously, and ' $T$ ' corresponds to the switching on of the light.

\subsection{Ozone experiments}

The ozone generator used for all experiments was an Ozonology Inc. Laboratory Ozone Generator, Model LC-1234, corona-arc type generator. For each experiment the voltage applied to the gas was $\sim 105$ volts. The exact amount of ozone entering the aqueous solution was determined via $\mathrm{UV}$-vis spectroscopy, using a $10 \mu \mathrm{M}$ solution of indigo trisulfonate, measuring its absorbance at $600 \mathrm{~nm}$.

For each experiment, $50 \mathrm{~mL}$ of the chosen contaminant was placed in a $50 \mathrm{~mL}$ quartz beaker and allowed to stir for at least five min. An initial $1 \mathrm{~mL}$ sample was taken and added to a chromatography vial. Then the ozone was bubbled into the beaker at the maximum flow rate. Samples were then taken from the beaker every 30 seconds for 300 seconds. To prevent the ozone from continuing to react with the contaminant once it was sampled, the solutions were quenched by bubbling nitrogen gas through the sample for at least 30 seconds to release the aqueous ozone still in solution. For MO experiments, a sipper cell was used for concentration measurements via UV-vis spectroscopy.

\subsection{Ozone-UV experiments}

Ozone-UV experiments were set up following the same procedure detailed above in the experimental photoreactor equipped with UVC bulbs. The samples were quenched by bubbling nitrogen gas through the sample for 
at least 30 seconds to release the aqueous ozone still in solution. The samples were analyzed with HPLC.

\subsection{Ozone hypochlorite experiments}

Ozone hypochlorite experiments were set up following the same procedure outlined above, with the addition of $2.5 \mu \mathrm{L}$ of $47 \mu \mathrm{M}$ calcium hypochlorite at the start of the reaction. At each sample time, hypochlorite and ozone were both quenched by addition of $100 \mu \mathrm{L} 0.025 \mathrm{M}$ sodium thiosulfate. The samples were analyzed with HPLC.

\subsection{Fenton and photo-Fenton experiments}

Reaction mixtures of $23 \mu \mathrm{M}$ solutions of MO, 5.4 or $16.5 \mu \mathrm{M} \mathrm{CM}, 46 \mu \mathrm{M}$ $\mathrm{NB}$, or a combination of all three model contaminants, and $12.5 \mu \mathrm{M} \mathrm{FeSO} 4$ were prepared by dilution with high purity water with the $\mathrm{pH}$ adjusted to 3 with sulfuric acid in $50 \mathrm{~mL}$ quartz beakers. Additionally, stock solutions of these reagents were prepared in $\mathrm{pH} 3$ sulfuric acid. After stirring for a minimum of five min, a $1 \mathrm{~mL}$ sample was withdrawn and added to a chromatography vial containing $100 \mu \mathrm{L}$ of methanol. Hydrogen peroxide, diluted 1000 fold, was then added for a concentration of $125 \mu \mathrm{M}$.

Subsequent $1 \mathrm{~mL}$ samples were withdrawn every 30 seconds up to $2.5 \mathrm{~min}$ and similarly added to the methanol ( $2.5 \mathrm{mM}, 500-1000$ fold excess) to halt the degradation by out competing the substrates with the alcohol.

Subsequent experiments were conducted with identical concentrations of all reagents the photo reactor equipped with six, $365 \mathrm{~nm}$ bulbs. To probe the effects of bulb emission wavelength on the enhancement of the rate experiments using $\mathrm{MO}$ were conducted using the same experimental parameters, but with medium pressure mercury arc lamps emitting primarily at $254 \mathrm{~nm}$. The experiments probing the effect of wavelength were monitored spectrophotometrically using a sipper cell to collect data in real time. 


\section{Results}

\subsection{Light characterization and cross-lab standardization}

Both optical (point radiometer and compact spectrometer) and chemical (ferrioxalate actinometry) methods were used to characterize the illumination set-ups at both laboratories. An uncalibrated compact spectrometer was used to characterize the spectral distribution of both UVA and UVC bulbs. In the UV to near visible range, the UVA bulbs have a single, broad peak centered at $365 \mathrm{~nm}$, and the UVC bulbs have a narrow peak at $254 \mathrm{~nm}$ and a second narrow peak at $360 \mathrm{~nm}$ (Appendix A, Figure A1a). A calibrated point radiometer equipped with sensors for 254, 310 and $365 \mathrm{~nm}$ was used to measure the radiance at relevant wavelengths. The UVC bulbs had a measured radiance of $0.20 \pm 0.04 \mathrm{~W} / \mathrm{m}^{2}$ at $254 \mathrm{~nm}$, and the UVA bulbs had a measured radiance of $0.9 \pm 0.1 \mathrm{~W} / \mathrm{m}^{2}$ at $365 \mathrm{~nm}$ (Appendix A, Figure A1b). The optical characterization was conducted with the experimental photoreactor at CRREL.

The CRREL and EL photoreactors were compared using ferrioxalate actinometry. This chemical reaction, which responds to light from 250$500 \mathrm{~nm}$, encompasses the wavelengths relevant to the UVA and UVC bulbs. Chemical actinometry can be used to calculate the photon flux (the rate at which photons reach the reaction system) from the rate of $\mathrm{Fe}(\mathrm{II})$ generation (Figure A2). The calculated flux values from the EL and CRREL photoboxes are shown in Table 2. For both bulb types, the flux from the CRREL and EL bulbs were within one standard deviation of each other, and thus, the two photoboxes were deemed directly comparable. For additional data and explanation of photon flux calculations, see Appendix A (Equations A1 and A2).

Table 2. Photon flux of each bulb type measured in experimental photo-reactors with ferrioxalate actinometry.

\begin{tabular}{|c|c|c|}
\hline \multirow{2}{*}{ Bulb Type } & \multicolumn{2}{|c|}{ Measured Photon Flux (Einsteins/s) } \\
\cline { 2 - 3 } & CRREL & EL \\
\hline UVA & $4.2 \pm 0.2$ E-09 & $4.0 \pm 0.2$ E-09 \\
\hline UVC & $4.4 \pm 0.4$ E-09 & $4.8 \pm 0.7$ E-09 \\
\hline
\end{tabular}




\subsection{Typically observed degradation products of contaminants}

The HPLC-MS method used to monitor degradation of the contaminants was also able to track the mass to charge ratio $(\mathrm{m} / \mathrm{z})$ of the products produced by the degradation of each contaminant. Absent of more advanced characterization equipment (e.g., tandem mass spectrometry), a review of the literature was relied upon to assist in identification of these byproducts. Three byproducts of the MO degradation were observed that were consistent with the $\mathrm{m} / \mathrm{z}$ and relative elution times reported by Chen et al. (2008) (Figure 4a). The retention times of the byproducts in from HPLC and the observed $\mathrm{m} / \mathrm{z}$ measured with mass spectrometry for each peak are labeled next to each observed product (chromatograms and mass spectra in Appendix B, Figures B1-B4). These byproducts involve the addition of a hydroxyl group and the removal of a methyl group from the parent MO molecule. The HPLC peaks corresponding to the MO byproducts are relatively large (roughly $5-20 \%$ of the area of the baseline MO peak) and tend to increase in size over the course of MO degradation. This is an indication that the degradation products of MO may be more recalcitrant than $\mathrm{MO}$ itself.

There are three unique places for the addition of a hydroxyl group to CM (Jelic et al. 2013), shown in Figure 4(b). In the typical HPLC-MS analysis, only one byproduct peak with $\mathrm{m} / \mathrm{z} 253$ is observed, eluting at $6.9 \mathrm{~min}$ (see Appendix B, Figure B2c). This peak is small relative to the initial CM peak (less than $1 \%$ of the area of the initial peak, which elutes at $9.1 \mathrm{~min}$ ). This is the case with the CRREL HPLC analysis, where the wavelengths from 200-600 nm were monitored, and stands in contrast to the MO product peaks, which are much larger. There is no way to determine which hydroxylated byproduct is being generated, however, the presence of only one may suggest that the production of one is more favored. The small size of the peak suggests that the products produced degrade more rapidly than the initial compound, and it may also be the case that other products are produced in such small quantities that they are not detectable. The fact that byproducts do not build up over the course of reactions indicates that they are less recalcitrant than CM.

Even with an increased concentration, NB, which elutes at $12 \mathrm{~min}$, did not ionize well enough to be visible above background ions in the mass detector used. Its HPLC peak decreases over the course of experiments (e.g., Figure 6), and a small byproduct peak is observed at $10.5 \mathrm{~min}$. Literature indicates that one likely byproduct is nitrophenol, shown in Figure 4c (Li et al. 2006). 
Figure 4. Frequently observed degradation products of (a) MO, (b) $\mathrm{CM}$, and (c) NB.

(a)
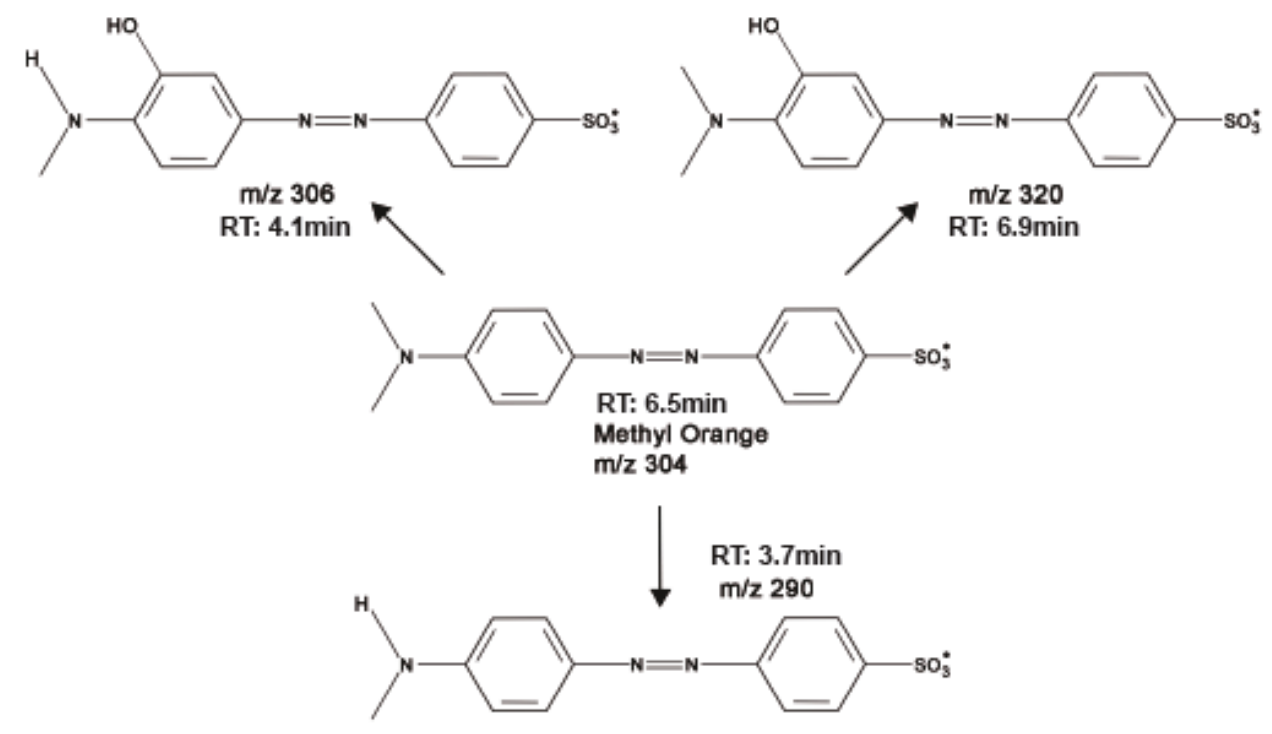

(b)

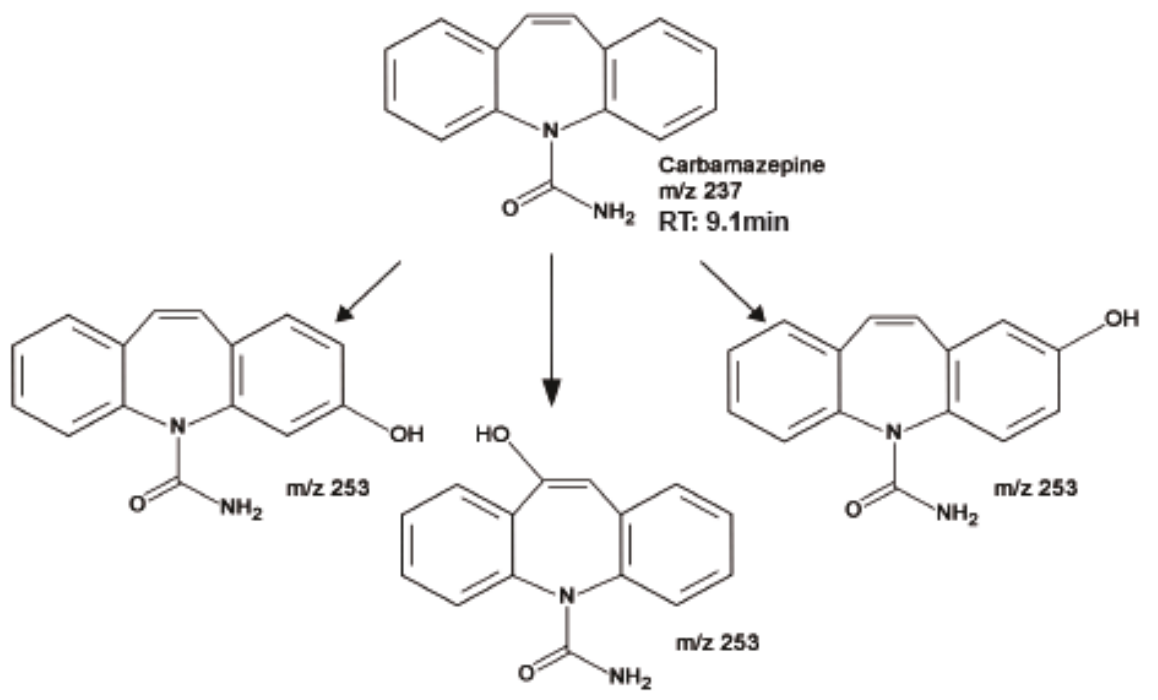

(c)

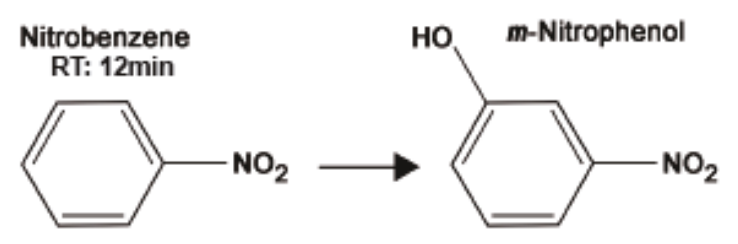




\section{3 $\mathrm{TiO}_{2}$ photocatalysis experiments}

\subsubsection{Reaction parameters and optimization}

Heterogeneous photocatalysis begins with the absorption of a photon by a semi-conductor material, generating an electron-hole pair, which can then react to form reactive oxygen species (Nosaka and Atsuko 2013). As such, the wavelength of incident illumination must match the bandgap of the semiconductor. For $\mathrm{TiO}_{2}$, whose bandgap can range from $3.0-3.3 \mathrm{eV}$ (Zhang et al. 2014), means the reaction requires incident light with wavelengths $375-413 \mathrm{~nm}$. In the $\mathrm{TiO}_{2}$ experiments, the UVA bulbs described above were used, as illumination with $365 \mathrm{~nm}$ light is common practice in the existing literature. The loading of $\mathrm{TiO}_{2}$ in photocatalytic experiments can vary in literature from 0.1-5 g/L (Mills et al. 1994, Brame et al. 2015). For these experiments, a constant $\mathrm{TiO}_{2}$ loading of $0.1 \mathrm{~g} / \mathrm{L}$ was used.

\subsubsection{Individual and combined kinetics}

The photocatalytic degradation of contaminants with $\mathrm{TiO}_{2}$ follows a pseudo-first order model. The kinetics for individual contaminants are shown in Figure 5a. The rate constants for degradation of the three contaminants are on the same order of magnitude, $0.020,0.015,0.027$ $\min ^{-1}$ for $\mathrm{MO}, \mathrm{CM}$, and $\mathrm{NB}$, respectively, indicating the unselective nature of photocatalysis as a treatment method for these three contaminants. NB shows the greatest degradation rate constant, even with its greater starting concentration ( $50 \mu \mathrm{M}$ as opposed to $25 \mu \mathrm{M}$ ).

The kinetics of the contaminant mixture, while still following a first-order regime, change dramatically (Figure 5b). The rate constant of MO remains relatively unchanged $\left(0.023 \mathrm{~min}^{-1}\right)$, but it is degraded three times as quickly as the other two contaminants, which had rate constants of 0.0076 and $0.0068 \mathrm{~min}^{-1}$ for $\mathrm{CM}$ and $\mathrm{NB}$, respectively. This favored degradation of MO may be a result of its light absorbance or its preferential adsorption to the catalyst. The other contaminants do continue to degrade in extended experiments. The byproducts observed in the HPLC chromatograms (Figure 6) all correspond to products described in Section 3.2 , which indicates the prevalence of hydroxyl radicals reacting with the contaminants to initiate degradation. 
Figure 5. Pseudo-first order degradation kinetics of (a) individual, and (b) mixed contaminants with commercial $\mathrm{TiO}_{2}$.

(a)

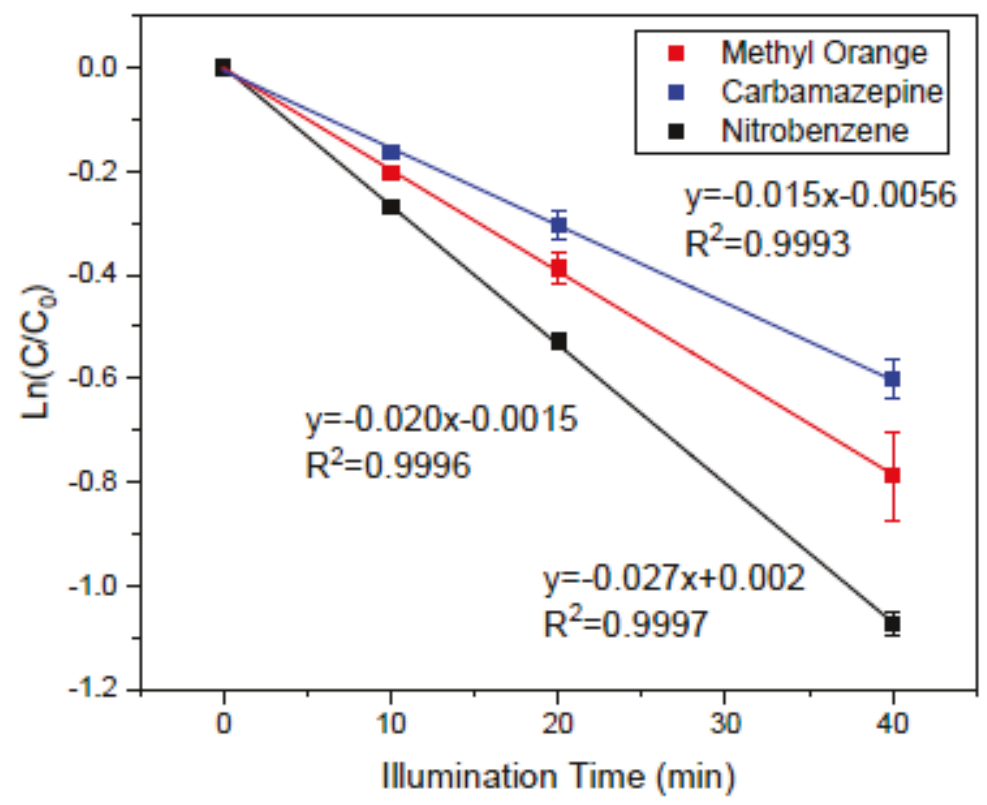

(b)

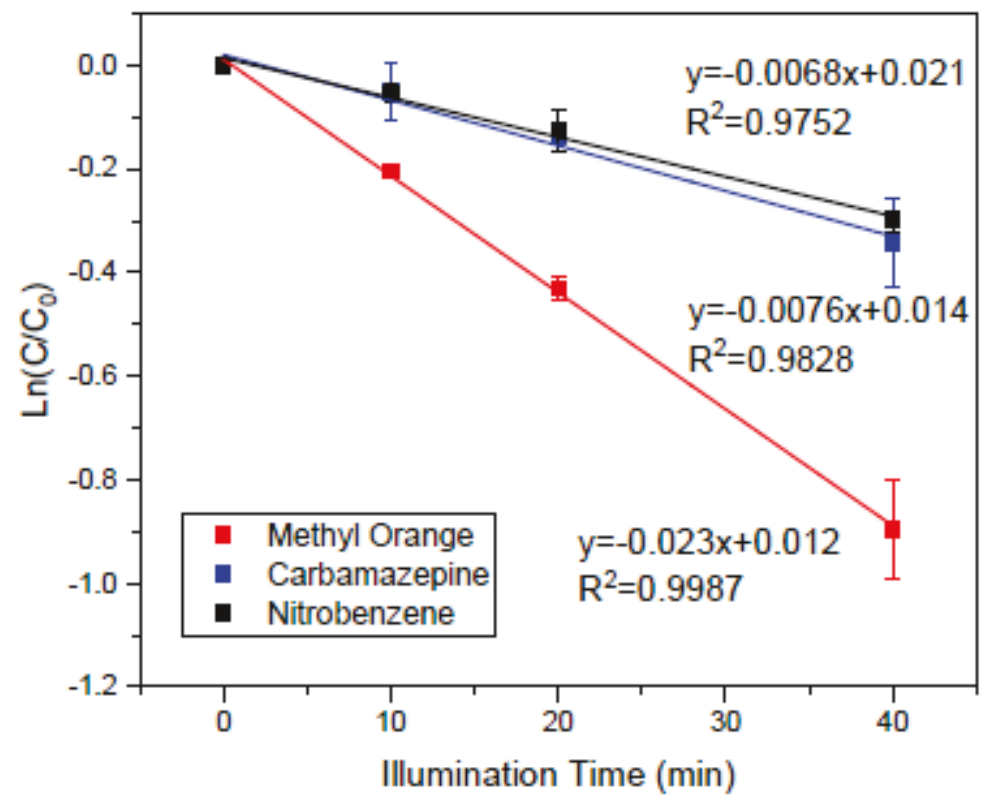


Figure 6. HPLC-MS chromatograms of individual contaminants degraded with $\mathrm{TiO}_{2}$ photocatalysis.

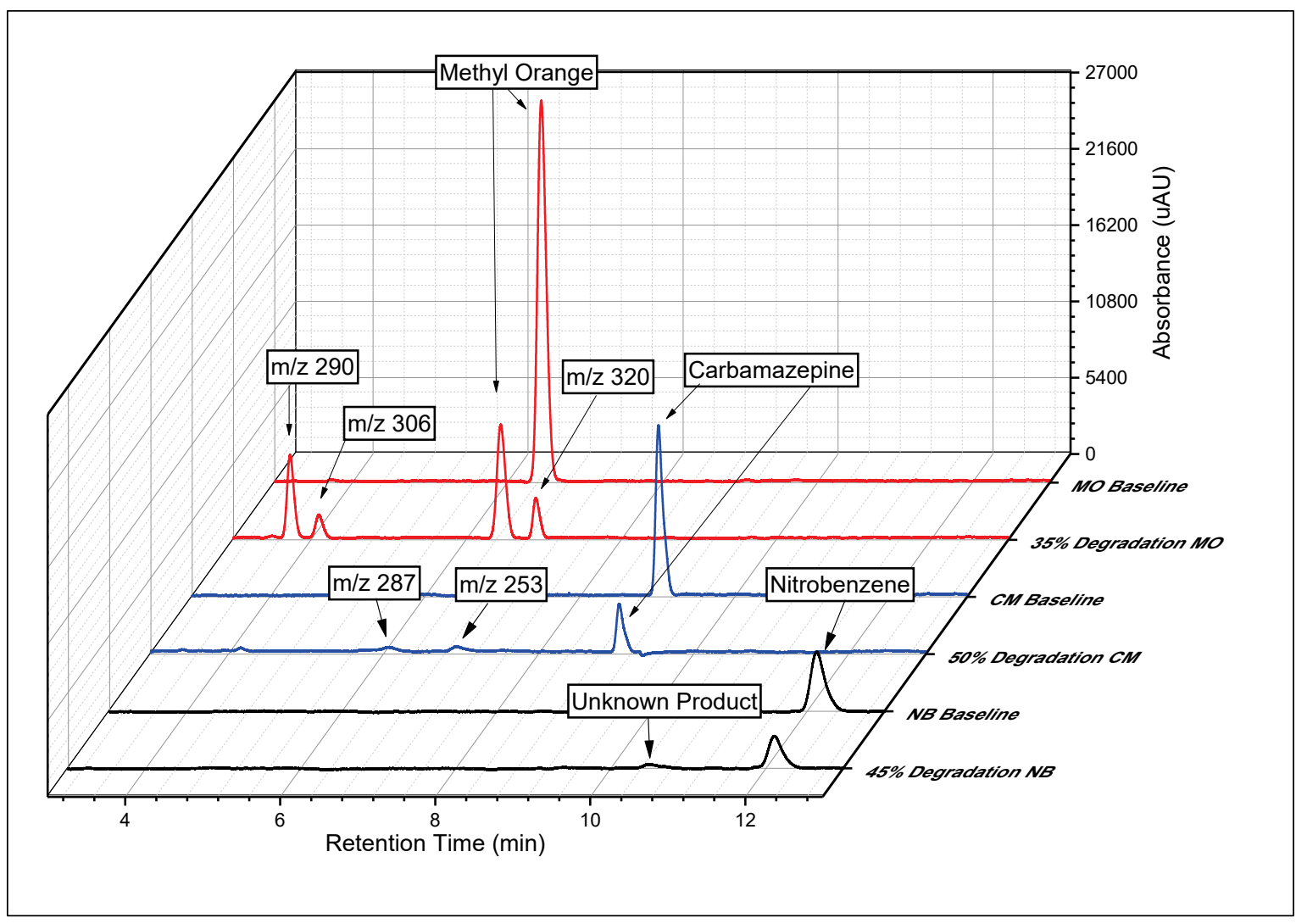

\subsection{UV-peroxide experiments}

\subsubsection{Reaction optimization and UV photolysis controls}

Reports from the City of Oxnard Advanced Water Purification Facility indicate the use of $6 \mathrm{mg} / \mathrm{L}$ peroxide in their treatment train (City of Oxnard California 2017). Concentrations around this reported level were tested in order to understand the effect of peroxide concentration on the reaction. UVC light was used as it is comparable to typical UV germicidal illumination employed in advanced water treatment facilities (City of Oxnard California 2017). A variety of peroxide concentrations were tested with each contaminant. With concentrations ranging from $1-18 \mathrm{mg} / \mathrm{L}$, a roughly linear relationship was observed between peroxide concentration and rate constant for each contaminant (Figure 7). The pseudo-first order kinetic plots are included in Appendix C (Figure C1). The control experiments with contaminants degraded by 1) UVC only (photolysis) (Figure C2), 2) peroxide and contaminants in the dark (Figure $\mathrm{C}_{3}$ ), and 3) peroxide and contaminants under UVA illumination (results not shown) yielded insignificant degradation of the contaminants. 
Figure 7. Pseudo-first order rate constants of contaminant degradation under UVC illumination with varying concentrations of $\mathrm{H}_{2} \mathrm{O}_{2}$.

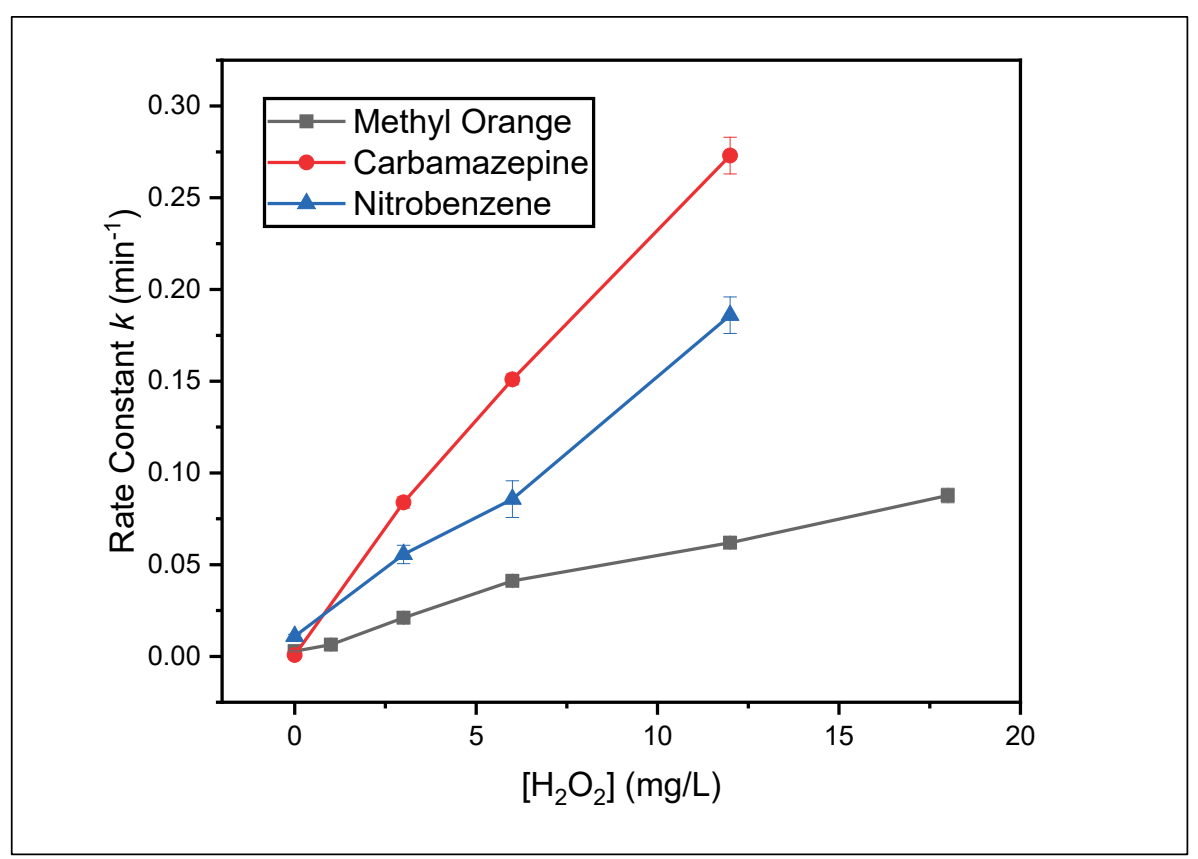

\subsubsection{Individual and combined kinetics and byproducts}

In order to obtain experimental data relevant to potential applications, the team proceeded with $6 \mathrm{mg} / \mathrm{L} \mathrm{H}_{2} \mathrm{O}_{2}$ for the UV-peroxide experiments. Although no reasoning was provided by the City of Oxnard water treatment facility for their use of this concentration, it was concluded that this level must fall within some operational or equipment constraint, and it was sensible to proceed with this concentration for further experiments. The experimental, pseudo-first order kinetics for all three contaminants individually under this UVC-peroxide regime are shown in Figure 8a. Carbamazepine was degraded most quickly $\left(0.151 \mathrm{~min}^{-1}\right)$, followed by NB $\left(0.086 \mathrm{~min}^{-1}\right)$, and then $\mathrm{MO}\left(0.041 \mathrm{~min}^{-1}\right)$. Note that all three rate constants were larger than the corresponding rate constants for UVC illumination alone, 0.0008, 0.0111, $0.0028 \mathrm{~min}^{-1}$, respectively (Figure C2a), indicating the efficacy of the UV-peroxide system. Only the degradation products described in Section 3.2 were observed in the HPLCMS analysis (see Appendix C, Figure C4).

A peroxide concentration of $6 \mathrm{mg} / \mathrm{L}$ was maintained for the experiments with the mixture of all three contaminants. The degradation kinetics of each contaminant in this experiment are shown in Figure 8b. In this experiment, the rate of MO degradation remained approximately the same (0.0512 $\mathrm{min}^{-1}$ ), while the rates of $\mathrm{CM}$ and $\mathrm{NB}$ degradation decreased by 
approximately an order of magnitude to 0.0141 , and $0.0114 \mathrm{~min}^{-1}$, respectively. This indicates that, as with the photocatalysis experiments, the degradation of MO is favored over the other two contaminants in solution.

The steep decline in rate constants may be due to the limited availability of peroxide in solution. In the individual contaminant experiments, the molar ratio of peroxide to contaminant molecules is approximately $7: 1$ for $\mathrm{CM}$ and MO, and 3.5:1 for NB. In the mixture experiments, the ratio of peroxide to total contaminants is less than 2:1. This means that the degradation of MO consumes a large amount of the total available peroxide, likely leaving little left for degradation of the other two contaminants. This hypothesis is confirmed by the fact that after $90 \%$ destruction of $\mathrm{MO}$, the degradation rates of the other two contaminants do not increase (See Appendix C, Figure $\mathrm{C}_{5}$ ). Furthermore, the degradation rate constant of NB in the mixture (0.0114 $\left.\mathrm{min}^{-1}\right)$ is equal to the UV photolysis rate of this compound (0.0111 $\mathrm{min}^{-1}$, Table 3), indicating that the NB degradation is driven entirely by the UV light and not by the presence of peroxide. This has tremendous implications for the use of UV peroxide as a treatment technique, because a reactor will almost certainly require continued dosing of peroxide for effective removal of all compounds. It also highlights the importance of studying the degradation of compounds in mixtures, because this preferential degradation is only observed when multiple contaminants are combined. 
Figure 8. Pseudo-first order degradation kinetics of (a) individual and (b) mixed contaminants with $6 \mathrm{mg} / \mathrm{L} \mathrm{H}_{2} \mathrm{O}_{2}$ and UVC illumination.

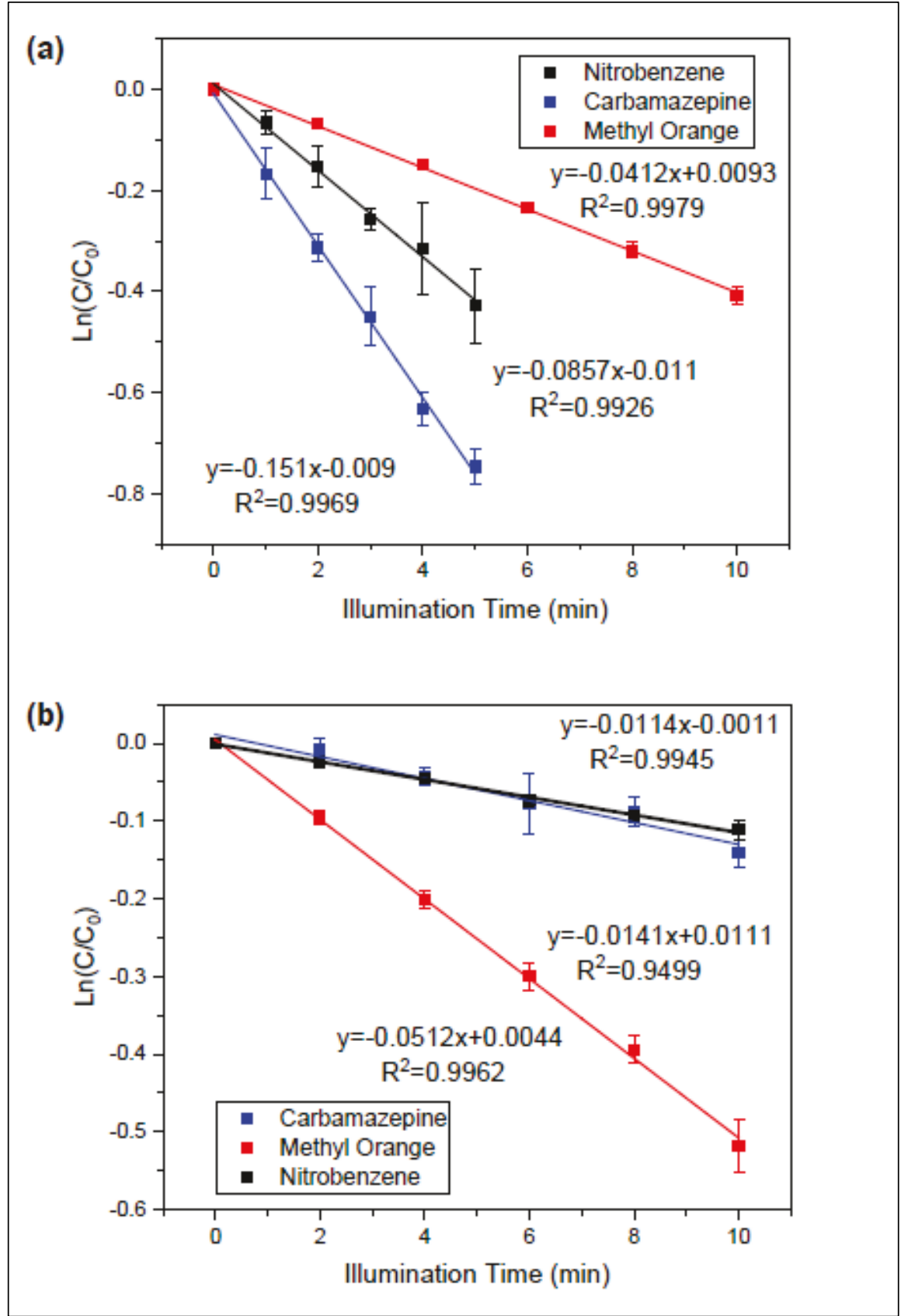

Table 3. Rate constants for UV-peroxide experiments and UVC photolysis experiments.

\begin{tabular}{|l|l|l|l|}
\hline \multirow{2}{*}{ Contaminant } & \multicolumn{3}{c|}{ Pseudo-First Order Rate Constant k (min-1) } \\
\cline { 2 - 4 } & \multicolumn{1}{|c|}{ Individual } & \multicolumn{1}{c|}{ Mixed } & \multicolumn{1}{c|}{ UV Photolysis } \\
\hline Methyl Orange (MO) & $0.0412 \pm 0.001$ & $0.0512 \pm 0.002$ & $0.0028 \pm 0.0004$ \\
\hline Carbamazepine (CM) & $0.151 \pm 0.003$ & $0.0141 \pm 0.002$ & $0.0008 \pm 0.0003$ \\
\hline Nitrobenzene (NB) & $0.09 \pm 0.01$ & $0.011 \pm 0.001$ & $0.011 \pm 0.001$ \\
\hline
\end{tabular}




\subsection{UV-hypochlorite experiments}

\subsubsection{Reaction optimization and dark (control) reactions}

Hypochlorite ( $\mathrm{NaOCl}$ ) and other chlorination methods are commonly used for disinfection during traditional water treatment processes. To ensure the relevance of our experiments, the team looked to reports from water treatment facilities for appropriate hypochlorite concentrations. These reports indicated that $70 \mathrm{mg} / \mathrm{L}$ was a typical concentration of chlorine in water that has completed traditional wastewater treatment (City of Oxnard California 2017). The report does not specify which chlorine species was used, therefore, the team tested the degradation of MO with 35, 70, and $140 \mathrm{mg} / \mathrm{L}$ hypochlorite without UV illumination. The pseudo-first order rate constants for these experiments are shown in Table 4 (plots are shown in Figure D1). No significant change in rate constant was observed with the doubling and halving of the $\mathrm{NaOCl}$ concentration, so the team chose to proceed with $70 \mathrm{mg} / \mathrm{L}$ for all future $\mathrm{NaOCl}$ experiments.

Table 4. Pseudo-first order rate constants of $\mathrm{MO}$ with sodium hypochlorite at varying concentrations.

\begin{tabular}{|c|c|}
\hline $\begin{array}{c}\text { Hypochlorite } \\
\text { Concentration } \\
(\mathrm{mg} / \mathrm{L})\end{array}$ & $\begin{array}{c}\text { Rate Constant, } k \\
\left(\mathrm{~min}^{-1}\right)\end{array}$ \\
\hline 35 & $0.222 \pm 0.006$ \\
\hline 70 & $0.20 \pm 0.01$ \\
\hline 140 & $0.20 \pm 0.02$ \\
\hline
\end{tabular}

The rate constants from the dark (without illumination) hypochlorite reactions are shown in Table 5 (plot included in Appendix D, Figure D2). $\mathrm{MO}$ is the only one of the three contaminants to be significantly affected by the presence of bleach without illumination, degrading over $25 \%$ in under two min. Carbamazepine was notably resistant to degradation by $\mathrm{NaOCl}$, and the slope of the best fit line was positive, leading to a negative degradation rate constant. UVC light was chosen as the appropriate illumination source for these experiments based on its common use in wastewater treatment scenarios. 
Table 5. Pseudo-first order rate constants of individual contaminants with $70 \mathrm{mg} / \mathrm{L} \mathrm{NaOCl}$ (dark reaction).

\begin{tabular}{|c|c|}
\hline Contaminant & $\begin{array}{c}\text { Rate Constant } \\
\left(\text { min }^{-1}\right)\end{array}$ \\
\hline Methyl Orange (MO) & $0.19 \pm 0.01$ \\
\hline Carbamazepine (CM) & $-0.001 \pm 0.004$ \\
\hline Nitrobenzene (NB) & $0.006 \pm 0.001$ \\
\hline
\end{tabular}

\subsubsection{Individual and combined kinetics and degradation products}

The UV-hypochlorite experiments with all three contaminants were conducted with a hypochlorite concentration of $70 \mathrm{mg} / \mathrm{L}$. In the individual experiments, different sampling times were used for each contaminant, in order to best capture the varied rates of degradation (Figure 9a). For example, for the MO degradation, four samples pulled over the course of one minute captured $75 \%$ degradation of $\mathrm{MO}$, whereas in the $\mathrm{NB}$ experiments, four samples pulled over the course of eight min measured less than 20\% degradation. The rate constants for the three contaminants vary by almost two orders of magnitude. MO, which degrades quickly with hypochlorite and no light (0.19 $\left.\mathrm{min}^{-1}\right)$, degrades even more quickly with the application of UVC light $\left(1.38 \mathrm{~min}^{-1}\right)$. Carbamazepine, which is totally resistant to degradation with hypochlorite in the dark, also degrades quickly $\left(0.423 \mathrm{~min}^{-1}\right)$, with its rate constant about $30 \%$ of the MO rate constant. UV-hypochlorite enhances the rate of $\mathrm{NB}$ (from $0.006 \mathrm{~min}^{-1}$ in the $\mathrm{NaOCl}$-dark experiment to $0.0252 \mathrm{~min}^{-1}$ with the application of both $\mathrm{NaOCl}$ and UVC light), but its rate constant remains approximately $1 \%$ of the MO rate constant. This suggests that the UV-hypochlorite process has a higher degree of selectiveness for certain contaminants.

The mixed contaminants data also demonstrates the selectivity of the UVhypochlorite process. In the mixed contaminant experiments (Figure 9b), the degradation rates for each contaminant only decrease slightly, in contrast to the results with other AOP methods (e.g., $\mathrm{TiO}_{2}$ photocatalysis, Section 3.3.2). Samples were pulled every 30 seconds for the first $2 \mathrm{~min}$, at which point the MO was completely degraded. Subsequent samples were pulled at 3, 5, and 10 min to capture the degradation rates of CM and NB. 
Figure 9. Pseudo-first order degradation kinetics of (a) individual and (b) mixed contaminants with $70 \mathrm{mg} / \mathrm{L} \mathrm{NaOCl}$ and UVC illumination.

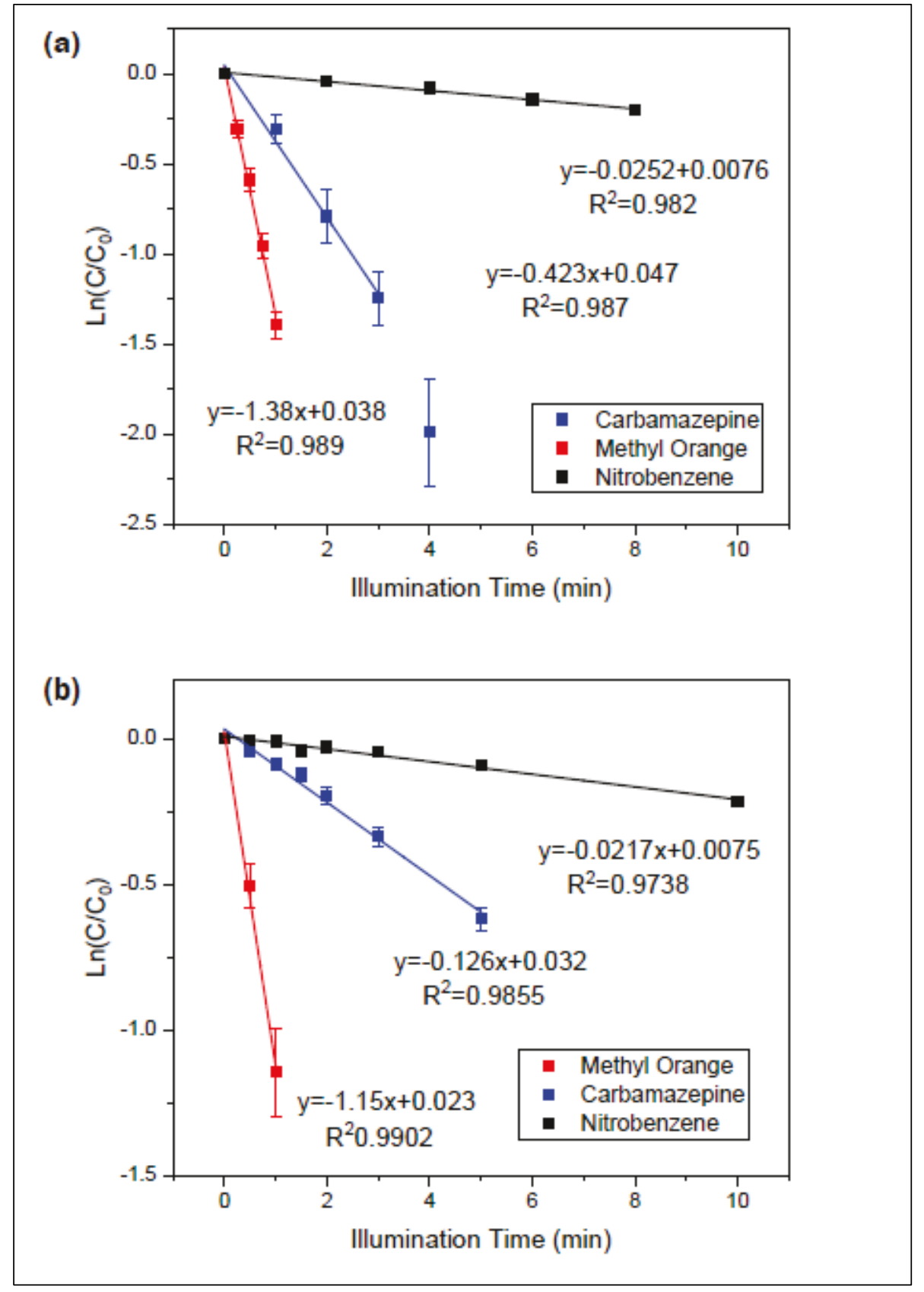

The lack of change in rate constants from the individual to mixed experiments is likely a result of the relative concentrations of hypochlorite and contaminants. In the $\mathrm{CM}$ and $\mathrm{MO}$ experiments, the molar ratio of hypochlorite to contaminant is almost 40:1, and the ratio is close to 20:1 in the NB experiments. In the mix experiments, the ratio of hypochlorite to contaminants is still over 9:1. With this excess of reagent, the bleach is not completely consumed by a single contaminant, therefore, the reaction 
rates are driven by the contaminants reactivity to hypochlorite and are not majorly affected by the presence of other organic molecules in solution. The difference in rate constants among the contaminants, almost two orders of magnitude between the fastest and the slowest rates, highlights a key pitfall of UV-hypochlorite as a water treatment AOP. This method is highly specific to certain contaminants and may not be able to efficiently removal all contaminants from water sources.

The products observed with the UV-NaOCl degradation of $\mathrm{CM}$ and $\mathrm{NB}$ were the same hydroxylated products discussed in Section 3.2. However, in the MO experiments, an additional product was observed. Eluting around 8 min, a very small peak with an $\mathrm{m} / \mathrm{z}$ of 338 is visible on the HPLC chromatogram (Figure 10). This mass corresponds with the addition of a chlorine to MO. This lone chlorination byproduct concurs with the kinetic data. Since MO is the only contaminant to react significantly with bleach without illumination, it can be concluded that MO is the only contaminant reacting with the hypochlorite directly, and that the other contaminants must primarily be reacting with radicals produced by the irradiation of the hypochlorite in solution. Thus, the fact that only MO degrades into chlorinated products supports the other experimental data. Interestingly, this byproduct does not accumulate in large amounts in the way that the other MO products do. This $\mathrm{m} / \mathrm{z} 338$ peak remains small (less than $1 \%$ in area of initial MO peak) over the course of the reaction, suggesting that this product continues to degrade. 
Figure 10. HPLC chromatogram of MO degraded with $70 \mathrm{mg} / \mathrm{L} \mathrm{NaOCl}$ and UVC illumination showing a chlorinated byproduct.

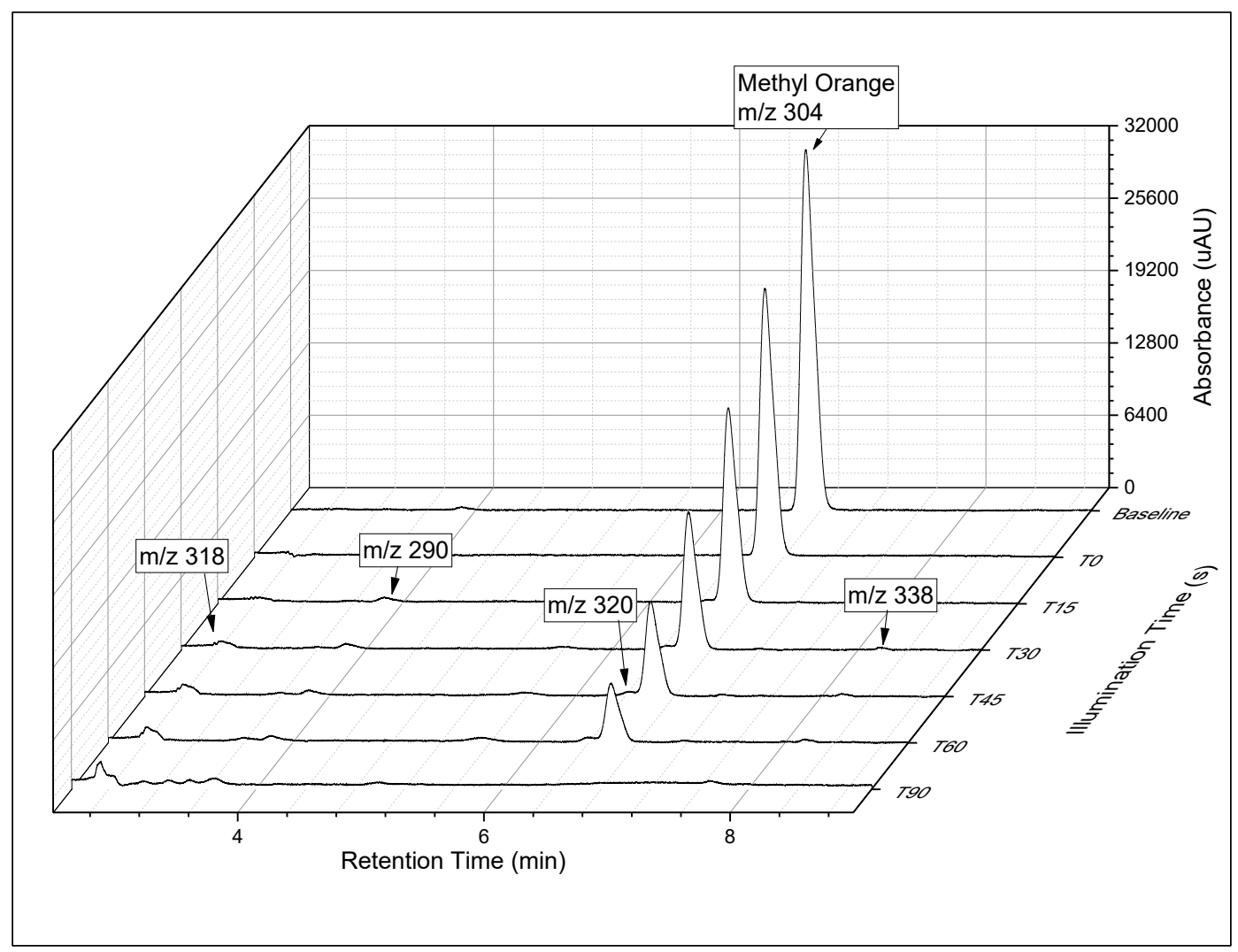

\subsection{Ozone based experiments}

\subsubsection{Ozone generator and reaction optimization}

Ozone is typically generated by applying high electric discharge or UV light to oxygen gas. An overview of the chemical reactions leading to ozone generation is shown in Figure 11. The EL ozone generator, a corona arc type generator, was operated at $105 \mathrm{~V}$. This voltage was selected to optimize the reaction rates while allowing for time to collect samples during the reaction. The ozone concentration at this level was measured with the addition of indigo trisulfonate to the solution. This dye reacts in a 1:1 molar ratio with ozone, so ozone flow rates and concentrations can be measured by monitoring the solution absorbance at $600 \mathrm{~nm}$ over time. The flow rate for our system was measured to $0.192 \mathrm{mg}$ ozone/minute (see Appendix E, Figures E1 and E2 for additional information and calculations). These operating conditions remained constant for all experiments. 
Figure 11. Overview of the generation of ozone from oxygen gas.

$$
\begin{gathered}
3 \mathrm{O}_{2} \longrightarrow 2 \mathrm{O}_{3} \\
\mathrm{O}_{2} \stackrel{\mathrm{E}}{\longrightarrow} 2 \mathrm{O} . \\
\mathrm{O}+\mathrm{O}_{2} \longrightarrow \mathrm{O}_{3}
\end{gathered}
$$

\subsubsection{Ozone kinetics and byproducts}

The pseudo-first order degradation kinetics for the reaction of individual and mixed contaminants with ozone is shown in Figure 12a. Individually, NB has the slowest rate (0.1069 $\left.\mathrm{min}^{-1}\right)$, an order of magnitude slower than MO (2.2034 $\left.\mathrm{min}^{-1}\right)$. CM, which reacts extremely quickly, completely disappears from solution in the first 30 seconds of reaction (Note: no data points are shown for CM in Figure 12a for this reason). Although the disappearance of CM is rapid, HPLC-MS analysis showed that a product of this reaction forms and persists in solution over the course of the reaction. 
Figure 12. Pseudo-first order degradation kinetics of (a) individual and (b) mixed contaminants with ozone.

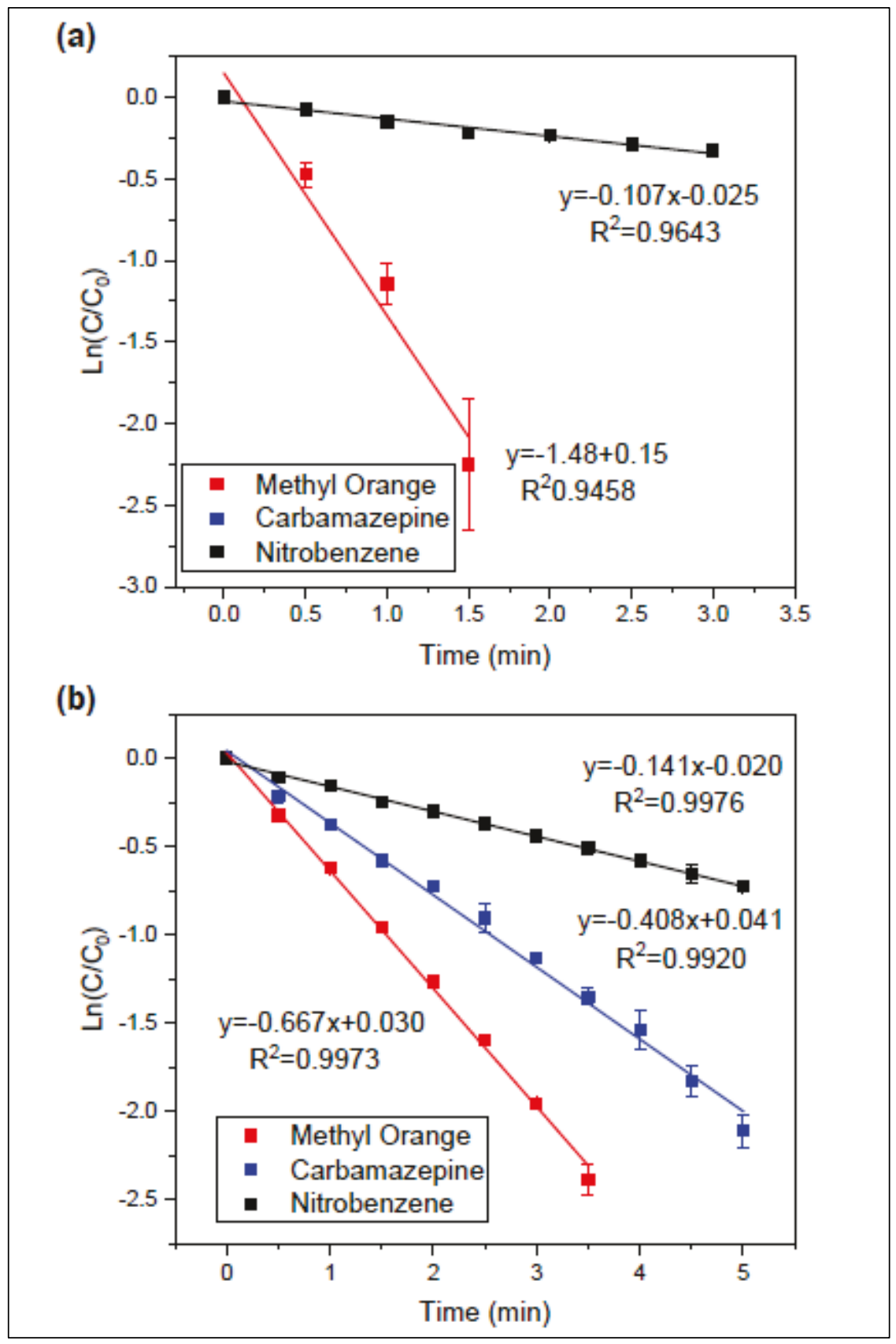

The HPLC-MS analysis at CRREL and information from literature were used to identify the CM degradation product formed under application of ozone. The HPLC-MS analysis showed a product, or possibly two products with a mass to charge ratio of 251 (See Appendix F and Figures F1-F3 for more details). McDowell et al. (2005) identified several CM ozonolysis products, one of which has a $\mathrm{m} / \mathrm{z}$ of 251 in mass spectrometry analysis. The structure of this product, which McDowell et al. (2005) label 1-(2- 
benzaldehyde)-4-hydro-( $(1 \mathrm{H}, 3 \mathrm{H})$-quinazoline-2-one (BQM), is shown in Figure 13. In the mixture reaction, this product does not appear, allowing us to measure rate constants for the degradation of all three contaminants in a mixture (Figure 12b). This indicates a degree of competition for ozone in solution in the mixed contaminants that is not present in the individual reactions.

Figure 13. Structure of BQM, proposed CM ozonolysis product.<smiles>O=Cc1ccccc1-n1c(=O)ncc2ccccc21</smiles>

\subsubsection{UV ozone kinetics and byproducts}

The pseudo-first order degradation kinetics for the reaction of individual and mixed contaminants with ozone and UVC illumination is shown in Figure 14. Unlike with the ozone only reactions, $\mathrm{CM}$ in not immediately transformed into the secondary product BQM in the individual experiments (Figure 14a). This is a direct consequence of the UV light, indicating that the light is powerful enough to degrade the ozone molecules more quickly than they can reach the $\mathrm{CM}$ in solution. The rates of $\mathrm{MO}\left(0.3252 \mathrm{~min}^{-1}\right)$ and $\mathrm{NB}\left(0.1337 \mathrm{~min}^{-1}\right)$ degradation were also slower than the rates with ozone alone (2.2034 and $0.1069 \mathrm{~min}^{-1}$ respectively), meaning that the UV light was not an effective enhancement of the ozone AOP. In addition, MO degradation was strongly favored in the contaminant mixture, with a rate constant more than four times greater than that of the other contaminants Figure 14b). The decrease in rate constants may be a result of the experimental design, which had ozone treatment and UV irradiation begin at the same time. If the ozone was permitted to react directly with contaminants for a short time, followed by pulses of light, it might allow for quick, direct ozonolysis of contaminants and also allow for the UV-Ozone process to degrade contaminants and byproducts that are recalcitrant to ozone. 
Figure 14. Pseudo-first order degradation kinetics of (a) individual and (b) mixed contaminants with ozone and UVC illumination.

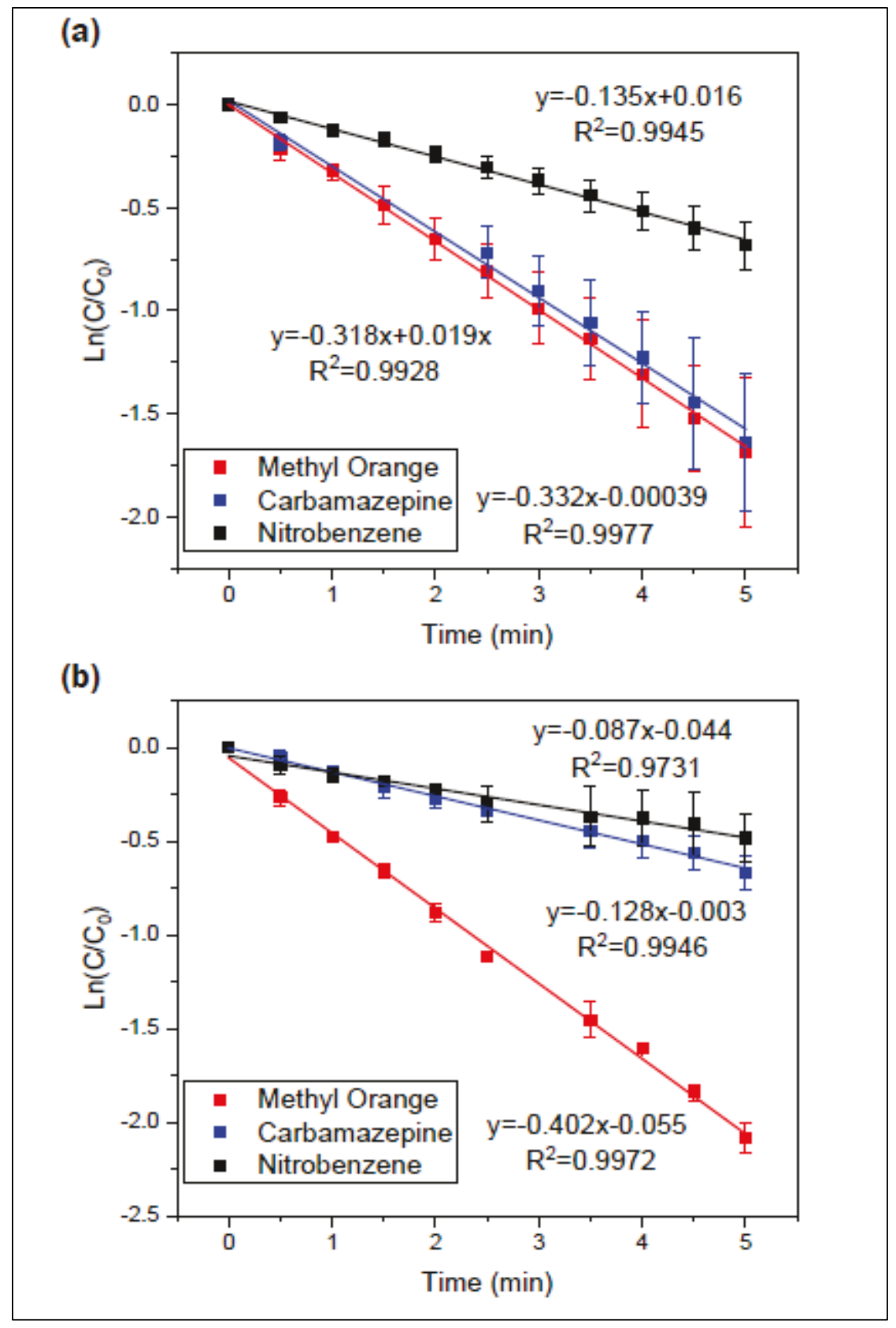

\subsubsection{Ozone- perchlorate $(\mathrm{OCI})$ kinetics and byproducts}

The pseudo-first order degradation kinetics for the reaction of individual and mixed contaminants treated with ozone and hypochlorite is shown in Figure 15. As with the ozone-alone experiments (Figure 12), the CM is immediately transformed into the ozonolysis product BQM (Figure 13). This indicates that while hypochlorite is present in excess, the ozone still reaches $\mathrm{CM}$ faster than hypochlorite under these reaction conditions. 
Similar to the ozone alone condition, the secondary CM product is not produced in the contaminant mixture. MO degradation is favored in the mixture (2.3749 $\mathrm{min}^{-1}$ ) over the degradation of the other two contaminants. Curiously, in the mixture, NB displayed no degradation $\left(-0.0029 \mathrm{~min}^{-1}\right)$, as the slope of the best-fit line was positive over the reaction time.

Figure 15. Pseudo-first order degradation kinetics of (a) individual and (b) mixed contaminants with ozone-hypochlorite.

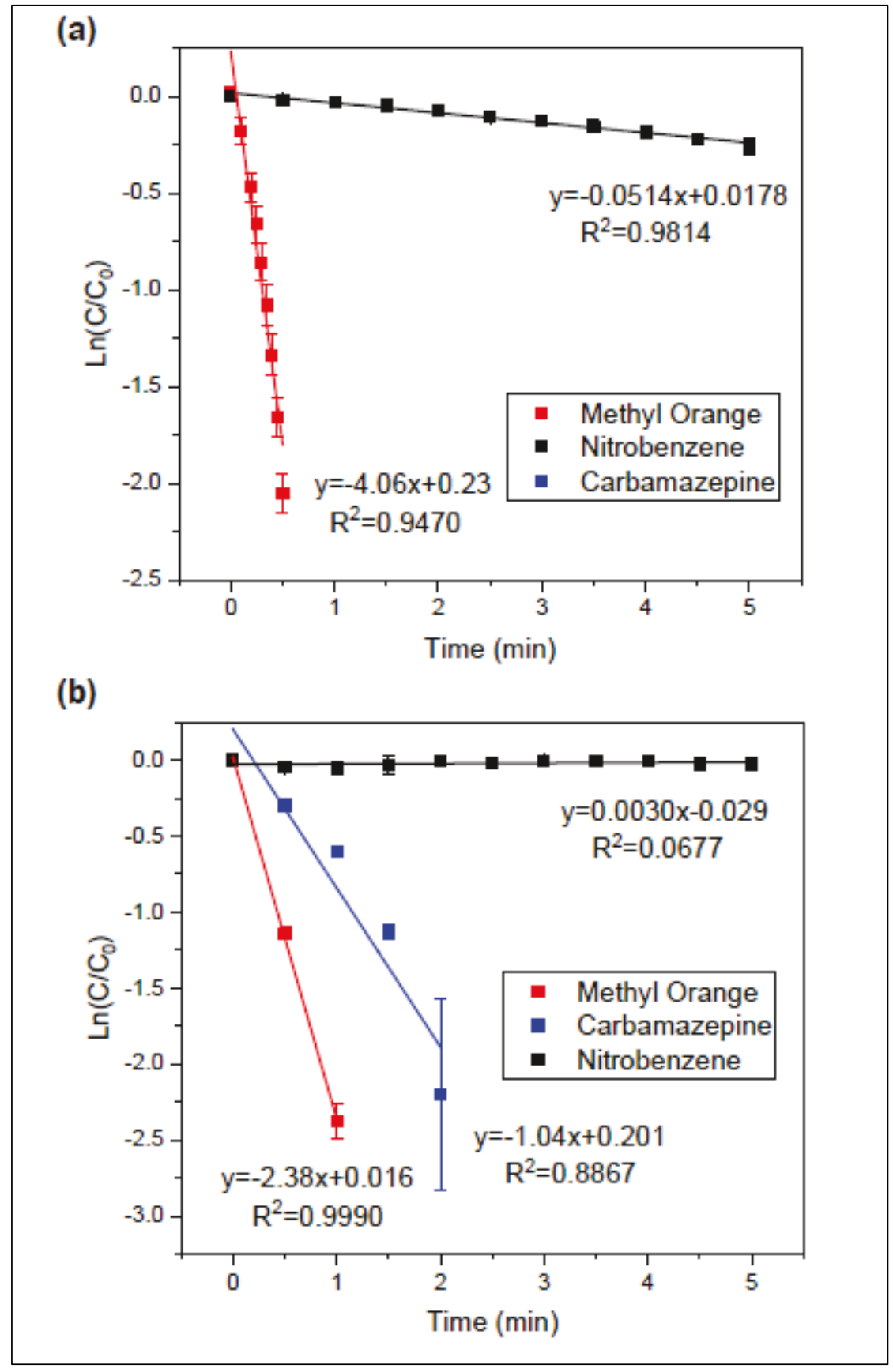




\subsection{Fenton-based experiments}

\subsubsection{Overview of the Fenton and photo-Fenton reactions}

The eponymous Fenton reaction, first discovered in the late $19^{\text {th }}$ century (Fenton 1984), was later shown to operate with a mechanism involving the catalytic cycle of ferric and ferrous ions reacting with hydrogen peroxide (1934). The proposed cycle generates a hydroxyl radical ( $\mathrm{HO} \bullet$ during the oxidation of ferrous ions. The iron was subsequently shown to be catalytic, with peroxide reducing the ferric ions to ferrous iron. This cycle is depicted in Figure 16. The reduction of ferric ions with hydrogen peroxide is the slowest step of the cycle, which is evidenced by the burst of reactivity observed with addition of hydrogen peroxide to a solution of ferrous salts (Chen and Pignatello 1997). The presence of ferric ions demands that the reaction must be conducted under acidic conditions to avoid precipitation of the mixed ferric oxides and hydroxides above $\mathrm{pH} 5$ (Sylva 1972).

Figure 16. Diagram of the Fenton cycle for both Fenton and photo-Fenton reactions.

\section{Fenton (Dark)}

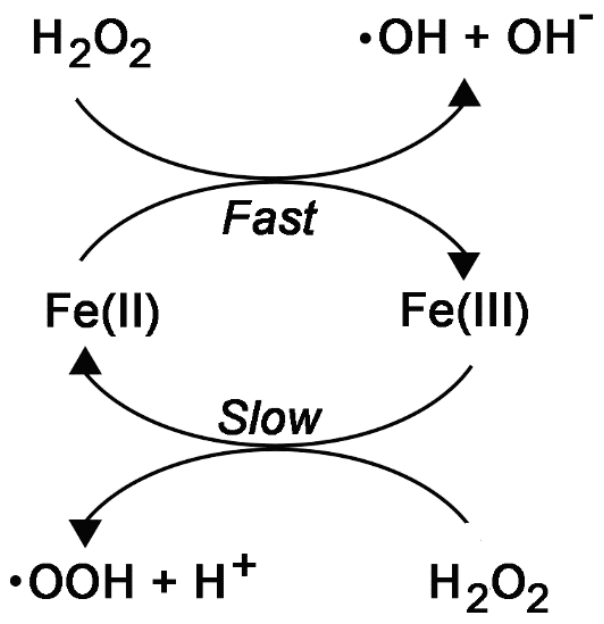

\section{Photo-Fenton}

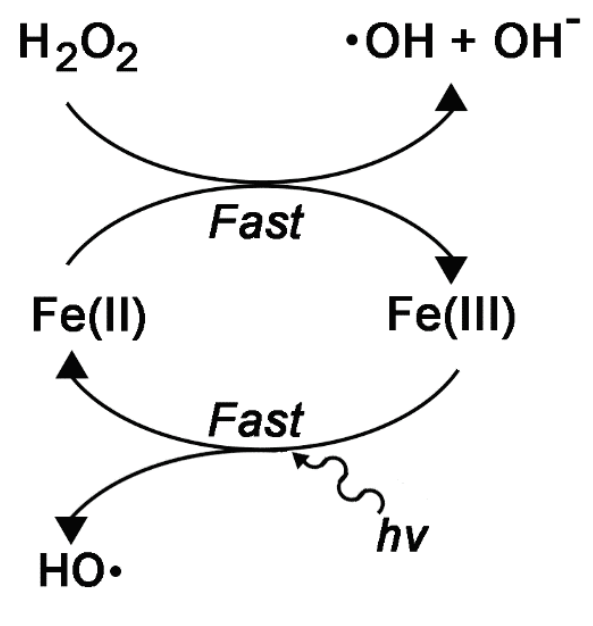

The rate limiting step of the cycle described in Figure 16 can be enhanced by introducing light to the system (Ruppert et al. 1993; Lei et al. 1998). The iron hydroxides absorb the light up to roughly $410 \mathrm{~nm}$ and undergo a photo-reduction to regenerate the highly reactive ferrous ions, although the quantum yield is higher for lower wavelengths of light (Wells and Salam 1968). This makes the process much more efficient by not consuming another equivalent of peroxide to reduce the iron, while 
making an equivalent of $\mathrm{HO}$, the chief oxidant. Another benefit of the photo-assisted Fenton process occurs when a majority of the organic carbon exists as small organic acids. Organic acids, especially oxalic acid, are quite recalcitrant to oxidation via $\mathrm{HO}^{\bullet}$, but can be efficiently mineralized when chelated to a ferric ion. In both processes, the reactive species generated is the electrophilic $\mathrm{HO} \bullet$ (DeMatteo et al. 2005), which reacts relatively non-selectively with organic compounds in solution.

\subsubsection{Fenton reaction kinetics}

The degradation of the individual contaminants with Fenton's reaction are shown in Figure 17a. For ease of comparison with the other AOP in this report, the degradation is fit to a first-order model although that is likely not the appropriate kinetic regime. The concentration vs. time data is shown in Appendix G, Figure G1. The data can also be fit to a second order model (See Appendix G, Figure G2). Neither $1^{\text {st }}$ nor $2^{\text {nd }}$ order kinetics appear appropriately model the reaction process. Instead, the following appear to be two different kinetic regimes occurring over the course of the reaction: a quick initial phase, occurring in the first 30 seconds to $1 \mathrm{~min}$ of reaction, and a slower phase, occurring in the subsequent minutes of reaction. This initial phase corresponds to the initial reaction of peroxide with the Fe(II), and the slower phase corresponds with the slowing recycling of $\mathrm{Fe}(\mathrm{III})$ to $\mathrm{Fe}(\mathrm{II})$.

Regardless of the kinetic model, the degradation appears to be equally effective for $\mathrm{MO}$ and $\mathrm{CM}$, each exhibit 23\% degradation during the course of the experiment (1.5 $\mathrm{min}$ ), and have rate constants of 0.091 and 0.103 $\mathrm{min}^{-1}$, respectively. A larger percentage (90\%) of the NB remains than the other contaminants (77\%), this is likely due to the greater starting concentration of the contaminant and the recalcitrance of the molecule towards $\mathrm{HO} \bullet$ radical addition. This is further complicated due to the enhanced reactivity of the product(s), nitrophenol(s), with respect to $\mathrm{HO} \bullet$ due to the now electron rich ring, a phenomenon described by Carlos et al. (2008). The $\mathrm{HO}^{\bullet}$ are still generated at the same rate because the starting concentrations of $\mathrm{H}_{2} \mathrm{O}_{2}$ and $\mathrm{Fe}(\mathrm{II})$ remain the same, but the lower efficiency of the degradation of $\mathrm{NB}$ and $\mathrm{CM}$ with respect to MO is likely due to recombination of two $\mathrm{HO} \bullet$ to return the $\mathrm{H}_{2} \mathrm{O}_{2}$ starting material, or is scavenged by the more reactive hydroxylated products (Pignatello et al. 2006; Carlos et al. 2008). The increased efficiency of the MO degradation is potentially also due to the abstraction of hydrogens from the methyl groups, a reaction not possible with $\mathrm{NB}$ or $\mathrm{CM}$. 
The degradation kinetics of the contaminant mixture are shown in Figure 17b, again fit to a first-order model. In the mixed contaminant experiments, $\mathrm{MO}$ degraded the fastest $\left(0.065 \mathrm{~min}^{-1}\right)$. As observed with other AOP in this report, preference was shown for MO degradation over CM (0.034 $\mathrm{min}^{-1}$ ) or NB degradation (0.026 $\mathrm{min}^{-1}$ ), although not as pronounced as with other AOP such as UV-peroxide (a rate constant three times greater instead of ten times greater).

Figure 17. Degradation of (a) individual and (b) mixed contaminants with Fenton reaction, fit to pseudo-first order model.

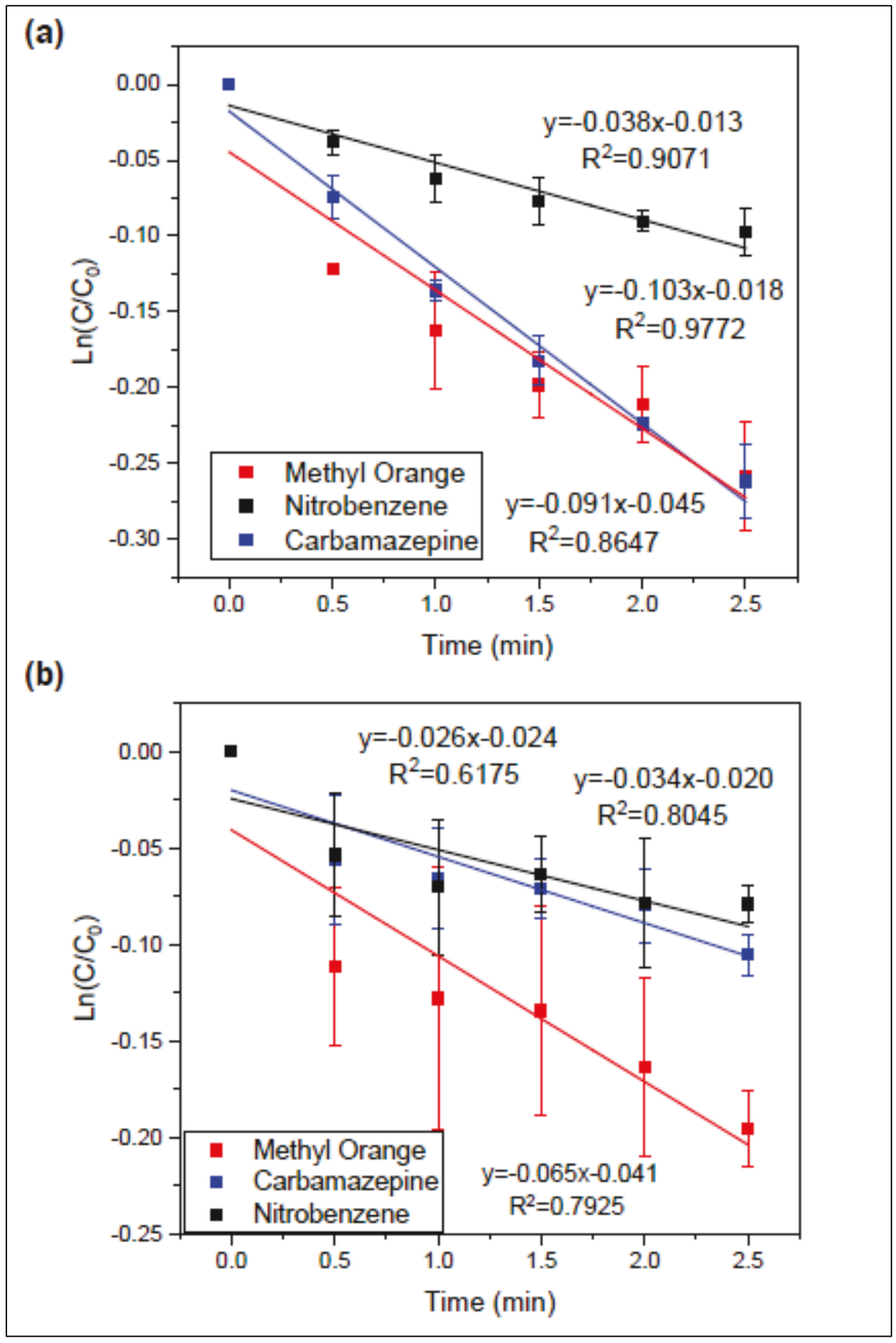




\subsubsection{Photo-Fenton reaction kinetics}

Before conducting the photo-assisted Fenton reaction with all contaminants, the team sought to investigate the dependence of the wavelength of the irradiation on the rate of degradation. To evaluate this, the team examined the end of a 20 min experiment, after the Fenton reaction has reached the rate limiting step of the ferric reduction. Under $365 \mathrm{~nm}$ light, the rate was enhanced six-fold over the dark reaction, and by an order of magnitude when UVC bulbs were used (Figure 18). The experiment with the UVC irradiation shows much greater degradation than the other experiments, which is due to the synergistic effects of direct photolysis of $\mathrm{MO}$, photolysis of $\mathrm{H}_{2} \mathrm{O}_{2}$, and the photoreduction of ferric oxyhydroxides. However, the slope of the curve at this point is the key factor in understanding the enhancing effects of the light on the catalytic cycle, rather than the amount of degradation.

Figure 18. Comparison of rate enhancement to Fenton reaction with UVA and UVC illumination.

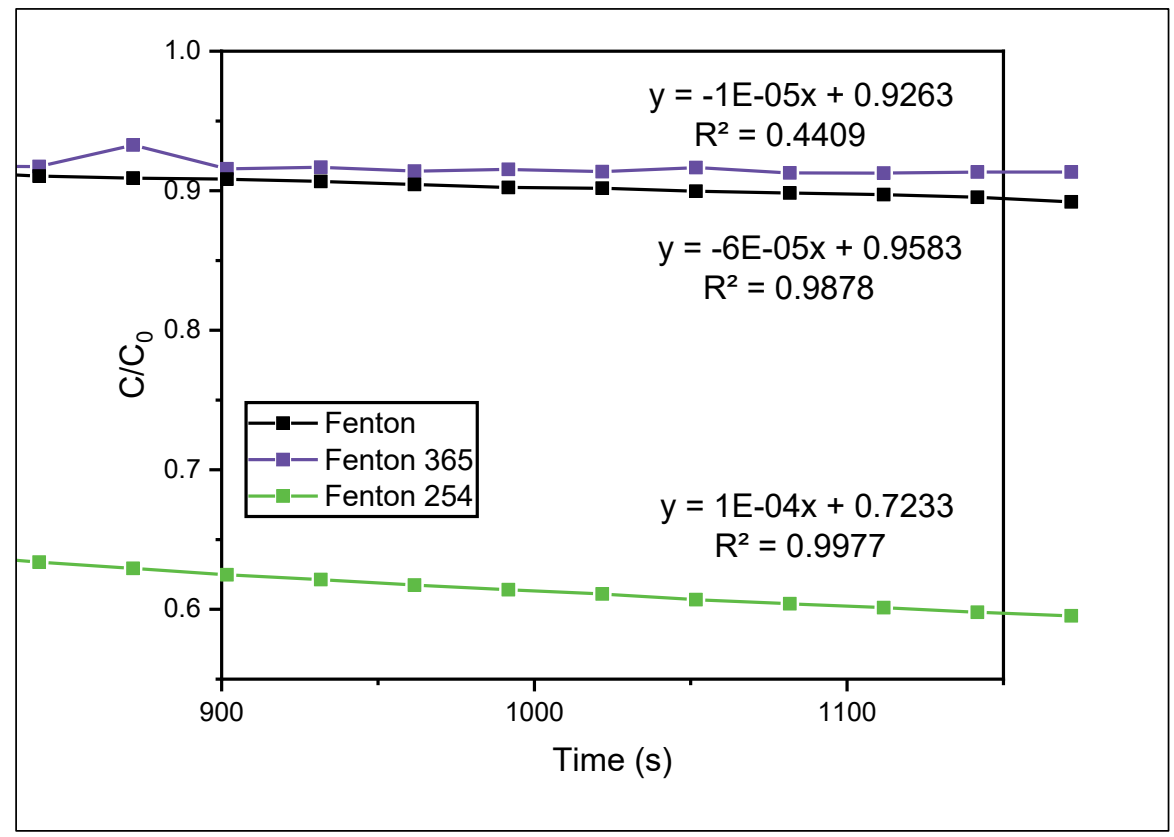

Because of the additional reactions that can take place under UVC illumination, the UVA lamps were used to make a more direct comparison of lights effects on the Fenton process. The individual contaminant degradation is shown in Figure 19a. In the short course of the experimental window, there is only a small apparent enhancement of the percent degraded (see Appendix G, Figure G1b) with the inclusion of light as a reactant. Without UVC light, MO degrades by Fenton reaction with a rate 
constant of $0.1269 \mathrm{~min}^{-1}$; when light is applied, the rate constant is 0.1110 $\min ^{-1}$; however, this apparent decrease may be a result of the significant error introduced by fitting the Fenton data to a first order model.

The results of photo-Fenton degradation of the contaminant mixture are shown in Figure 19b and Figure G1d. As in previous experiments, MO is the favored contaminant with respect to reactions with the $\mathrm{HO}^{\bullet}$. The incorporation of light into the reaction mixture resulted in a greater efficiency for MO degradation with photo-Fenton (0.1533 $\left.\mathrm{min}^{-1}\right)$ when compared to the dark Fenton reaction (0.0792 $\left.\mathrm{min}^{-1}\right)$. For both Fenton and photo-Fenton processes, reaction rates could be enhanced through experiment design, involving continued addition of peroxide, and selective illumination at specific times for maximum enhancement of $\mathrm{Fe}$ (III) to Fe(II) conversion. 
Figure 19. Degradation of (a) individual and (b) mixed contaminants with photo-Fenton, fit to pseudo-first order model.

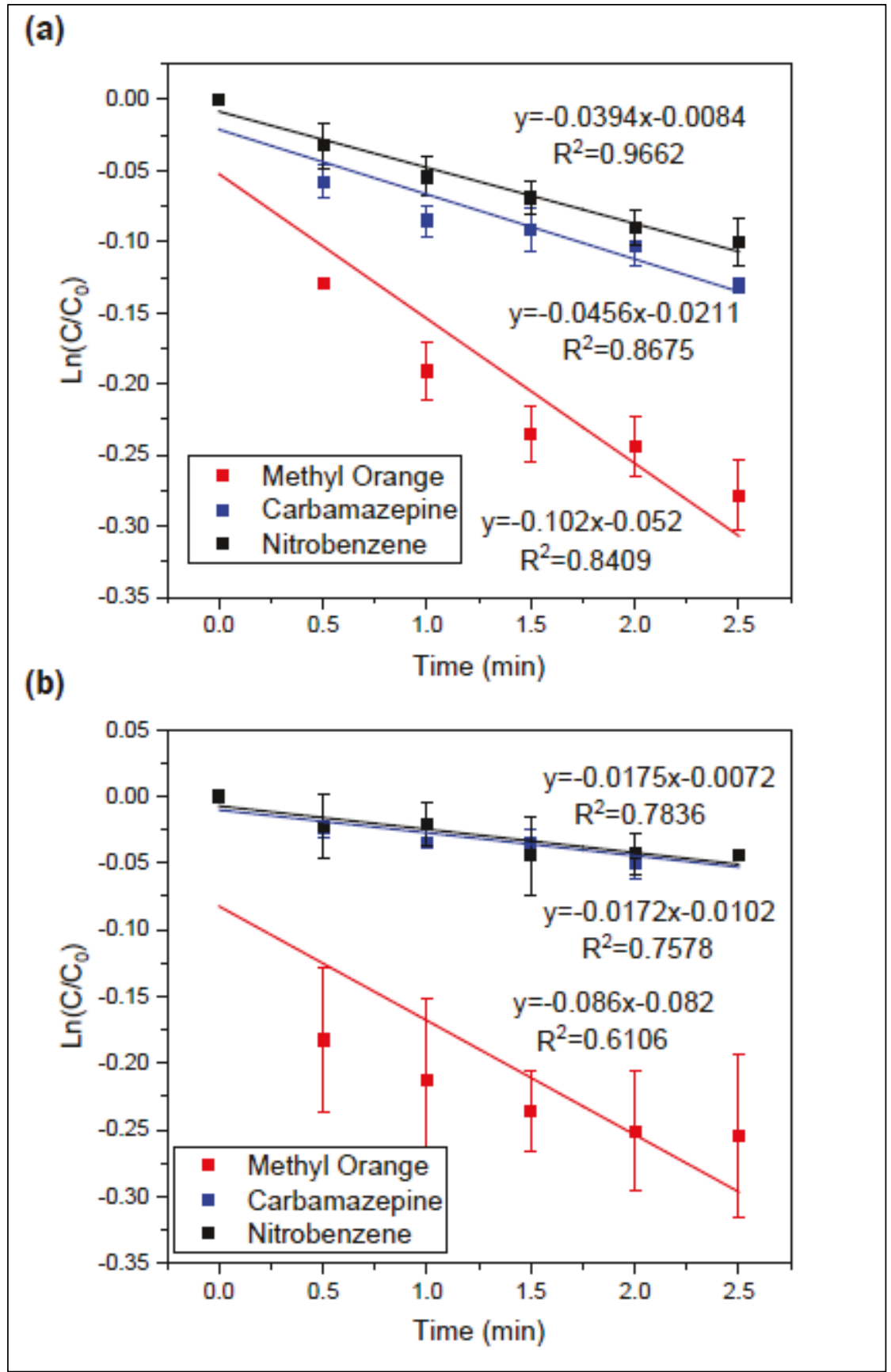




\section{Discussion}

The breadth of data described above dictates that some metrics be employed for cross-comparisons and evaluation of AOP. Described below are a few (but not the only) methods for comparison.

\subsection{Comparison of first-order rate constants}

One method for comparison of AOP is to examine the first order rate constants. Table 6 contains all of the calculated rate constants for the mixed and individual contaminants. The error values shown are the standard deviations of linear fits. Several rows of the table stand out with large rate constants for one or more contaminants. UV-hypochlorite has large rate constant values for $\mathrm{MO}$ and $\mathrm{CM}$, but the rate constants for $\mathrm{NB}$ are less impressive. The ozone rate constants are quite large, especially for $\mathrm{CM}$, but this value is something of a false positive, as the disappearance of $\mathrm{CM}$ is associated with the formation of an ozonolysis product (see Section 3.6.2 and Appendix F), which takes much longer to degrade than the parent compound. In terms of broad effectiveness across multiple contaminants, UV peroxide, and the Fenton based methods look to be quite effective, as does photocatalysis. In short, no single AOP stands out as distinctly more effective than any other with this comparison. Comparison by rate constant is also unable to account for the costs of energy and reagents required to operate the system. 
Table 6. Pseudo first-order rate constants for all AOP and contaminants.

\begin{tabular}{|c|c|c|c|c|c|c|c|}
\hline \multirow[t]{2}{*}{ AOP } & & \multicolumn{2}{|c|}{ Methyl Orange (MO) } & \multicolumn{2}{|c|}{ Carbamazepine (CM) } & \multicolumn{2}{|c|}{ Nitrobenzene (NB) } \\
\hline & & Indiv. & Mix & Indiv. & Mix & Indiv. & Mix \\
\hline \multirow{3}{*}{ 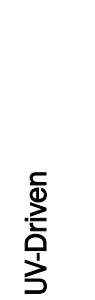 } & $\begin{array}{l}\mathrm{TiO}_{2} \\
\text { Photocatalysis }\end{array}$ & $0.020 \pm 0.001$ & $0.023 \pm 0.002$ & $0.015 \pm 0.001$ & $\begin{array}{l}0.0076 \pm 0.00 \\
2\end{array}$ & $0.027 \pm 0.001$ & $\begin{array}{l}0.0068 \pm 0.000 \\
6\end{array}$ \\
\hline & UV-OCI & $1.38 \pm 0.06$ & $1.15 \pm 0.1$ & $0.423 \pm 0.05$ & $0.126 \pm 0.006$ & $0.0252 \pm 0.003$ & $\begin{array}{l}0.0217 \pm 0.000 \\
5\end{array}$ \\
\hline & $\mathrm{UV}-\mathrm{H}_{2} \mathrm{O}_{2}$ & $0.0412 \pm 0.001$ & $0.0512 \pm 0.002$ & $0.151 \pm 0.003$ & $\begin{array}{l}0.0141 \pm 0.00 \\
2\end{array}$ & $0.0857 \pm 0.01$ & $0.0114 \pm 0.001$ \\
\hline \multirow{3}{*}{ 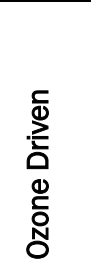 } & Ozone & $2.2 \pm 0.4$ & $1.5 \pm 0.1$ & $>8^{*}$ & $1.01 \pm 0.08$ & $0.107 \pm 0.008$ & $0.257 \pm 0.005$ \\
\hline & UV-Ozone & $0.325 \pm 0.004$ & $0.403 \pm 0.006$ & $0.309 \pm 0.008$ & $0.128 \pm 0.003$ & $0.134 \pm 0.003$ & $0.0865 \pm 0.006$ \\
\hline & Ozone-OCl & $3.0 \pm 0.6$ & $2.37 \pm 0.05$ & $>8^{*}$ & $1.0 \pm 0.1$ & $0.051 \pm 0.002$ & $-0.003 \pm 0.003$ \\
\hline \multirow{2}{*}{ 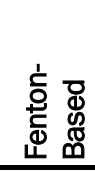 } & Fenton & $0.09 \pm 0.01$ & $0.07 \pm 0.01$ & $0.103 \pm 0.007$ & $0.034 \pm 0.007$ & $0.038 \pm 0.005$ & $0.026 \pm 0.009$ \\
\hline & Photo-Fenton & $0.10 \pm 0.02$ & $0.09 \pm 0.03$ & $0.046 \pm 0.008$ & $0.017 \pm 0.004$ & $0.039 \pm 0.003$ & $0.017 \pm 0.004$ \\
\hline \multirow[b]{2}{*}{$\begin{array}{l}\frac{0}{0} \\
\frac{0}{0} \\
\delta\end{array}$} & UVC & $\begin{array}{l}0.0028 \pm 0.000 \\
4\end{array}$ & $n / a$ & $\begin{array}{l}0.0008 \pm 0.00 \\
03\end{array}$ & $n / a$ & $0.011 \pm 0.001$ & $n / a$ \\
\hline & OCl (Dark) & $0.19 \pm 0.01$ & $n / a$ & $-0.001 \pm 0.004$ & $n / a$ & $0.006 \pm 0.001$ & $n / a$ \\
\hline
\end{tabular}

*Estimated rate constant based on total removal after 30s. See Section 3.6.2 for more details.

\subsection{Comparison of efficiency and feasibility}

Another metric for evaluating AOP is the Electrical Energy per Order, or EEO, proposed by Bolton and colleagues in the late 1990 (Bolton et al. 1996). This metric, defined as the energy required to decrease the contaminant concentration in solution by one order of magnitude, evaluates an entire AOP system, including the power required for lights and other equipment, including the reaction rate. Equations 1 and 2 show how EEO is defined and calculated for a given reaction. A lower EEO value indicates that less energy is required to achieve the same amount of degradation, and therefore, a process with a lower EEO is more efficient. Advanced oxidation water facilities have used target EEO values of $<1$ for a process to be viable (City of Oxnard California 2017).

$$
E E / O=\frac{P t 1000}{V \log \left(\frac{C_{0}}{C}\right)}
$$


Where:

$P$ is the power of the AOP system (in $\mathrm{kW}$ ),

$V$ is the volume (in L) of water treated in time $t$ (in hours),

$C$ is the concentration of contaminant at time $t$, and

$C_{o}$ is the initial concentration of the contaminant.

$$
E E / O=\frac{38.4 P}{V 60 k}
$$

Where:

$k$ is the pseudo-first order rate constant of the system, $P$ and $V$ are the same as in Equation 1, and

a factor of 60 is added to convert rate constants to $h^{-1}$ from min $^{-1}$.

EEO values were calculated for each AOP that were investigated, both for contaminants in the individual and mixed condition. EEO values separated by AOP are shown in Figure 20. Several factors are immediately noticeable. First, the lowest EEO, both for individual and mixed contaminants is for the degradation of MO with UV-hypochlorite. Yet the EEO values for the other two contaminants with this reaction are orders of magnitude larger. Thus, in an application setting, UV-hypochlorite may not be a suitable AOP for degrading a wide variety of contaminants simultaneously, despite its performance in research settings with a model compound (e.g., MO). Secondly, even though the ozone-based reactions had large rate constants, the EEO values are larger than might be expected due to the large energy requirements of the ozone generator. In an expeditionary setting with energy requirements, ozone methods for water treatment may be less feasible. From a reaction kinetics standpoint, ozone appears very efficient, but the energy requirements of producing ozone detract from its suitability for use in an energy restricted environment. The marked recalcitrance of NB under ozone-hypochlorite in the mixture is also very notable. 
Figure 20. EEO for each AOP with (a) individual and (b) mixed contaminants.

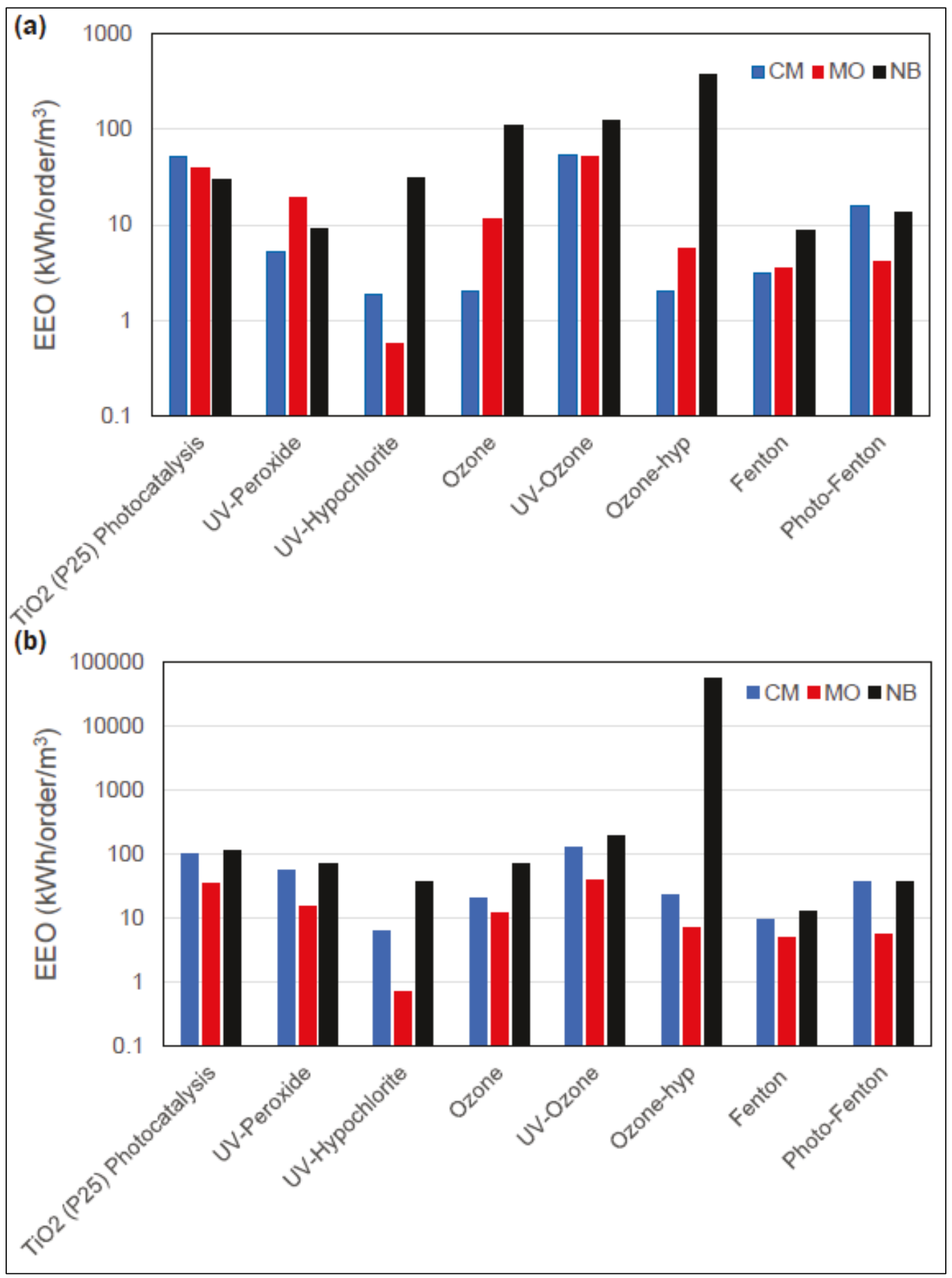

The EEO values, organized by contaminant, with values for mixed and individual contaminants, are shown in Figure 21. This presentation format serves to underscore the changes between reactions with individual contaminants and mixtures of contaminants. The favorability of MO degradation in mixtures is evident, as the EEO values do not change 
appreciably from individual to mixture. However, for NB and CM, considerable increases can be seen when these contaminants are degraded in the presence of other compounds. This highlights the need for further thorough evaluation of AOP with realistic conditions, including mixed contaminants, including other organic matter present in solution to aid in the accurate prediction of field performance of the AOP methods. 
Figure 21. EEO for the degradation of (a) MO, (b) CM and (c) NB with each AOP.

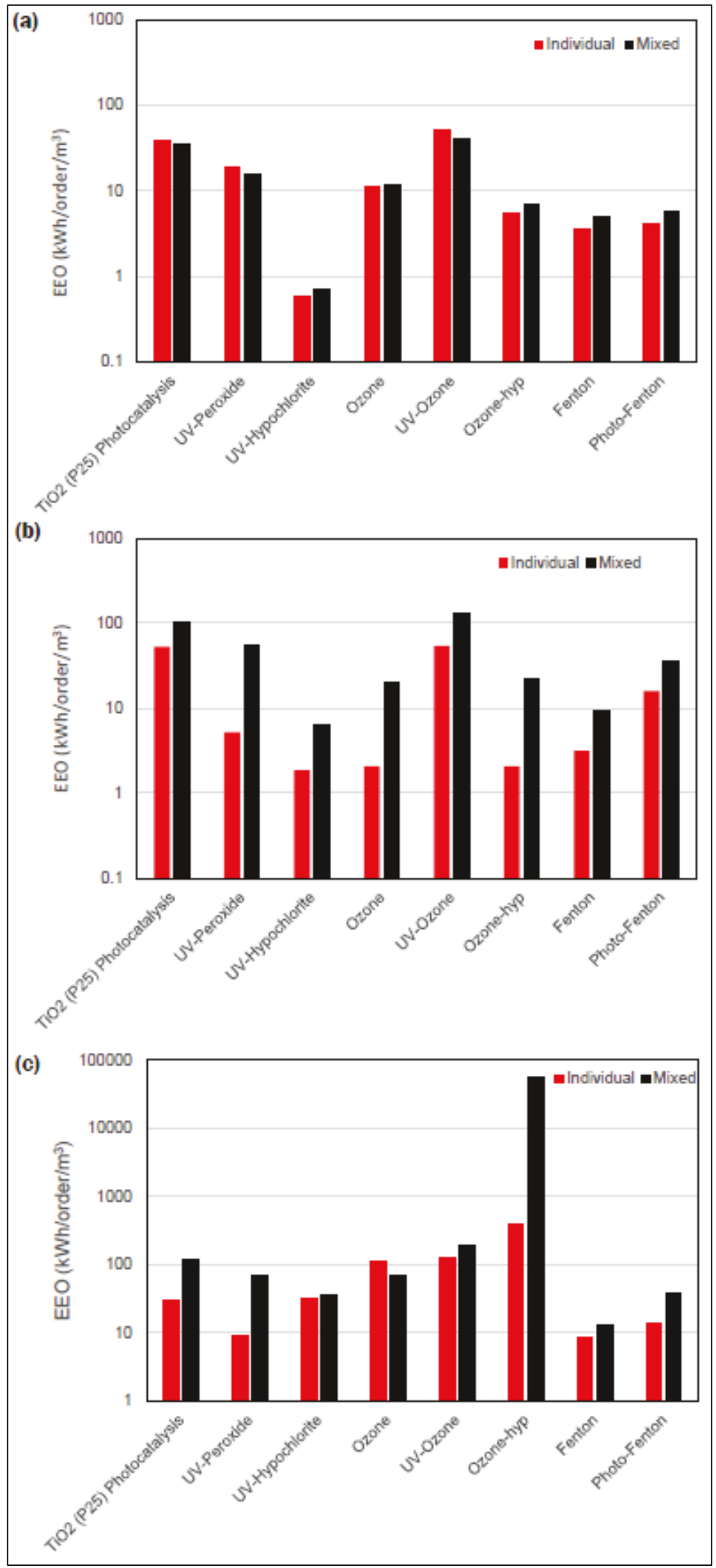


The EEO values displayed above for the Fenton-based reactions were calculated using Equation 2 and the first order rate constants. Because of the inadequacy of a first-order model for Fenton reactions, the EEO was also calculated using Equation 1 and the relative concentrations at two different time points. These values, obtained with these different calculation methods, which differ by orders of magnitude, are shown in Appendix H, Table H1. These differences highlight the complications associated with using EEO to evaluate Fenton-based technologies, which have been done in different ways, albeit infrequently (Ureña de Vivanco et al. 2013; Miklos et al. 2018).

One important caveat of EEO is that it evaluates an entire AOP system. All of the aspects of the reactor, and the reaction, are combined in a single metric. Therefore, the EEO values presented in this report are to be interpreted as evaluations of our system, and not necessarily as ratings of an entire category of systems. For example, the ozone generator used was selected for its ability to control ozone output, and not for its efficiency. Higher efficiency generators exist, and could be employed in a situation where the goal was to maximize contaminant removal or reduce operational expenses. Similarly, experimental and industrial reactors can take on a variety of geometries, and be better suited to handle real water treatment volumes in an efficient manner. The experimental photoreactors used facilitated direct comparison between laboratories, but they did not necessarily result in maximization of efficiency for each AOP.

Another important caveat is that EEO does not take into account the cost or efficiency of obtaining reagents. For example, the Fenton reaction's only power requirement is the stirring of solution. Further, the EEO is not able to account for the cost of regular dosing of peroxide that would be required to operate a Fenton-based treatment on a large scale. Correction factors that account for reagent cost have been developed, but these calculations are based on a typical industrial setting, and not the unique position of the U.S. Army expeditionary settings, where the regular shipment of supplies presents significant cost and risk of loss of life. 


\section{Conclusions and Outlook}

No single AOP in this investigation stood out as highly suitable for mobile/deployable water treatment applications. On the contrary, this investigation uncovered some of the important subtleties that must be considered when developing advanced oxidation water treatment systems. These include the effects of contaminant mixtures, the creation of recalcitrant byproducts, and the ability of combined AOP methods to be less effective than a single method (e.g., UV-ozone in comparison with ozone alone). This investigation represents an excellent initial survey into the use of AOP in Army-relevant contexts, but further work is required in this area before advanced water treatment in remote Army operations can be realized.

\subsection{Additional AOP for consideration}

Several categories of non-chemical based AOP were not considered in this investigation. Electro-oxidation (Liu et al. 2018) and sonolysis (Kim et al. 2012) are two notable and promising AOP systems that have demonstrated broad applicability for water treatment scenarios. These AOP both have the advantage of not requiring the regular supply of reagents. Both of the AOP can be combined with other methods/reagents including UV illumination (Jelic et al. 2013) or ozone (Wang and Huang 2017) to produce even more efficient and broadly effective degradation.

\subsection{Considerations for AOP use in real applications}

Further consideration of real water treatment conditions is also necessary. In this work, all experiments were conducted with high-purity laboratory water. This is most certainly very different from real wastewater, gray water, or even potable tap water, where a number of ions, minerals, and organic compounds can be present. The mechanisms of the AOP examined in this study will all be affected by such conditions, and studies of real wastewater are required before any AOP system can be implemented. In addition, several important categories of Army relevant contaminants were not considered in this study, including munitions compounds and hydrocarbon fuel residues. These compounds may present unique degradation mechanisms (including unique safety risks) and their removal is essential in an Army expeditionary setting. 


\section{References}

Anderson, H. G., S. W. Maloney, K Kinnevan, E. D. Smith, K. J. Hay and G. L. Gerdes. 2013. Baseline Water Demand at Forward Operating Bases. TR-13-16

Vicksburg, MS: Engineer Research and Development Center-Construction Engineering Research Laboratory (ERDC-CERL). https://apps.dtic.mil/dtic/tr/fulltext/u2/a613424.pdf.

Bader, H., and J. Hoigné. 1981. Determination of ozone in water by the indigo method. Water Research 15(4):449-456. https://doi.org/10.1016/0043-1354(81)90054-3.

Benotti, M. J., R. A. Trenholm, B. J. Vanderford, J. C. Holady, B. D. Stanford, and S. A. Snyder. 2009. Pharmaceuticals and endocrine disrupting compounds in U.S. drinking water. Environmental Science and Technology 43(3):597-603. doi: 10.1021/es801845a.

Bolton, J. R., K. G. Bircher, W. Tumas, W. Tumas, and C. A. Tolman. 1996. Figures-ofmerit for the technical development and application of advanced oxidation processes. Journal of Advanced Oxidation Technologies 1(1):13-17. https://doi.org/10.1515/jaots-1996-0104.

Bolton, J. R., K. G. Bircher, W. Tumas, and C. A. Tolman. 2001. Figures-of-merit for the technical development and application of advanced oxidation technologies for both electric and solar-driven systems. Pure and Applied Chemistry 73(4):627637. https://doi.org/10.1351/pac200173040627.

Brame, J., M. Long, Q. Li, and P. Alvarez. 2015. Inhibitory effect of natural organic matter or other background constituents on photocatalytic advanced oxidation processes: Mechanistic model development and validation. Water Research 84:362-371.https://doi.org/10.1016/i.watres.2015.07.044.

Carlos, L., D. Fabbri, A. L. Capparelli, A. B. Prevot, E. Pramauro, and F. S. G. Einschlag. 2008. Intermediate distributions and primary yields of phenolic products in nitrobenzene degradation by Fenton's reagent. Chemosphere 72(6):952-958. https://doi.org/10.1016/i.chemosphere.2008.03.042.

Chen, R., and J. J. Pignatello. 1997. Role of quinone intermediates as electron suttles in Fenton and photoassisted Fenton oxidations of aromatic compounds. Environmental Science and Technology 31(8): 2399-2406.

Chen, T., Y. Zheng, J. M. Lin and G. Chen. 2008. Study on the photocatalytic degradation of methyl orange in water using $\mathrm{Ag} / \mathrm{ZnO}$ as catalyst by liquid chromatography electrospray ionization ion-trap mass spectrometry. Journal of the American Society for Mass Spectrometry 19(7):997-1003. https://doi.org/10.1016/i.jasms.2008.03.008.

City of Oxnard California. 2017. Advanced Water Purification Facility: Indirect Potable Reuse Engineering Report. Walnut Creek, CA: Carollo Volume 1.

City of Oxnard California. 2018. Recycled Water. (Accessed on 26 November 2018) https://www.oxnard.org/city-department/public-works/water/recycled-water/. 
DeMatteo, M. P., J. S. Poole, X. Shi, R. Sachdeva, Pl G. Hatcher, C. M. Hadad, and M. S. Platz. 2005. On the electrophilicity of hydroxyl radical: A laser flash photolysis and computational study. Journal of the American Chemical Society 127(19):7094-7109.

Deng, J., Y. Shao, N. Gao, S. Xia, C. Tan, S. Zhou and X. Hu. 2013. Degradation of the antiepileptic drug carbamazepine upon different UV-based advanced oxidation processes in water. Chemical Engineering Journal 222:150-158. https://doi.org/10.1016/j.cej.2013.02.045.

Eady, D. S., S. B. Siegel, R. S. Bell and S. H. Dicke. 2009. Sustain the Mission Project: Casualty Factors for Fuel and Water Resupply Convoys. Arlington, VA: Army Environmental Policy Institute (AEPI).

Fenton, H. J. H. 1984. Oxidation of tartaric acid in presence of iron. Journal of the Chemical Society 65:899-910.

Furlong, E. T., A. L. Batt, S. T. Glassmeyer, M. C. Noriega, D. W. Kolpin, H. Mash, and K. M. Schenck. 2017. Nationwide reconnaissance of contaminants of emerging concern in source and treated drinking waters of the United States: Pharmaceuticals. Science of the Total Environment 579:1629-1642. https://doi.org/10.1016/i.scitotenv.2016.03.128.

Haber, F. W. J. 1934. The catalytic decomposition of hydrogen peroxide by iron salts. In Proceedings of the Royal Society A 134:332-351. doi: 10.1098/rspa.1934.0221.

Jelic, A., I. Michael, A. Achilleos, E. Hapeshi, D. Lambropoulou, S. Perez, M. Petrovic, D. Fatta-Kassinos, and D. Barcelo. 2013. Transformation products and reaction pathways of carbamazepine during photocatalytic and sonophotocatalytic treatment. Journal of Hazardous Materials 263 Pt 1:177-186. https://doi.org/10.1016/i.jhazmat.2013.07.068.

Jimenez, S., M. M. Mico, M. Arnaldos, F. Medina, and S. Contreras. 2018. State of the art of produced water treatment. Chemosphere 192:186-208. https://doi.org/10.1016/i.chemosphere.2017.10.139.

Kim, D. K., K. E. O'Shea, and W. J. Cooper. 2012. Oxidative degradation of alternative gasoline oxygenates in aqueous solution by ultrasonic irradiation: Mechanistic study. Science of the Total Environment 430:246-259. https://doi.org/10.1016/i.scitotenv.2011.09.016.

Lei, L. H., X. HU, P. L. Yue, S. H. Bossmann, S. Göb, and A. M. Braun. 1998. Oxidative degradation of polyvinyl alcohol by the photochemically enhanced Fenton reaction. Journal of Photochemistry and Photobiology A: Chemistry 116(2):159166. https://doi.org/10.1016/S1010-6030(98)00293-7.

Li, Q-R., C-Z. Gu, Y. Di, H. Yin, and J-Y. Zhang. 2006. Photodegradation of nitrobenzene using 172nm excimer UV lamp. Journal of Hazardous Materials 133(1-3):6874. https://doi.org/10.1016/i.jhazmat.2005.09.061.

Liang, X., X. Zhu, and E. C. Butler. 2011. Comparison of four advanced oxidation processes for the removal of naphthenic acids from model oil sands process water. Journal of Hazardous Materials 190(1-3):168-176. 
Liu, T., J. Luo, X. Meng, L. Yang, B. Liang, M. Liu, C. Liu, A. Wang, X. Liu, Y. Pei, J. Yuan, and J. Crittenden. 2018. Electrocatalytic dechlorination of halogenated antibiotics via synergistic effect of chlorine-cobalt bond and atomic H. Journal of Hazardous Materials 358:294-301. https://doi.org/10.1016/i.jhazmat.2018.06.064.

Los Angeles Sanitation, City of Los Angeles. 2018. Terminal Island Water Reclamation Plant. (Accessed on 26 November 2018).

https://www.lacitysan.org/san/faces/home/portal/s-lsh-wwd/s-lsh-wwd-cw/s-lsh-wwd-cw-p/sIsh-wwd-cw-p-tiwrp;jsessionid=XiuwEPdnMwuKgTFpzegoRCcWxoUPt30ltxBOVbvbr9PEITbuboko!1446707989 !-

821932583?_afrLoop $=6623166093532866 \&$ afrWindowMode $=0$ \&_afrWindowld=null\&_adf.ct rl-state=199460dn0_1\#!\%40\%40\%3F_afrWindowld\%3Dnull\%26_afrLoop\%3D6623166093532 866\%26_afrWindowMode\%3D0\%26_adf.ctrl-state\%3DI99460dn0_5.

Malchi, T., Y. Maor, G. Tadmor, M. Shenker, and B. Chefetz. 2014. Irrigation of root vegetables with treated wastewater: Evaluating uptake of pharmaceuticals and the associated human health risks. Environmental Science and Technology 48(16):9325-9333.

McDowell, D. C., M. M. Huber, M. Wagner, U. von Gunton, and T. A. Ternes. 2005. Ozonation of carbamazepine in drinking water: Identification and kinetic study of major oxidation products. Environmental Science and Technology 39(20):80148022. doi: 10.1021/es050043l.

Miklos, D. B., C. Remy, M. Jekel, K. G. Linden, J. E. Drewes and U. Hubner 2018. Evaluation of advanced oxidation processes for water and wastewater treatment A critical review. Water Research 139: 118-131.

Mills, A., C. E. Holland, R. H. Davies, and D. Worsley. 1994. Photomineralization of salicylic acid: A kinetic study. Journal of Photochemistry and Photobiology A: Chemistry 83(3): 257-263. https://doi.org/10.1016/1010-6030(94)03825-2.

Nosaka, Y. N., and Y. Atsuko. 2013. Identification and roles of the active species generated on various photocatalysts. Photocatalysis and Water Purification: From Fundamentals to Recent Applications. P. Pichat editor. Weinheim, Germany: Wiley VCH. 3-24.

Pignatello, J. J., E. Oliveros, and A. MacKay. 2006. Advanced oxidation processes for organic contaminant destruction based on the Fenton Reaction and related chemistry. Critical Reviews in Environmental Science and Technology 36(1):184. https://doi.org/10.1080/10643380500326564.

Rao, B., W. Wang, Q. Cai, T. Anderson, and B. Gu. 2013. Photochemical transformation of the insensitive munitions compound 2,4-dinitroanisole. Science of The Total Environment 443:692-699. https://doi.org/10.1016/j.scitotenv.2012.11.033.

Richardson, S. D., and T. A. Ternes. 2011. Water analysis: Emerging contaminants and current issues. Analytical Chemistry 83(12):4614-4648.

Ruppert, G., R. Bauer, and G. Heisler. 1993. The photo-Fenton reaction-an effective photochemical wastewater treatment process. Journal of Photochemistry and Photobiology: A Chemistry 73(1):75-78. https://doi.org/10.1016/10106030(93)80035-8. 
Shu, Z., J. R. Bolton, M. Belosevic, and M. G. El Din. 2013. Photodegradation of emerging micropollutants using the medium-pressure UV/H2O2 Advanced Oxidation Process. Water Research 47(8):2881-2889. https://doi.org/10.1016/i.watres.2013.02.045.

Strategic Environmental Research and Development Program (SERDP). 2010. Sustainable Forward Operating Bases. Falls Church, VA: Noblis. https://apps.dtic.mil/dtic/tr/fulltext/u2/a571503.pdf.

Sylva, R. N. 1972. The hydrolysis of iron (III). Reviews of Pure Applied Chemistry 22: $115^{-130 .}$

Ureña de Vivanco, M., M. Rajab, C. Heim, T. Letzel, and B. Helmreich. 2013. Setup and energetic considerations for three advanced oxidation reactors treating organic compounds. Chemical Engineering and Technology 36(2):355-361. https://doi.org/10.1002/ceat.201200478.

U. S. Environmental Protection Agency (USEPA). 2012. Guidelines for Water Reuse. AR1530. Washington, DC: Office of Wastewater Management, Office of water. https://www3.epa.gov/region1/npdes/merrimackstation/pdfs/ar/AR-1530.pdf.

U. S. Environmental Protection Agency (USEPA). 2017. Contaminant Candidate List (CCL) and Regulatory Determination: Chemical Contaminants-CCL 4. (Accessed on 26 November 2018). https://www.epa.gov/ccl/chemical-contaminants-ccl-4.

Wang, C., and B.-M. Huang. 2017. Degradation of tetracycline by advanced oxidation processes: Sono-Fenton and ozonation processes. Desalination and Water Treatment 96:161-168.

Wells, C. F., and M. A. Salam. 1968. The effect of pH on the kinetics of the reaction of iron(II) with hydrogen peroxide in perchlorate media. Journal of Chemical Society A 0: 24-29.

Zhang, J., P. Zhou, J. Liu, and J. Yu. 2014. New understanding of the difference of photocatalytic activity among anatase, rutile and brookite $\mathrm{TiO}_{2}$. Physical Chemistry Chemical Physics 16(38): 20382-20386. 


\section{Appendix A: Additional Light Characterization Data}

Light characterization was conducted with both optical equipment and chemical actinometry, to ensure that output of the bulbs used matched the experimental processes being studied, and that experiments conducted in the experimental reactors at different labs could be compared. The two bulb types selected for experiments, UVA and UVC bulbs, were both characterized at CRREL.

A qualitative measure of the spectral distribution of the bulbs was obtained using a compact spectrometer, which gives values with arbitrary intensity at individual wavelengths of light. The spectral distribution of the bulbs in the UV region is shown in Figure A1a. The UVA bulbs emit a single, relatively broad peak centered on $365 \mathrm{~nm}$. The UVC bulbs emit two sharp peaks, one located at $254 \mathrm{~nm}$, and one located at $360 \mathrm{~nm}$.

Quantitative measurements of the bulbs' radiance was measured with a calibrated point radiometer equipped with sensors for three separate wavelengths, 254, 310, and $365 \mathrm{~nm}$. The measured irradiance for each bulb type is show in Figure A1b. The UVA bulbs emit $0.9 \mathrm{~W} / \mathrm{m}^{2}$ at $365 \mathrm{~nm}$, and very little light intensity at the other wavelengths, which matches the spectral distribution measured by the compact spectrometer. The UVC bulbs emit $0.2 \mathrm{~W} / \mathrm{m}^{2}$ at $254 \mathrm{~nm}$, and little light intensity at the other wavelengths. This data appears to conflict with spectral distribution data, but the uncalibrated nature of this instrument and the scale of the peak at $360 \mathrm{~nm}$ may actually be much smaller in scale than the $254 \mathrm{~nm}$ peak. 
Figure A1. Light characterization of UVA and UVC bulbs in experimental photoreactor with (a) compact spectrometer and (b) calibrated point radiometer.

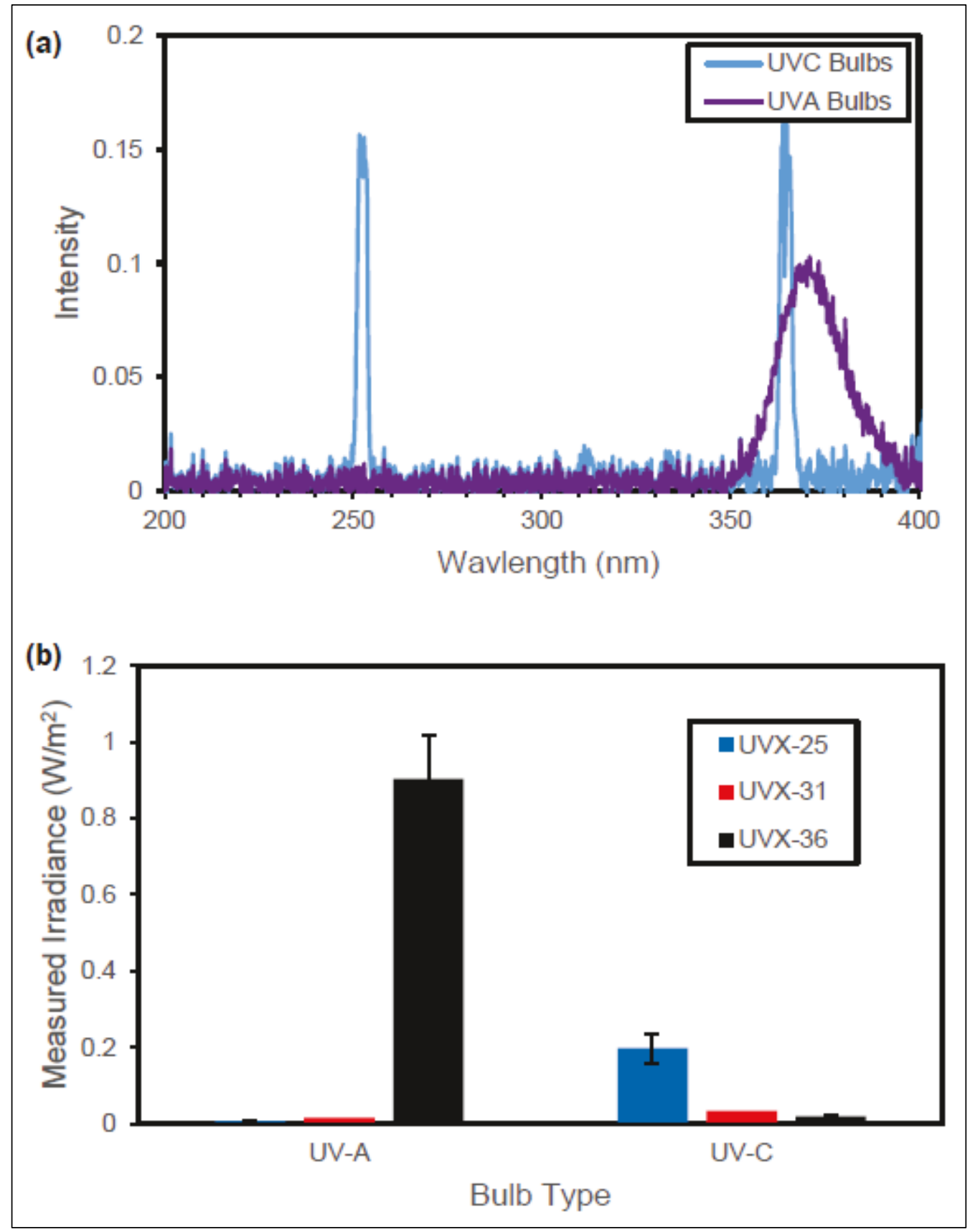

Ferrioxalate actinometry was conducted under both bulb types at each lab in order to ensure that light output in both reactors was comparable. For experimental details, see Section 2.3. The experimental data collection, solution absorbances over the course of the illumination experiments, allowed for the calculation of the moles of Fe(II) generated at each time point (Equation A1). The data for CRREL and EL photoreactors is shown in Figure A2. 
Figure A2. Fe(II) generation with ferrioxalate actinometry conducted under UVA and UVC illumination in experimental photoreactor at (a) CRREL and (b) EL.

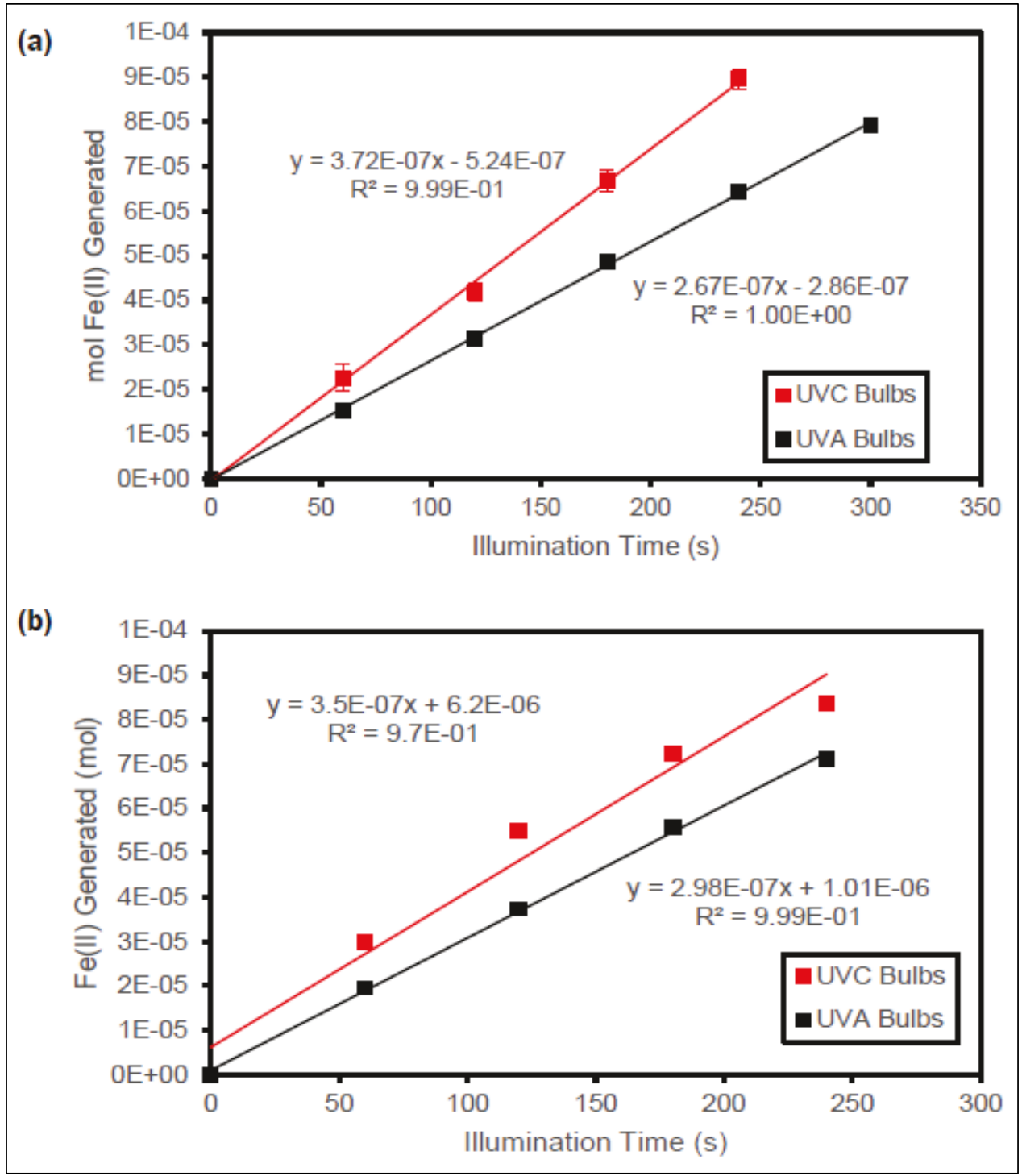

Equation A1 calculates the moles of Fe(II) generated by the ferrioxalate actinometer from the measured absorbance of the Fe(II)-Ferrozine ${ }^{\mathrm{TM}}$ complex at each sampling time point

$$
F e(I I)=\frac{A_{563}}{\varepsilon_{563} l} \times \frac{V_{5}}{V_{4}} \times \frac{V_{3}}{V_{2}} \times V_{1}
$$

Where:

$\mathrm{Fe}(\mathrm{II})$ is the moles of $\mathrm{Fe}(\mathrm{II})$ generated, $A_{563}$ is the solution absorbance at $563 \mathrm{~nm}$, $\mathcal{E}_{563}$ is the molar absorptivity of the $\mathrm{Fe}(\mathrm{II})-$ Ferrozine $^{\mathrm{TM}}$ complex, $l$ is the spectrometer path length (in $\mathrm{cm}$ ), $V_{1}$ is the volume of the irradiated reaction solution (in $\mathrm{L}$ ), 
$V_{2}$ is the volume sampled from irradiation solution (in $\mathrm{mL}$ ), $V_{3}$ is the volume of the sample after dilution (in $\mathrm{mL}$ ), $V_{4}$ is the volume of diluted solution added to cuvette (in $\mathrm{mL}$ ), and $V_{5}$ is the final volume in cuvette after addition of Ferrozine ${ }^{\mathrm{TM}}$ (in $\mathrm{mL}$ ).

For CRREL experiments, $\varepsilon_{56}=24372 \mathrm{~mol}^{-1} \mathrm{~cm}^{-1}, l=1 \mathrm{~cm}, \mathrm{~V}_{1}=0.040 \mathrm{~L}$, $\mathrm{V}_{2}=0.1 \mathrm{~mL}, \mathrm{~V}_{3}=10 \mathrm{~mL}, \mathrm{~V}_{4}=1 \mathrm{~mL}$, and $\mathrm{V}_{5}=1.065 \mathrm{~mL}$.

For EL experiments, $\varepsilon_{563}=26136 \mathrm{~mol}^{-1} \mathrm{~cm}^{-1}, l=1 \mathrm{~cm}, \mathrm{~V}_{1}=0.050 \mathrm{~L}, \mathrm{~V}_{2}=0.05$ $\mathrm{mL}, \mathrm{V}_{3}=2 \mathrm{~mL}, \mathrm{~V}_{4}=1 \mathrm{~mL}$, and $\mathrm{V}_{5}=1.065 \mathrm{~mL}$.

Equation A2 converts moles of Fe(II) generated to photon flux for each time point

$$
E_{F e O x}=\frac{F e(I I) \text { generated }}{\mathbf{S A} * \Phi * t}
$$

Where:

$E_{F e O x}$ is the photon flux (in einsteins/s), $\mathrm{Fe}(\mathrm{II})$ generated is the moles $\mathrm{Fe}(\mathrm{II})$ calculated with Equation A1, $S A$ is the surface area of the reaction flask, $\Phi$ is the quantum yield, and $t$ is the sample time point.

For experiments with UVC bulbs, $\Phi=1.40$. For experiments with UVA bulbs, $\Phi=1.22$. For EL experiments, the flux values for five samples were averaged. For CRREL experiments, the flux values for five samples from each of three replicates were averaged. 


\section{Appendix B: Chemical Analysis Data on Contaminants and Degradation Products}

Figure B1. (a) HPLC chromatogram and (b) ESI-MS total ion chromatogram (TOC) for the contaminant mixture.

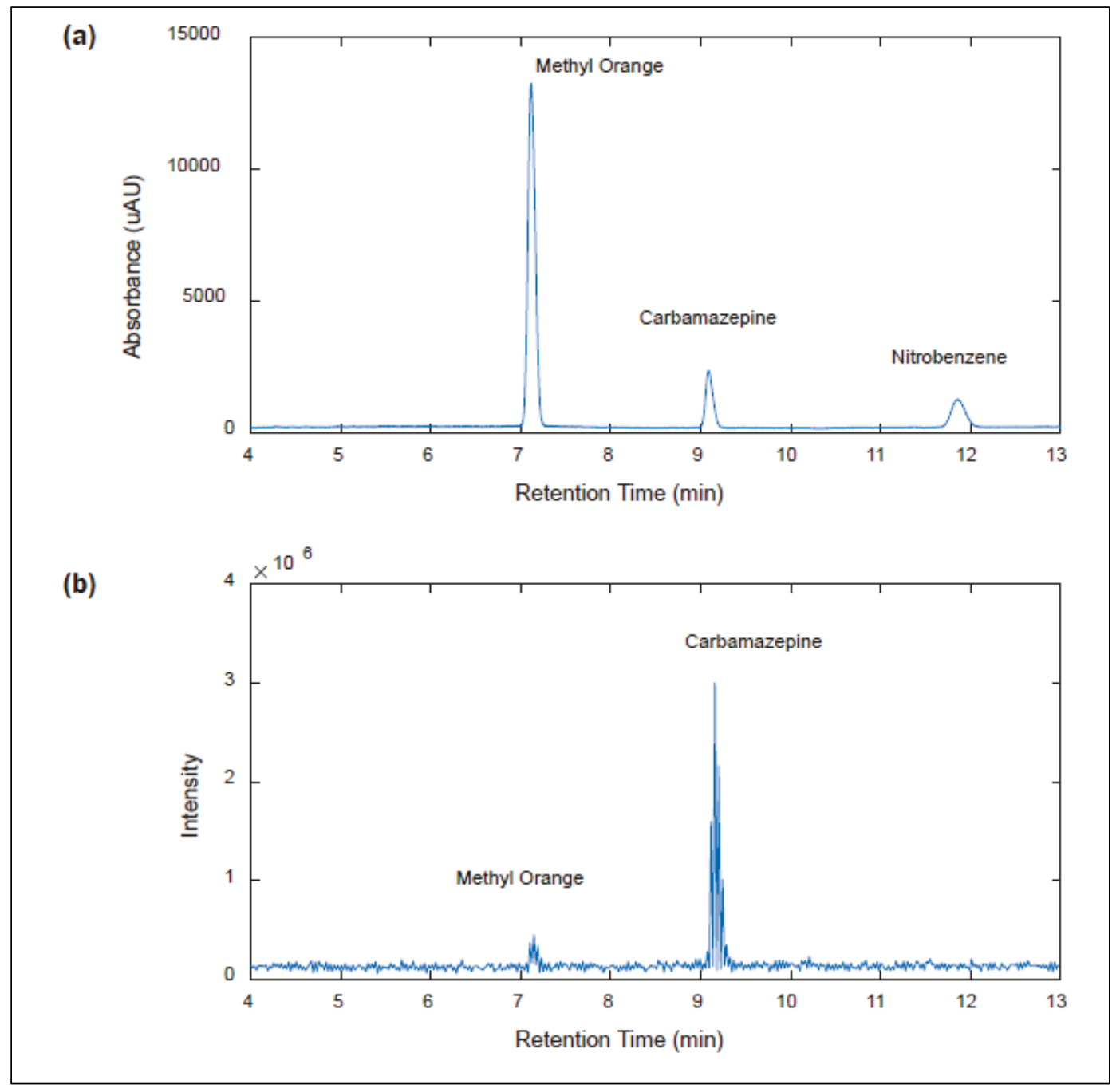


Figure B2. Electro-spray ionization mass spectra of MO in (a) negative and (b) positive ion mode, and (c) CM in positive ion mode.

(a)

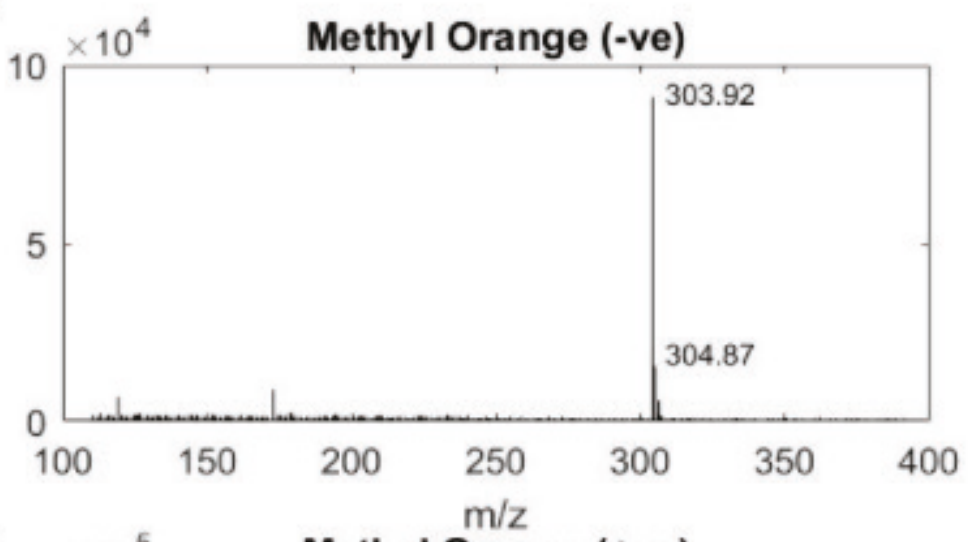

(b)

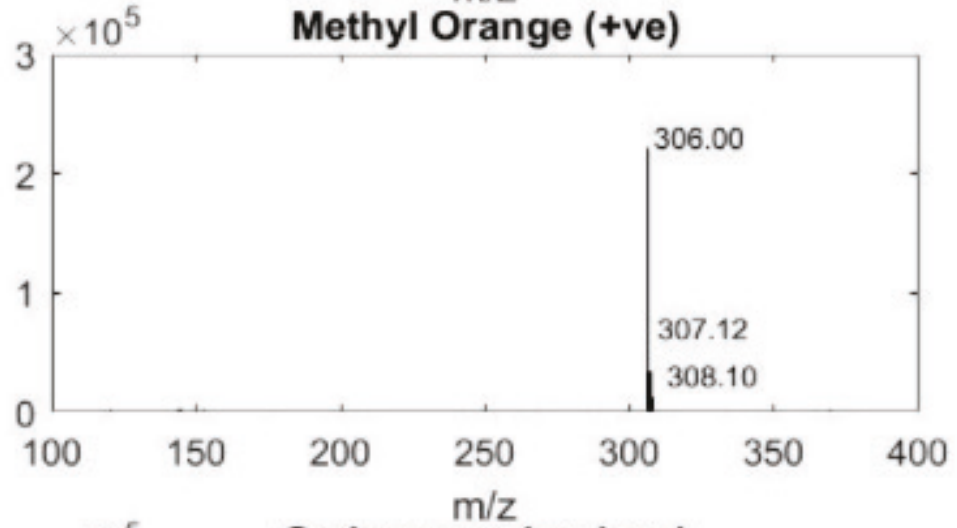

(c)

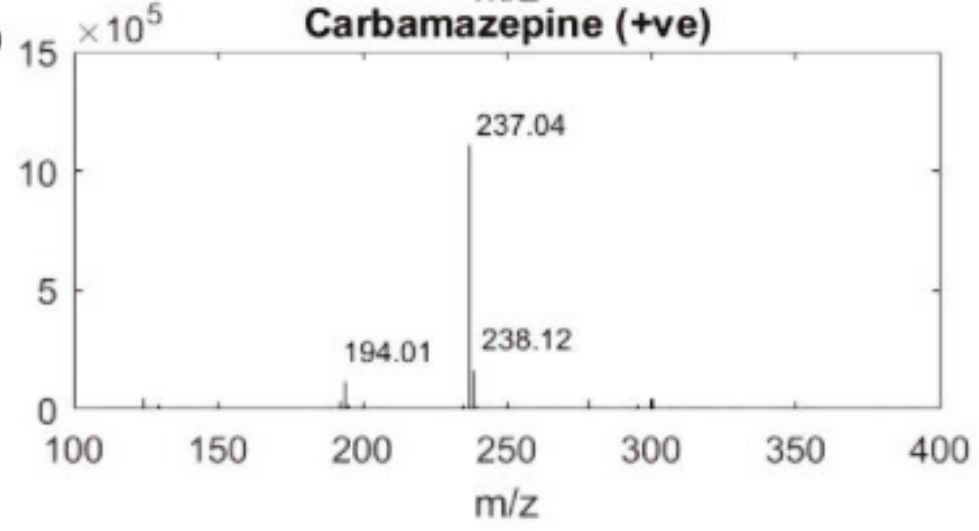


Figure B3. Mass spectra of MO degradation products eluting at (a) $3.7 \mathrm{~min}$, (b) 4.1 $\mathrm{min}$, (c) $6.9 \mathrm{~min}$, and (d) CM degradation product eluting at $6.9 \mathrm{~min}$.
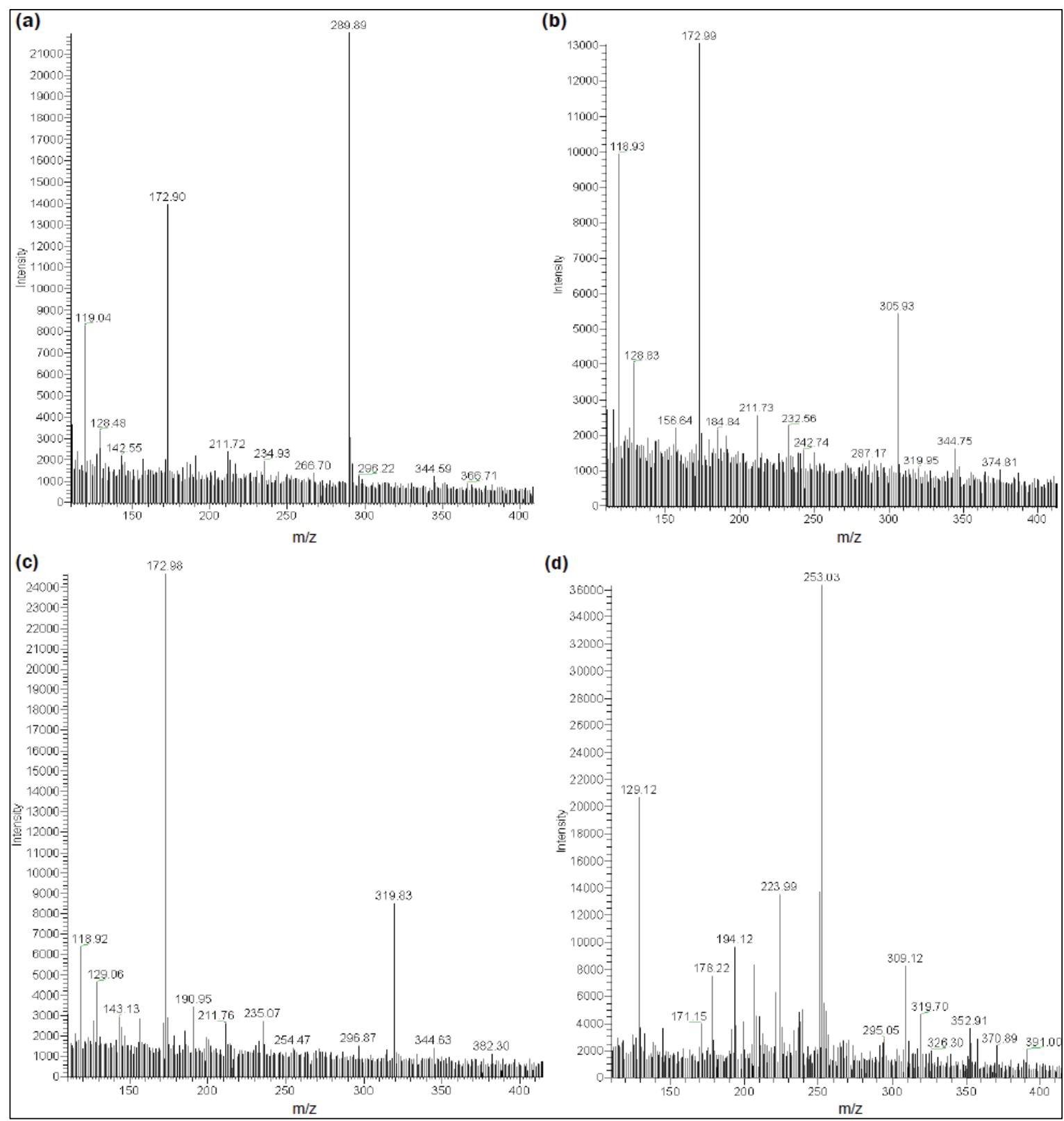


\section{Appendix C: Additional UV-Peroxide Experimental Data}

Figure C1. Pseudo-first order degradation kinetics of (a) MO, (b) CM, and (c) NB with varying concentrations of $\mathrm{H}_{2} \mathrm{O}_{2}$ and UVC illumination.

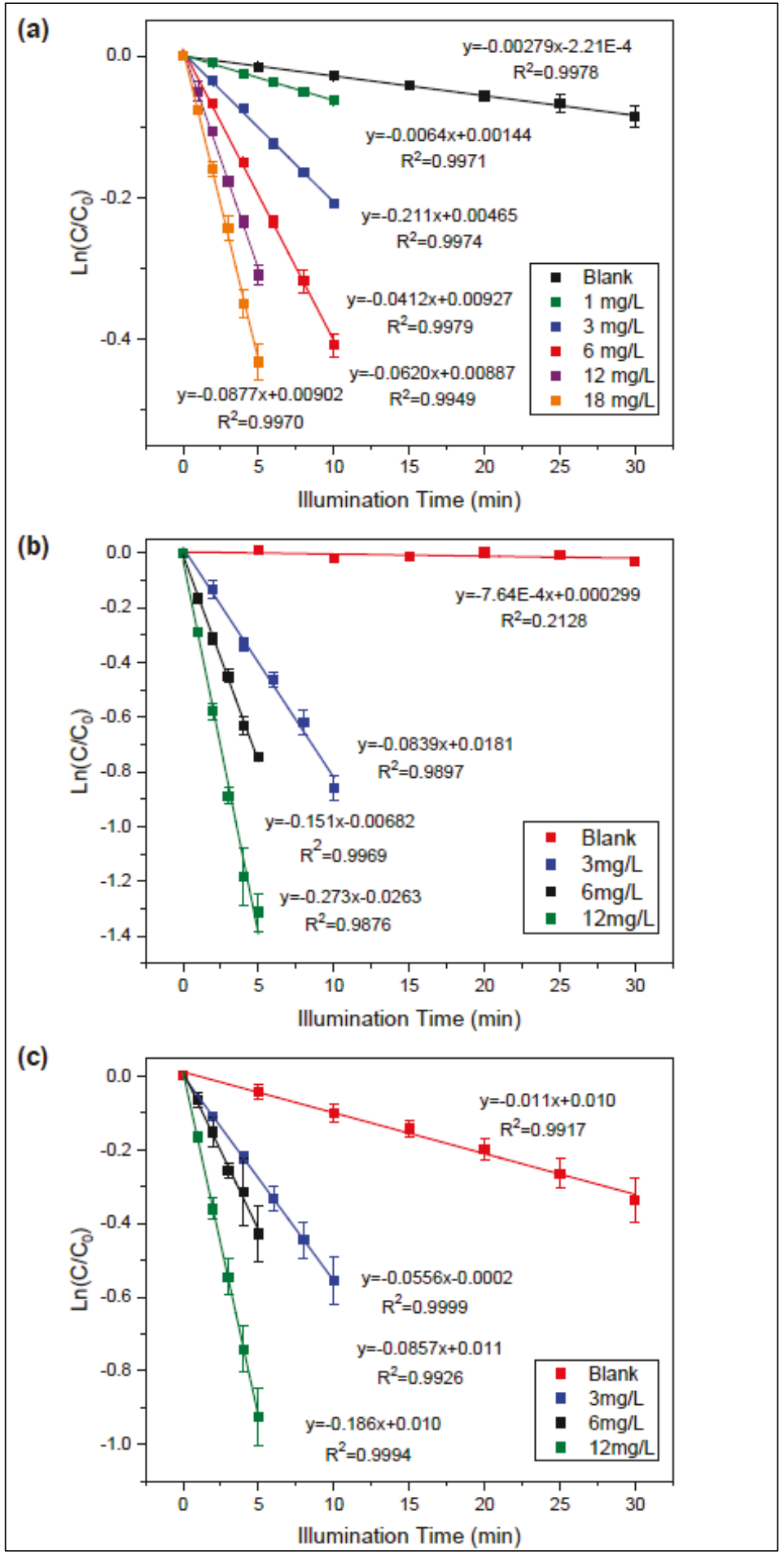


Figure C2. Pseudo-first order degradation kinetics of contaminants illuminated with UVC light.

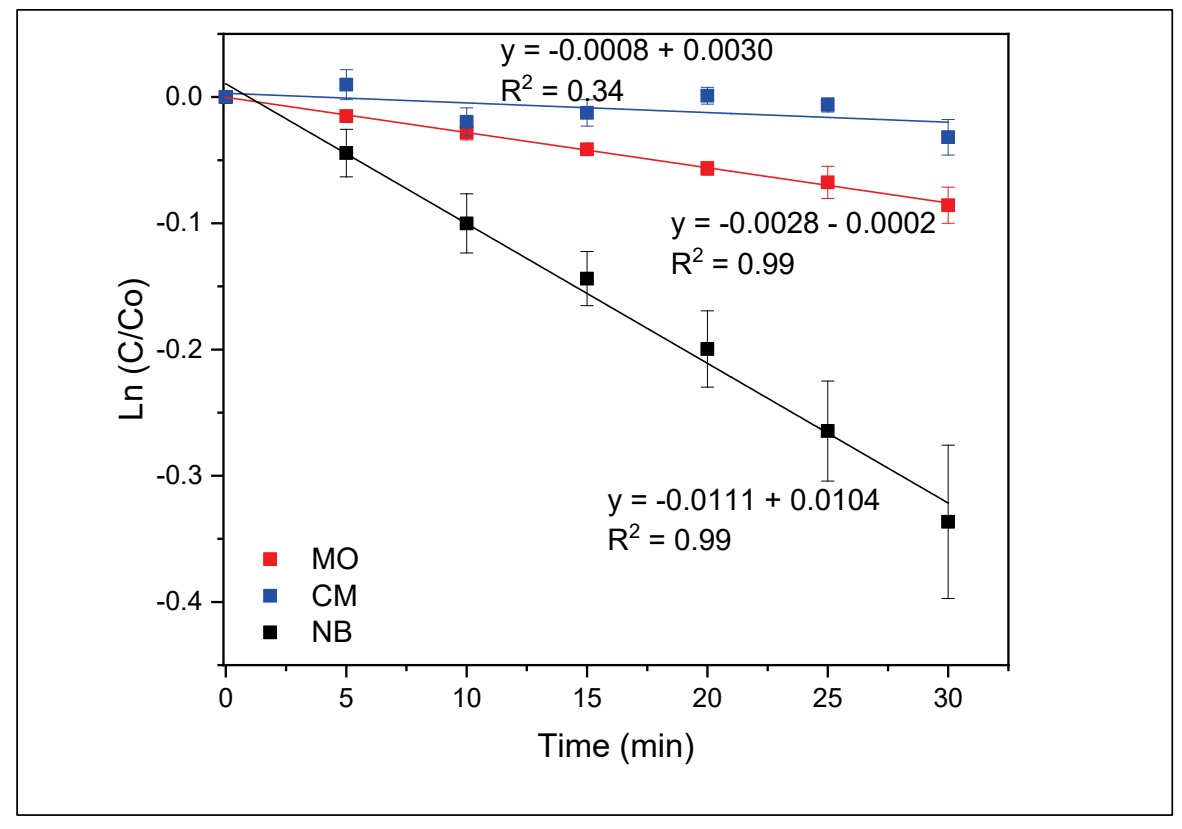

Figure $\mathrm{C3}$. Concentration profile of $\mathrm{MO}$ under three control conditions, peroxide (no Illumination), UVA, and UVC illumination.

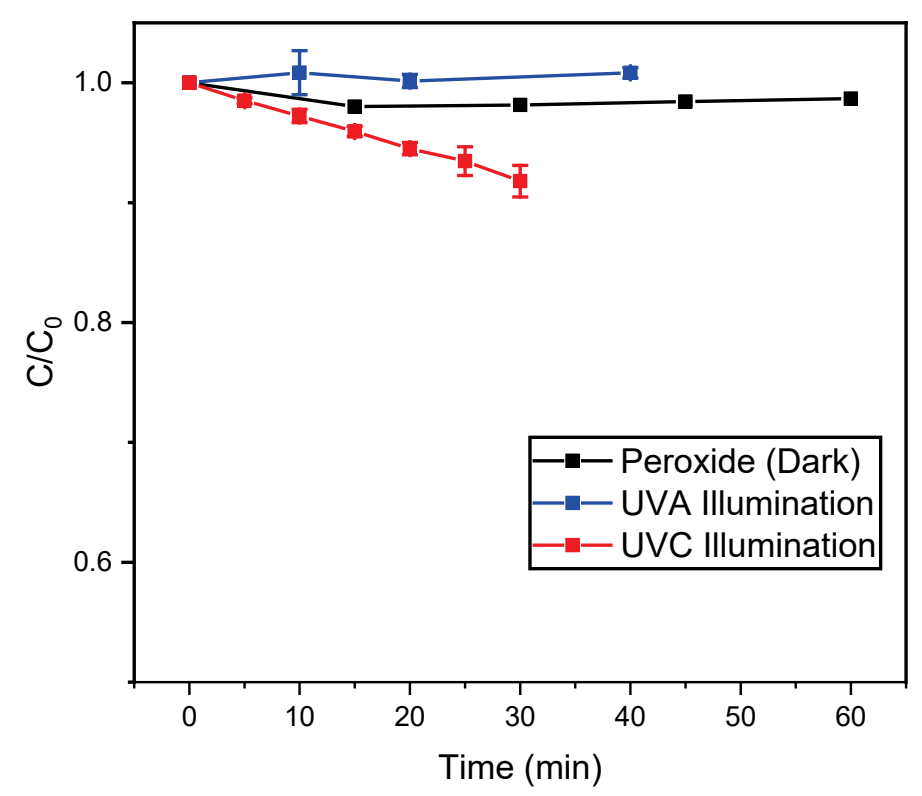


Figure C4. HPLC chromatogram of mixed contaminants degraded with $6 \mathrm{mg} / \mathrm{L} \mathrm{H}_{2} \mathrm{O}_{2}$ and UVC illumination.

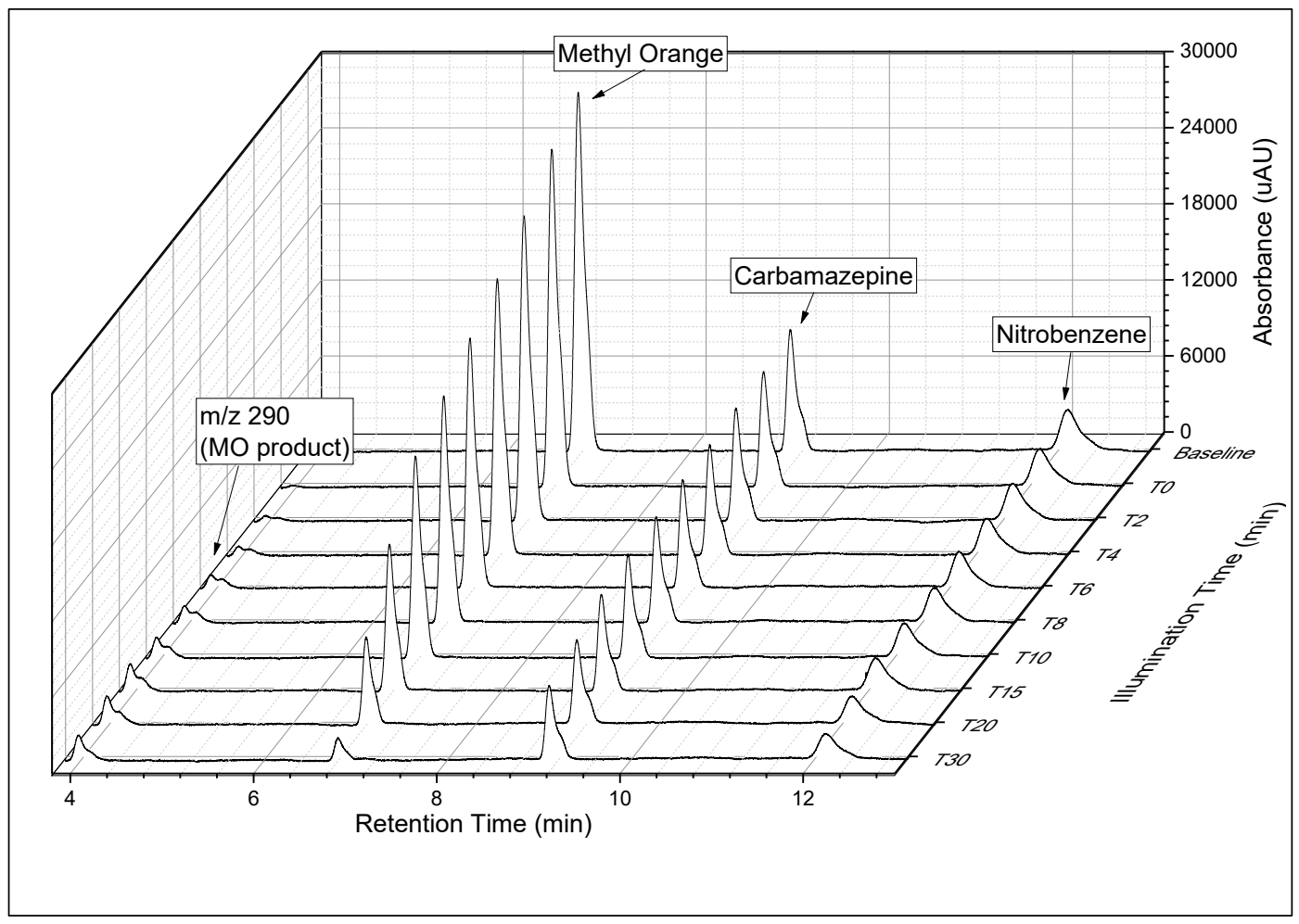

Figure C5. Concentration profile for mixed contaminants degraded with UV-peroxide. $\mathrm{MO}$ is favored, and after MO destruction, $\mathrm{CM}$ and NB rates do not increase.

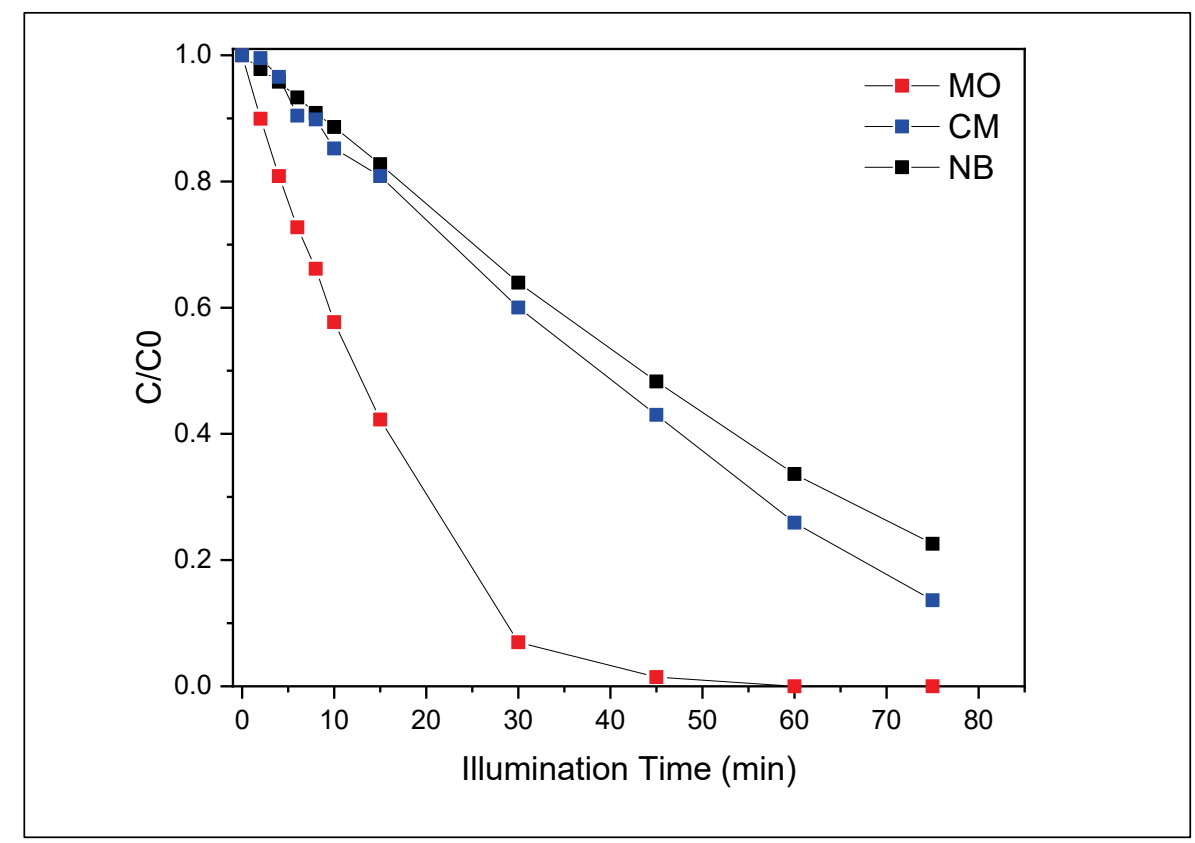




\section{Appendix D: Additional UV-Hypochlorite Experimental Data}

Figure D1. Pseudo-first order kinetics of $\mathrm{MO}$ and $\mathrm{NaOCl}$ at various concentrations.

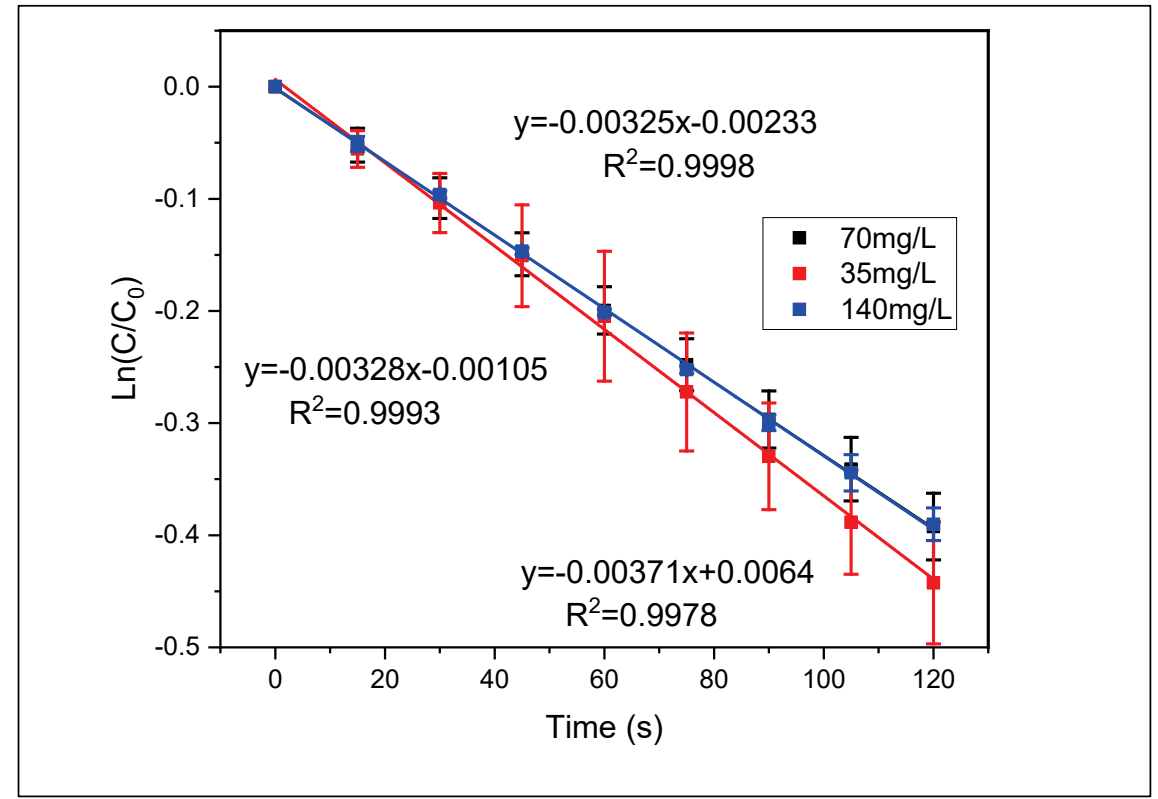

Figure D2. Pseudo-first order kinetics of dark hypochlorite reaction with individual contaminants.

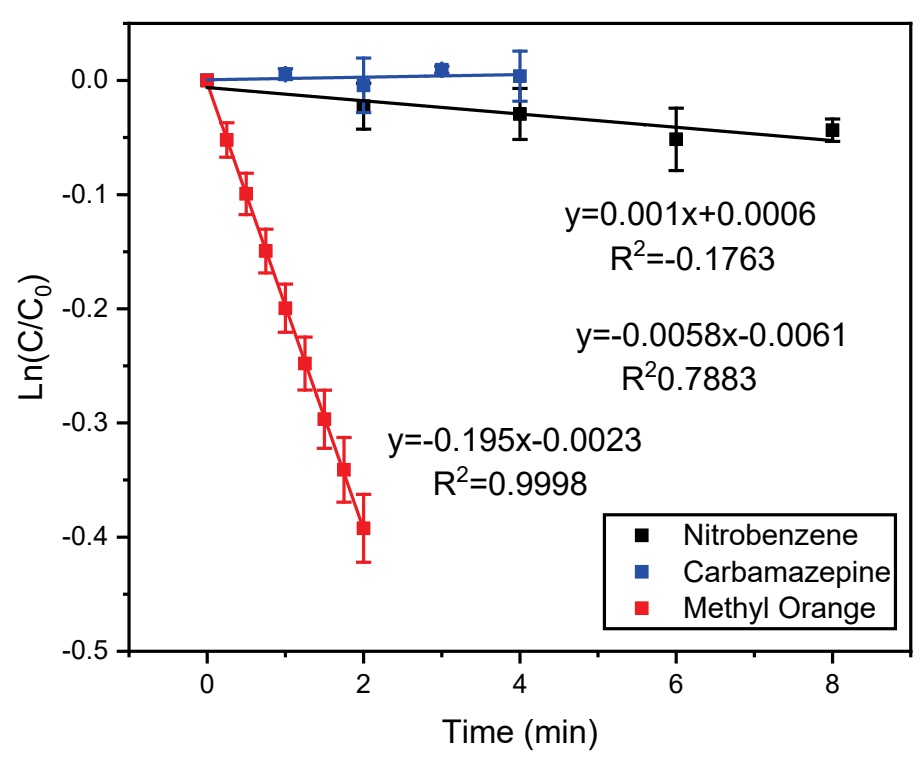




\section{Appendix E: Ozone Concentration Measurements with Indigo Trisulfonate}

Figure E1. Calibration curve of indigo trisulfonate.

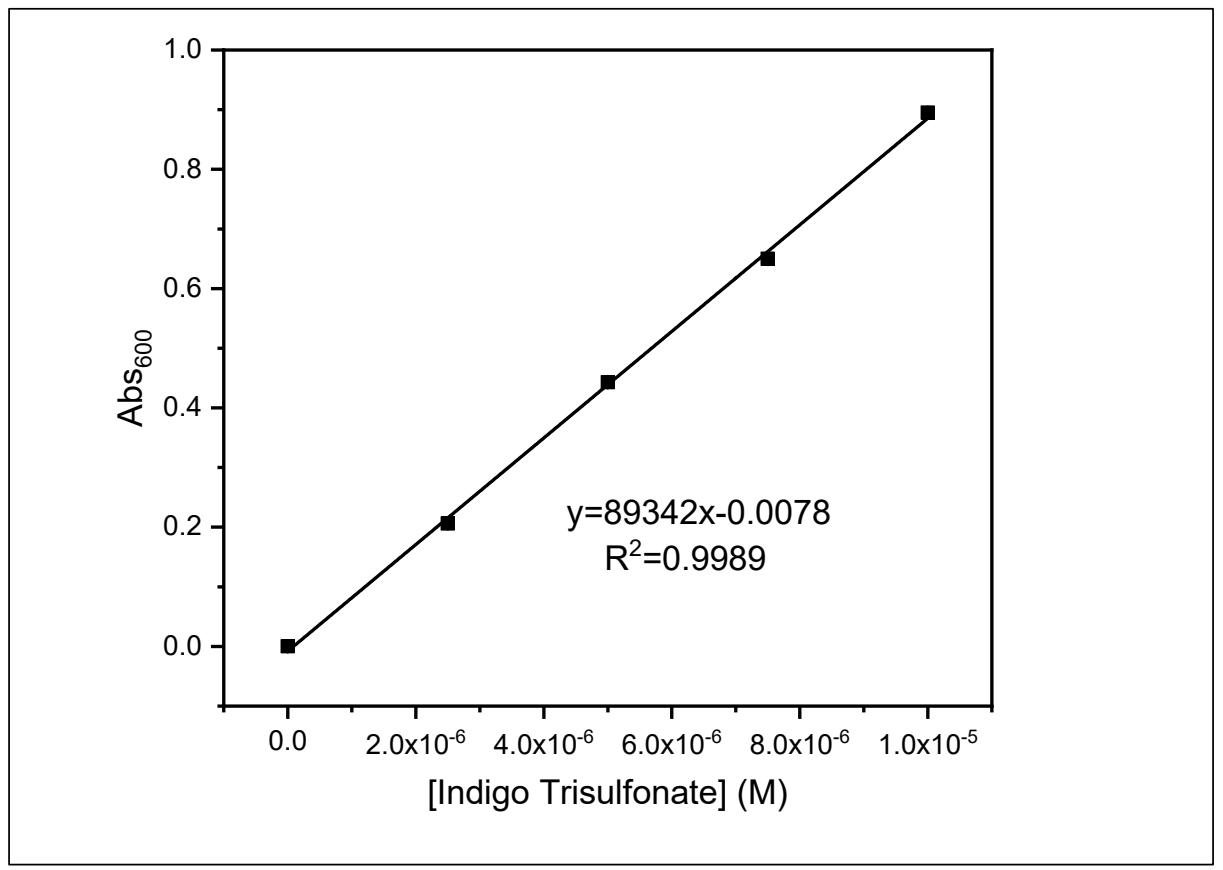

Figure E2: Disappearance of indigo trisulfate with reaction with ozone in solution.

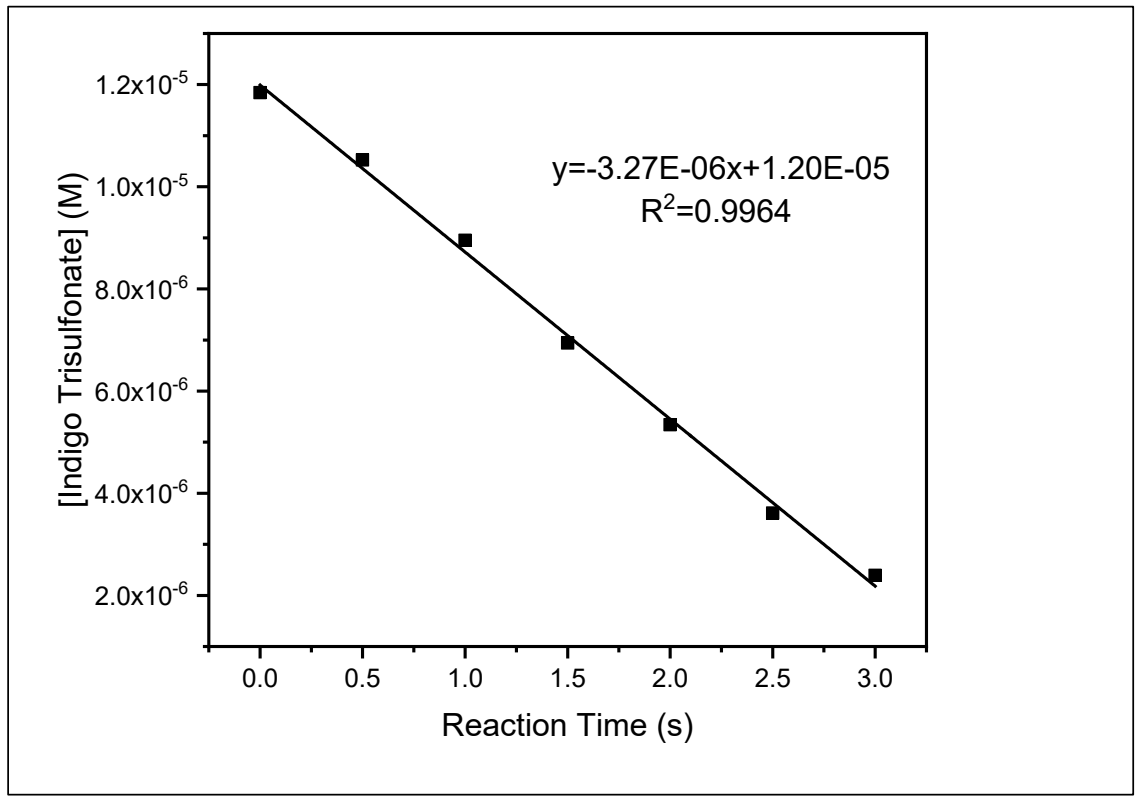


Indigo trisulfonate is proven to react stochiometrically at a 1:1 ratio with the ozone molecule. To determine how much ozone was generated by the system in question, a $2 \mathrm{~mL}$ cuvette of $10 \mu \mathrm{M}$ indigo trisulfonate solution was bubbled with ozone according to standard procedure (Bader and Hoigné 1981).

The starting dye concentration was $0.2 \mu \mathrm{mol}$. With a constant ozone flow over three seconds, $0.066 \mu \mathrm{mol}$ of dye were being destroyed each second, therefore, the same amount of ozone must be entering the aqueous solution over that time to react with the dye. The molar mass of ozone is 48 grams per mole, therefore, the amount of ozone enters the system at a rate of $3.2 \mu \mathrm{g} / \mathrm{s}$.

Note that this does not speak to the total amount of ozone produced by the generator, only the amount entering the aqueous system per time unit. Some ozone bubbles out of the solution and is not absorbed, but the relevant experimental parameter is ozone absorbed. 


\section{Appendix F: HPLC-MS Analysis of Carbamazepine Ozonolysis Product}

Samples containing the CM ozonolysis product observed in EL experiments were sent to CRREL for HPLC-MS analysis. The peak corresponding to this product, shown in Figure F1, appears to be a combination of multiple peaks. The UV-vis absorbance for the first and second peak are different (Figure F2 a, b), but the mass spectra show the same masses (Figure F2 c, d). Attempts to fully separate the peaks proved unsuccessful (Figure F3), indicating that one of the two products may be the result of a transformation occurring during analysis.

Figure F1. HPLC-MS chromatogram of CM ozonolysis product, including UV-Vis photodiode array trace and total ion chromatogram (TIC)

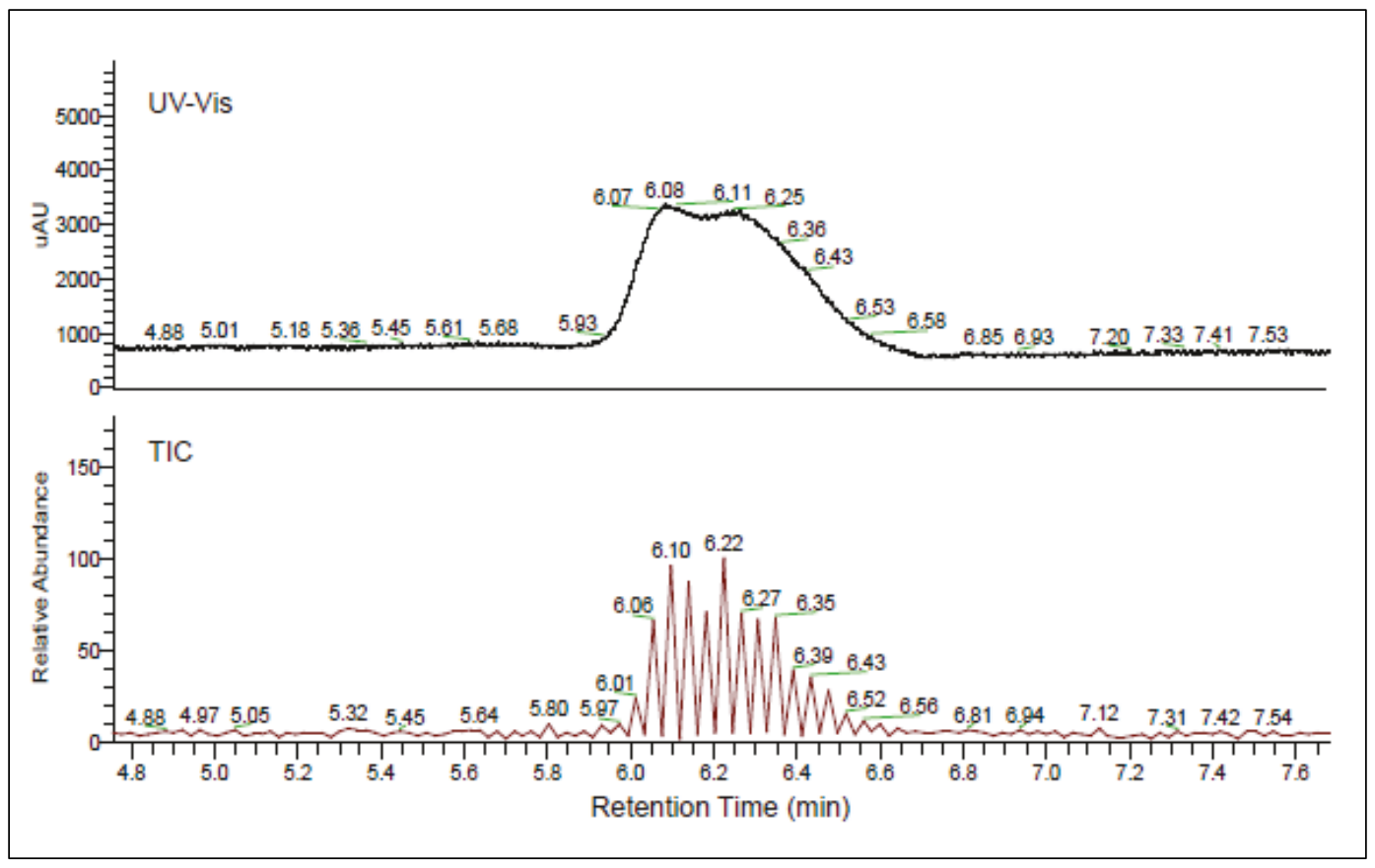


Figure F2. UV-vis absorbance profiles (a, b) and mass spectra (c, d) of the first $(a, c)$ and second $(b, d) C M$ products.

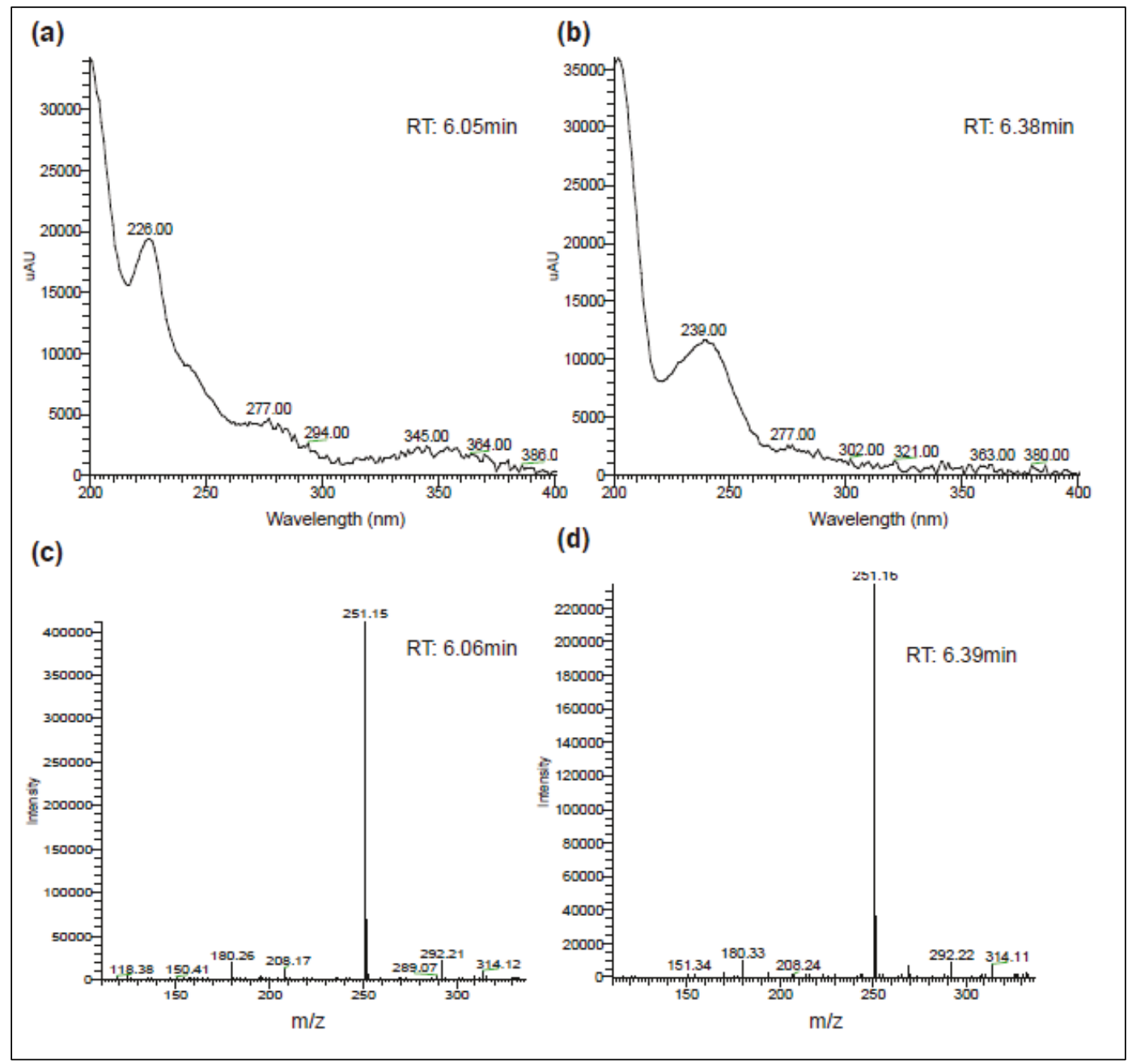

Figure F3. Attempted separation of CM-ozonolysis product with $76 / 24 \mathrm{H}_{2} \mathrm{O} /$ can.

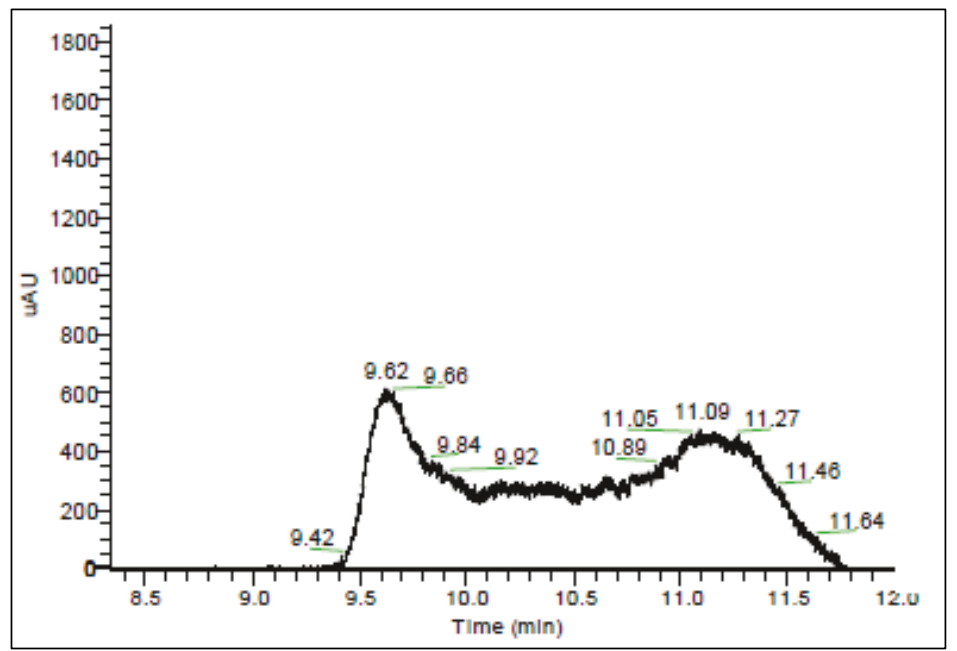




\section{Appendix G: Additional Data on Contaminant Degradation Reactions by Fenton and Photo- Fenton Processes}

Figure G1: Concentration vs. time for Fenton ( $a$ and $c$ ) and photo-Fenton ( $b$ and d) with individual ( $a$ and $b$ ) and mixed ( $c$ and $d)$ contaminants.

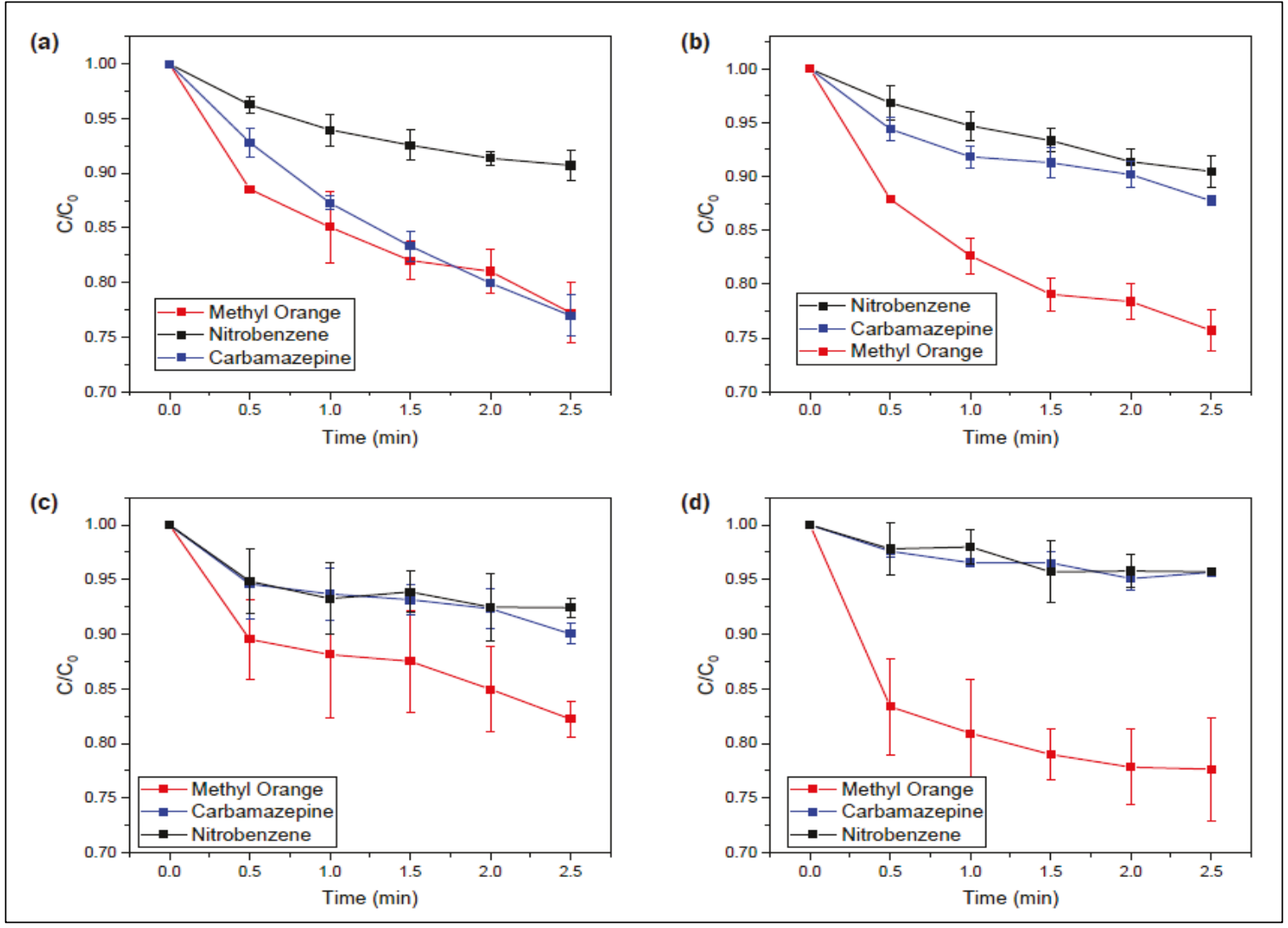


Figure G2: Fenton reaction with individual contaminants fit to three kinetic models, $0^{\text {th }}$ Order/C vs. T (a), $1^{\text {st }}$ Order/Ln(C) vs. T (b) and $2^{\text {nd }} \operatorname{Order} /(1 / C)$ vs. T (c).

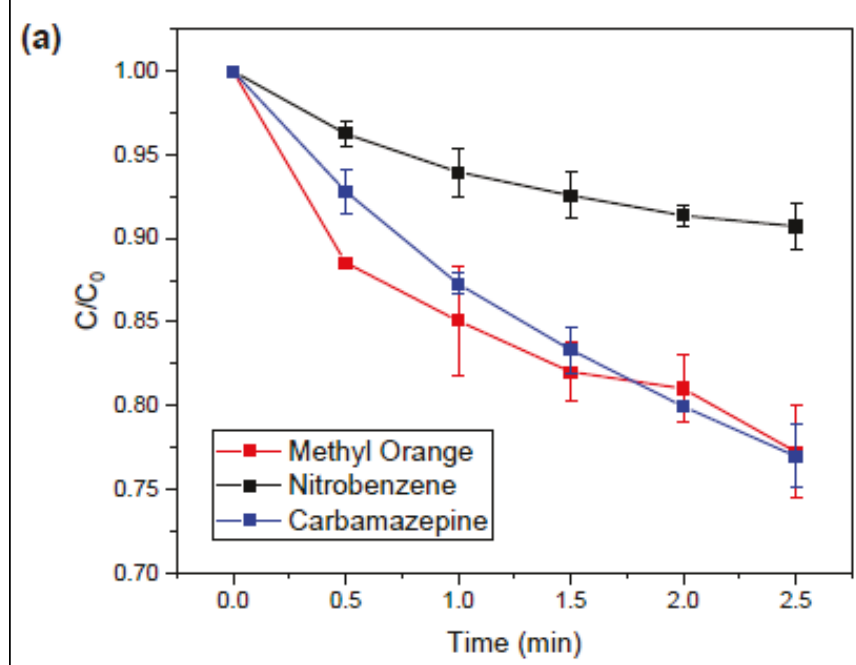

(b)

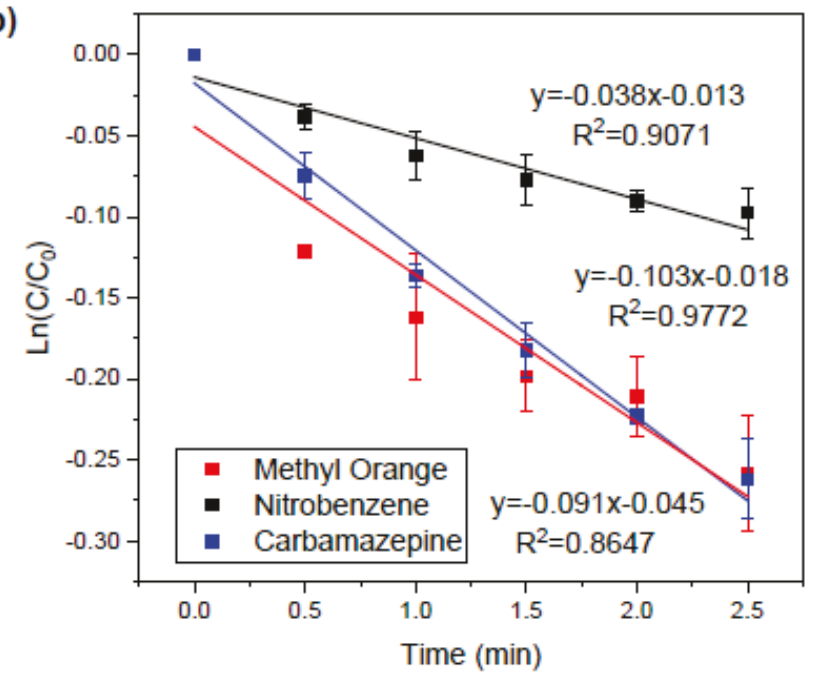

(c)

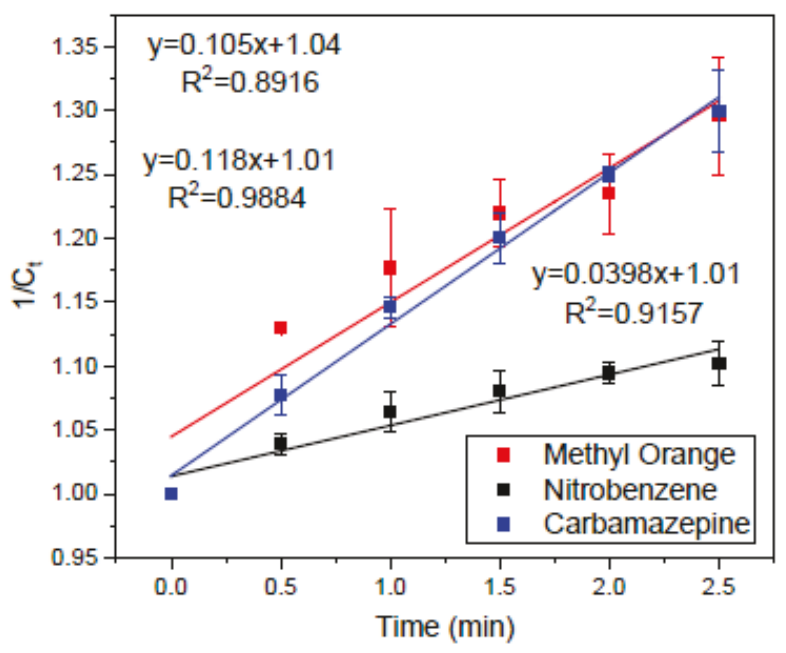




\section{Appendix H: EEO Determinations for Fenton Reactions}

Table H1: EEO for Fenton reaction with individual contaminants calculated based on rate constant, and percent degradation at different time points.

\begin{tabular}{|l|c|c|c|}
\hline \multirow{2}{*}{ Contaminant } & \multicolumn{3}{|c|}{ EEO (kWh/order/m ${ }^{3}$} \\
\cline { 2 - 4 } & 1st Order $k$ & \% Degradation after 0.5 min & \% Degradation after 2.5 min \\
\hline Methyl Orange (MO) & 3.54 & 82 & 185 \\
\hline $\begin{array}{l}\text { Carbamazepine } \\
\text { (CM) }\end{array}$ & 3.13 & 115 & 185 \\
\hline Nitrobenezene (NB) & 8.57 & 236 & 512 \\
\hline
\end{tabular}

The data in the $1^{\text {st }}$ Order $k$ column of table $\mathrm{H} 1$ was calculated using Equation 2 and the rate constant values shown in Table 6. The data in the \% Degradation columns were calculated with Equation 1. For these calculations, $C_{o}$ was $1, C$ was the value of $\mathrm{C} / \mathrm{C}_{o}$ at time $t$, and $t$ was either 0.5 or $2.5 \mathrm{~min}$. 


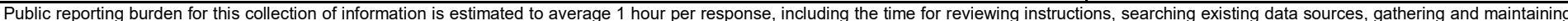

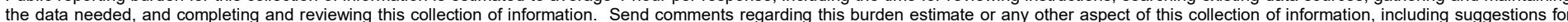

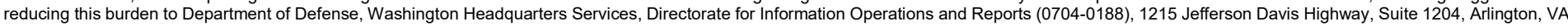

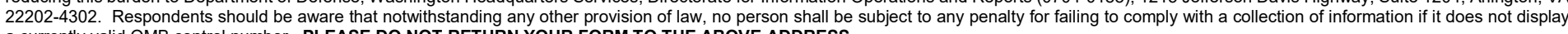
a currently valid OMB control number. PLEASE DO NOT RETURN YOUR FORM TO THE ABOVE ADDRESS.
1. REPORT DATE (DD-MM-YYYY) 2. REPORT TYPE
January 2019 Final report

3. DATES COVERED (From - To)

\section{TITLE AND SUBTITLE}

Cross-Comparison of Advanced Oxidation Processes for Remediation of Organic Pollutants in Water Treatment Systems

5a. CONTRACT NUMBER

5b. GRANT NUMBER

5c. PROGRAM ELEMENT NUMBER 622720048

\section{AUTHOR(S)}

Emma K. Ambrogi, Emily Asenath-Smith, Will A. Ballard,

5d. PROJECT NUMBER

Lee C. Moores, and Jonathon A. Brame

5e. TASK NUMBER

5f. WORK UNIT NUMBER

\section{PERFORMING ORGANIZATION NAME(S) AND ADDRESS(ES)}

8. PERFORMING ORGANIZATION REPORT NUMBER

U.S. Army Engineer Research and Development Center

Environmental Laboratory

ERDC TR-19-3

3909 Halls Ferry Road, Vicksburg, MS 39180-6199

\section{SPONSORING / MONITORING AGENCY NAME(S) AND ADDRESS(ES)}

10. SPONSOR/MONITOR'S ACRONYM(S)

Headquarters, U.S. Army Corps of Engineers

Washington, DC 20314-1000

11. SPONSOR/MONITOR'S REPORT NUMBER(S)

\section{DISTRIBUTION / AVAILABILITY STATEMENT}

Approved for public release; distribution unlimited.

\section{SUPPLEMENTARY NOTES}

\section{ABSTRACT}

A vital issue in military and civilian water treatment is the persistence of pollutants that are difficult to remove via traditional physical, chemical, and biological treatment technologies. Advanced oxidation processes (AOP) are a viable treatment alternative that allow targeting of specific organic pollutants for removal prior to release or reuse of treated water. Many methods have shown positive potential at the bench scale, however, their relative effectiveness in real treatment trains is difficult to assess. To achieve viable technology transfer, bench-scale research needs to feed into pilot-scale and full-scale studies; and that cannot happen without wellestablished metrics and means of comparison.

The goal of this research is to validate and compare the effectiveness of AOP technologies to degrade and eliminate contaminants so that their use in wastewater treatment trains for military and civil applications can be realized. To this end, several AOP that can effectively remove emerging pollutants from a treated wastewater effluent stream have been tested, enabling the water to be reused as potable fresh water. Reaction kinetics for the degradation of pollutants with eight AOP were monitored. With these results, the energy inputs required by calculating electrical energy per order (EEO) for each AOP as a potentially important metric for comparison was analyzed.

\begin{tabular}{|c|c|c|c|c|c|}
\hline \multicolumn{2}{|l|}{ 15. SUBJECT TERMS } & \multicolumn{2}{|c|}{$\begin{array}{l}\text { Water quality } \\
\text { Water--Purification } \\
\text { Water--Purification--Oxidation }\end{array}$} & \multicolumn{2}{|c|}{$\begin{array}{l}\text { Water-supply engineering } \\
\text { Organic water pollutants }\end{array}$} \\
\hline \multicolumn{3}{|c|}{ 16. SECURITY CLASSIFICATION OF: } & $\begin{array}{l}\text { 17. LIMITATION } \\
\text { OF ABSTRACT }\end{array}$ & $\begin{array}{l}\text { 18. NUMBER } \\
\text { OF PAGES }\end{array}$ & $\begin{array}{l}\text { 19a. NAME OF RESPONSIBLE } \\
\text { PERSON }\end{array}$ \\
\hline $\begin{array}{l}\text { a. REPORT } \\
\text { UNCLASSIFIED }\end{array}$ & $\begin{array}{l}\text { b. ABSTRACT } \\
\text { UNCLASSIFIED }\end{array}$ & $\begin{array}{l}\text { c. THIS PAGE } \\
\text { UNCLASSIFIED }\end{array}$ & & 79 & $\begin{array}{l}\text { 19b. TELEPHONE NUMBER (include } \\
\text { area code) }\end{array}$ \\
\hline
\end{tabular}

